\title{
Thermoresponsive polymer nanocarriers for biomedical applications
}

\author{
Alexandre Bordat, Tanguy Boissenot, Julien Nicolas, Nicolas Tsapis* \\ Institut Galien Paris-Sud, CNRS, Univ. Paris-Sud, Université Paris-Saclay, 92290 Châtenay-Malabry, \\ France \\ *Corresponding author : Nicolas Tsapis \\ Institut Galien Paris-Sud, UMR CNRS 8612, LabEx LERMIT \\ Faculté de Pharmacie, Univ. Paris-Sud, Université Paris-Saclay \\ 5 , rue JB Clément, 92296 Châtenay-Malabry, France \\ Tel 331468358 1, Fax 33146835946 \\ nicolas.tsapis@u-psud.fr
}

\begin{abstract}
Polymer nanocarriers allow drug encapsulation leading to fragile molecule protection from early degradation/metabolization, increased solubility of poorly soluble drugs and improved plasmatic half-life. However, efficiently controlling the drug release from nanocarriers is still challenging. Thermoresponsive polymers exhibiting either a lower critical solubility temperature (LCST) or an upper critical solubility temperature (UCST) in aqueous medium may be the key to build spatially and temporally controlled drug delivery systems. In this review, we provide an overview of LCST and UCST polymers used as building blocks for thermoresponsive nanocarriers for biomedical applications. Recent nanocarriers based on thermoresponsive polymer exhibiting unprecedented features useful for biomedical applications are also discussed. While LCST nanocarriers have been studied for over two decades, UCST nanocarriers have recently emerged and already show great potential for effective thermoresponsive drug release.

Keywords: Polymers, Thermoresponsiveness, lower critical solubility temperature (LCST), upper critical solubility temperature (UCST), nanocarriers
\end{abstract}




\section{Introduction}

Nanomedicine is being regarded as a promising way to tackle the problems and limitations of both drug delivery and diagnostics. Changing the pharmacokinetics and biodistribution of an active pharmaceutical ingredient (API) through its incorporation into a nanocarrier, to prevent severe side effects and even increase the efficacy of the original API, has been a major breakthrough[1-3]. Moreover, nanocarriers are able to penetrate into the tumors, allowing for specific imaging of the diseased tissues and monitoring disease evolution[4]. These nanocarriers come in diverse forms among which: liposomes[5], micelles[6], polymeric nanoparticles[7,8], albumin-based formulations[9,10], or metal-containing nanoparticles[11-13]. While some of these formulations have been approved for clinical use (e.g., Abraxane ${ }^{\circledR}$, Doxil ${ }^{\circledR}[14]$, AmBisome ${ }^{\circledR}[15]$, Genexol PM[16]), they are vastly outnumbered by the amount of nanocarriers still under investigation. The poor bench-to-bedside translation stems from several limitations specific to nanocarriers, mainly the limited gain in efficacy due to little nanoparticle accumulation in tumors[17,18] and the little specificity for the targeted disease[19]. Until recently, nanoparticles were indeed thought to preferentially accumulate in the tumor microenvironment because of the porosity of the surrounding endothelial cells[20]. This phenomenon, also termed enhanced permeation and retention (EPR) effect[21,22], is today somewhat controversial because not all tumors exhibit this feature and there is a significant variability from one patient to another[23,24]. Another way to target a specific tissue is to use stimulus-sensitive nanoscale systems[25] and apply the stimulus at the desired area and time. Among the different stimuli, temperature is a stimulus of choice. Tissues can indeed withstand moderate hyperthermia up to $43{ }^{\circ} \mathrm{C}$ for a prolonged period of time, without irreversible consequences. This mild hyperthermia can be obtained by using microwaves[26], ultrasound[27], radiofrequency[28], infrared illumination[29] or magnetic fluid hyperthermia[30]. These methods do not require invasive surgery and are therefore simple to implement for the physician. Many thermoresponsive nanocarriers have been investigated for the past 20 years, but only one of them is currently under Phase III clinical trial: ThermoDox ${ }^{\circledR}$ (Celsion)[31]. ThermoDox ${ }^{\circledR}$ is a thermoresponsive liposomal formulation loaded by doxorubicin to treat primary liver cancer. The liposomes consist in a mixture of regular lipids and lysolipids, enabling thermoresponsiveness between $40{ }^{\circ} \mathrm{C}$ and $45{ }^{\circ} \mathrm{C}$. While thermoresponsive liposomes are well represented in literature and are in a late development stage, a considerable amount of work has been devoted to thermoresponsive polymers and their application to medicine[32]. This review provides an insight on the inner workings of the thermoresponsiveness of the described polymers from a physico-chemical point of view, the set of parameters governing the thermoresponsiveness and how they can be tuned to reach a specific temperature response, and an overview of the currently investigated nanocarriers used for therapy and diagnostics. This review will cover some examples of lower critical solubility temperature (LCST) and upper critical solubility temperature (UCST) polymers. As the literature on thermoresponsive polymers is very rich and the amount of nanocarriers based on these polymers is important, we focused on recent reports showcasing interesting uses of thermoresponsiveness as well as reporting a clear effect in vitro on cells or in vivo in animal models. This review will likely stimulate the development of innovative nanocarriers based on thermoresponsive polymers. 


\section{Thermoresponsive polymers}

Thermoresponsiveness is the ability for a polymer in solution to drastically change at least one of its physico-chemical properties depending on the temperature. Here we will consider thermoresponsiveness as the polymer's ability to be solubilized in aqueous medium, as organic solvents are not suitable for use in a biological setting. These polymers are classified into two groups, those exhibiting a lower critical solution temperature (LCST) and those exhibiting an upper critical solution temperature (UCST). A LCST polymer is soluble below a critical temperature, and insoluble above, whereas it is the opposite for a UCST polymer (Figure 1). In both cases, there is a balance between polymer-polymer interactions and polymer-aqueous medium interactions. The temperature of the solution determines whether a polymer chain is likely to make more interactions with another polymer chain or with the surrounding medium. In the case where polymer-polymer interactions prevail, the polymer chains tend to associate together and eventually phase out from the solution, thus leading to a turbid suspension. For UCST polymers, the polymer chains are well solubilized above the UCST. They maintain a high affinity with the surrounding medium and the solution is transparent. An effective way of measuring the temperature at which the visual aspect of the solution changes from turbid to transparent, also known as the cloud point, is to monitor the light transmittance of the solution upon heating and cooling. This is usually achieved by using UV/VIS spectrophotometry at a high wavelength (typically above $500 \mathrm{~nm}$ ), to avoid any absorbance phenomenon in the lower range of wavelengths, coupled to a Peltier system allowing the heating and cooling of the samples at a desired rate (typically $1^{\circ} \mathrm{C} / \mathrm{min}$ ). Light transmittance is at a maximum when the solution is completely transparent, meaning that the polymer is fully soluble in the aqueous medium, whereas it is at a minimum when the solution becomes turbid. The cloud point depends on the polymer concentration, and the LCST (or UCST) of a polymer corresponds to a specific cloud point obtained at the concentration where the binodal curve of the phase diagram presents an extremum (Figure 1). In the literature the terms cloud point and LCST (or UCST) are often confused, and as such, we will be using these abbreviations to characterize the critical temperature of the polymers discussed in this review. In practical terms, the LCST (or UCST) can be defined as the temperature from which the solution has a constant transmittance, either close to $0 \%$ (i.e., turbid, for LCST polymers) or close to $100 \%$ (i.e., transparent, for UCST polymers) (Figure 2). 


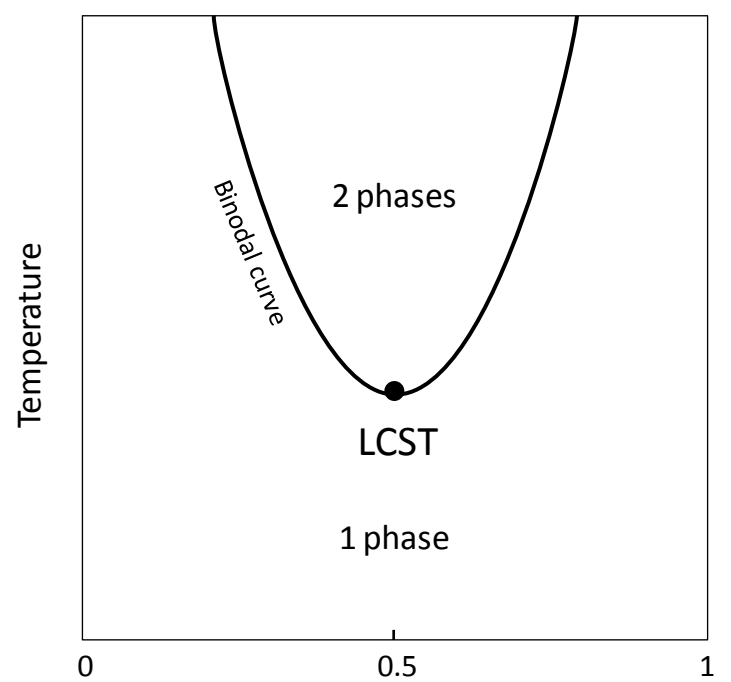

Polymer molar fraction

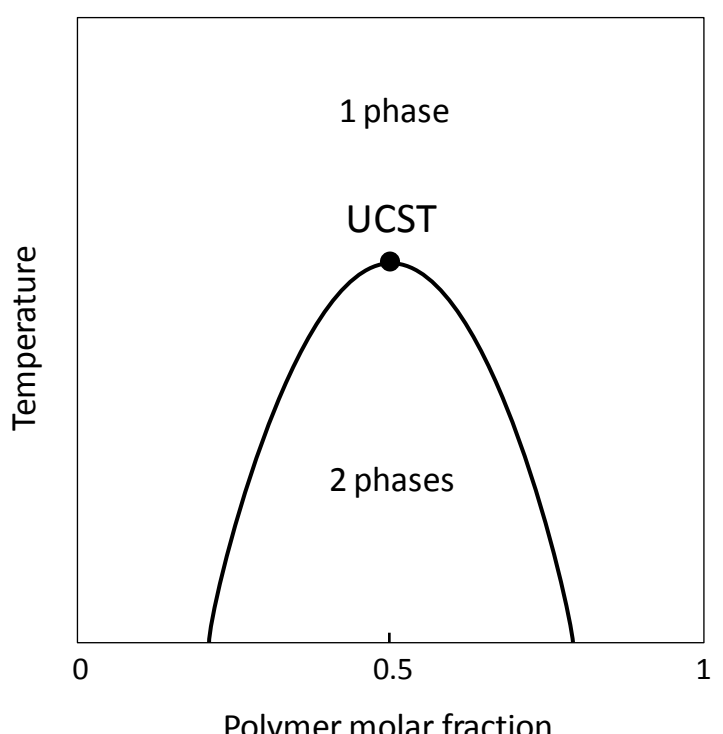

Polymer molar fraction

Figure 1: Simplified phase diagrams of thermoresponsive polymers. Outside the region delimited by the binodal curve, there is a homogeneous solution of solubilized polymer in aqueous solution (1 phase). Inside the region, the solution is not stable anymore and the polymer phases out (2 phases).

Inside the region delimited by the binodal curve, polymer chains interact with each other and start aggregating. This uncontrolled aggregation can lead to the formation of nanoparticles. However, as this region of the phase diagram depicts a thermodynamically unstable state of the system, this aggregation can worsen and give microparticles or even visible aggregates. As long as no polymer degradation occurs, the thermoresponsiveness is a reversible feature and these polymers still exhibit a critical temperature even after several heating/cooling cycles. Nevertheless, a hysteresis may be observed upon cooling and heating as the critical temperature can vary between the two thermodynamic pathways.
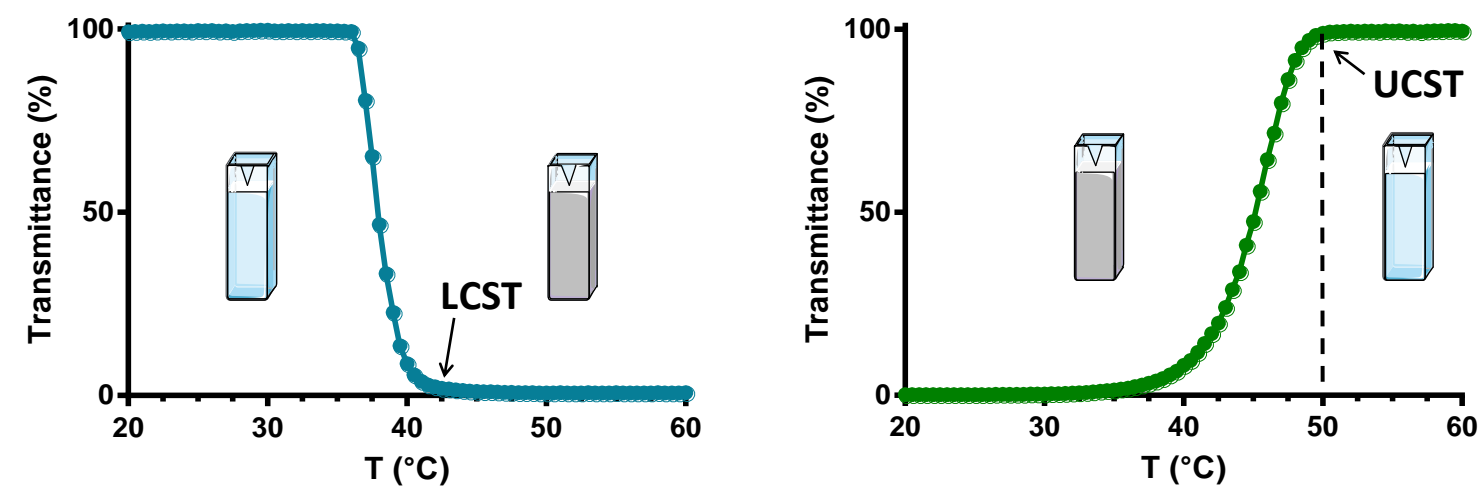

Figure 2: Model transmittance curves as a function of temperature for LCST (left) and UCST (right) polymers. When transmittance is at 100\%, the sample is completely transparent and there are no apparent particles in solution. When transmittance is close to $0 \%$, the sample appears turbid due to the presence of particles. In this case, the depicted LCST corresponds to $42.5^{\circ} \mathrm{C}$, and the UCST $50^{\circ} \mathrm{C}$.

The development of new thermoresponsive polymers and new ways of functionalizing them have been made possible by the development of advanced polymerization techniques. Among them, 
reversible deactivation radical polymerization (RDRP) techniques, including atom-transfer radicalpolymerization (ATRP)[33], reversible addition-fragmentation chain-transfer (RAFT) polymerization[34], and nitroxide-mediated polymerization (NMP)[35], allow to prepare well-defined, complex macromolecular architectures with low dispersity, high chain-end fidelity and a broad range of different functionalization possibilities. Ring-opening polymerization (ROP)[36] also enables welldefined polymers to be synthesized[37]. Given those modern polymerization techniques allow to finely control the chain length of the polymers, the impact of this parameter on thermoresponsiveness has been extensively studied. Overall, designing well-defined objects is preferred when working on nanocarriers used for diagnostics or therapy.

This review will cover the different thermoresponsive polymers existing that can be used to formulate nanoscale systems intended for drug delivery and/or diagnostic applications. A selection of recent reports on thermoresponsive nanocarriers based on LCST and UCST polymers will be presented.

\section{LCST polymers}

II.1. Understanding the LCST behavior through the example of poly( $N$-isopropylacrylamide)

Reports on polymers exhibiting a LCST behavior largely outnumber those on UCST polymers. Historically, LCST polymer behaviors in solution were first described 50 years ago with what would become the most studied LCST polymer, poly- $N$-isopropylacrylamide (PNIPAAm)[38]. This pioneering work shed light on the physics underlying the aqueous solution properties of PNIPAAm, and LCST polymers in general. PNIPAAm is a vinyl polymer with secondary amide pendant groups. The two lone pairs of the oxygen atom and the lone pair of the nitrogen atom of the amide bond are acceptors of hydrogen bonds, whereas the hydrogen covalently attached to the nitrogen atom is a donor of hydrogen bonds. These features allow for both types of $\mathrm{H}$-bonding interactions with water (Figure 3). The energy of a hydrogen bond is governed by temperature. As temperature increases, molecular agitation increases, and molecules do not remain in a stable position from one another, weakening the hydrogen bonds. In this case, interaction of water molecules with the pendant groups is weaker as temperature increases. A rise in temperature also increases the intensity of the hydrophobic effect upon which two hydrophobic solutes aggregate. The secondary amide group of PNIPAAm contains an isopropyl alkyne moiety that is hydrophobic. Upon heating, the polymer chains are no longer hydrated as well as they were at lower temperature, and the hydrophobic effect becomes predominant, as such polymer-polymer interactions are more important than polymerwater interactions, and polymer phases out from the solution. 

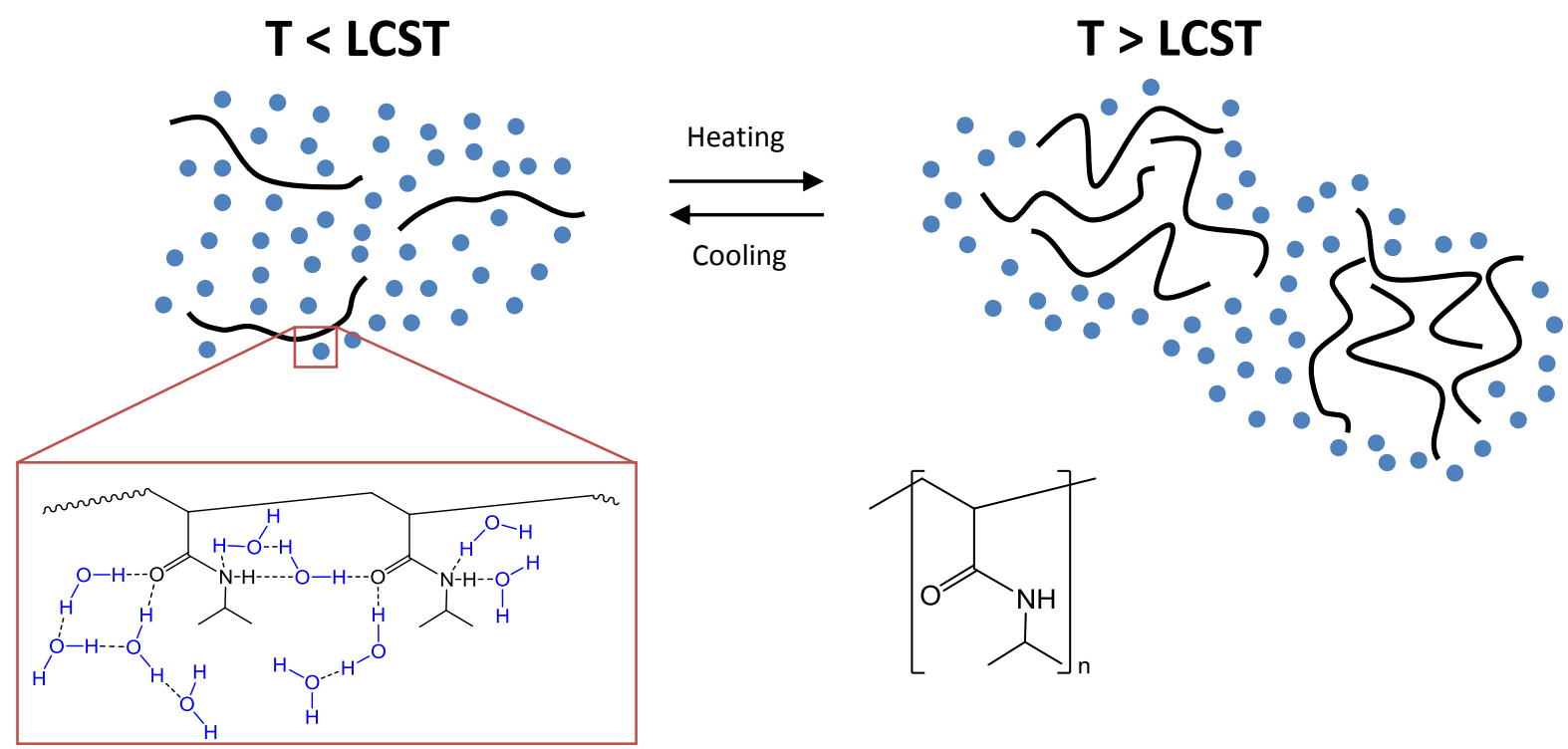

Figure 3: Top: Schematic representation of PNIPAAm chains (black) surrounded by water molecules (blue) as a function of temperature. Bottom-right: chemical structure of PNIPAAm. The red inset shows the possible hydrogen bonds between water molecules and polymer chains. Below the LCST, polymer chains are fully hydrated and solubilized, whereas above the LCST, they interact strongly with one another, the intrachain hydrophobic effect changes the conformation of the polymer chains to a coil state, they aggregate, and phase separate from the water phase to yield a turbid suspension.

The LCST is the temperature at which this switch happens. This phenomenon is reversible, meaning that when the temperature decreases, the hydrophilic-hydrophobic balance is restored towards more hydrophilicity of the polymer and the polymer chains become soluble again. Nevertheless, the temperature at which the polymer solubilizes again may be slightly different resulting in a hysteresis of the system[39]. The case of PNIPAAm is interesting because of its unique phase diagram (Figure 4) which exhibits a cloud point around $32{ }^{\circ} \mathrm{C}$, over a wide range of polymer concentrations (from 5 to 30 wt.\%).

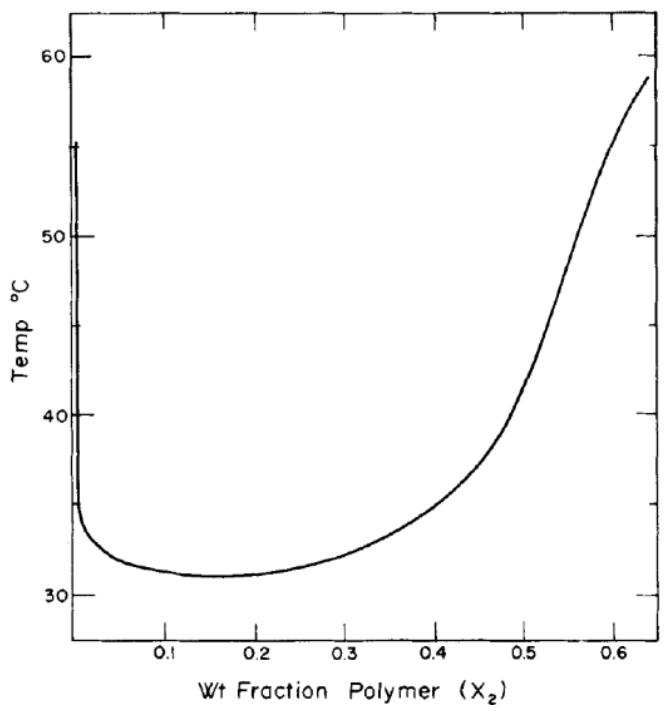

Figure 4: Phase diagram of PNIPAAm, from M. Heskins and J. E. Guillet[38].

While $32{ }^{\circ} \mathrm{C}$ as the LCST temperature can be interesting for designing a formulation that changes its properties from room temperature to $37^{\circ} \mathrm{C}$ (i.e., temperature of the human body), research groups 
have come up with a way to easily tune PNIPAAm's LCST to higher temperatures. The rationale behind this approach is to obtain an LCST higher than $37{ }^{\circ} \mathrm{C}$, to heat the diseased tissue at a mild hyperthermia $\left(43^{\circ} \mathrm{C}\right)$ and trigger the drug release in a spatio-temporal fashion. This can be easily achieved by copolymerizing NIPAAm with a hydrophilic monomer. Indeed, the hydrophilic monomer will shift the hydrophilic / hydrophobic balance towards more hydrophilicity, leading to more interactions with the surrounding water molecules. Consequently, the resulting copolymer needs to be heated at a higher temperature to disrupt these newly-formed hydrogen bonds and let the copolymer chains self-assemble. While the discovery of the physico-chemical properties of PNIPAAm dates back half a century, fundamental work is still carried out to fully understand the behavior of PNIPAAm in aqueous solution. Recently, Bischofberger and Trappe have described previously unseen characteristics of PNIPAAm in solution above its LCST[40]. They initially prepared microgels at a temperature above the LCST which started, from a certain concentration, to gather together to form a gel occupying the whole volume of the container. Surprisingly, this gel shrinked as temperature was maintained above the LCST. The gel retained the shape of the container and the shrinkage was irreversible. These new findings could be exploited by formulation research groups to finely tune thermoresponsive nanocarriers.

Early uses of PNIPAAm as a material to build nanocarriers intended for drug delivery applications were reported in the late 90s by the group of Teruo Okano. They synthesized block copolymer micelles containing a PNIPAAm block and hydrophobic blocks of different nature such as polystyrene or poly-L-lactide (PLA) to encapsulate doxorubicin. They studied the drug release as well as cell viability at 37 and $42.5^{\circ} \mathrm{C}$ and showed selective cytotoxicity on bovine aortic endothelial cells at $42.5^{\circ} \mathrm{C}$ and not at $37{ }^{\circ} \mathrm{C}$ [41-43]. A lot of investigation has been carried out on PNIPAAm and its derivatives since the early works of Okano's group, and many thermoresponsive nanocarriers have shown great promise mainly for cancer treatment. Despite these academic successes, neither attempts of translation to the clinics nor clinical trials on any polymeric thermoresponsive nanocarriers have been reported, contrary to thermoresponsive liposomes such as ThermoDox ${ }^{\circledR}$.

Table 1 summarizes the different polymers based on PNIPAAm used to build the thermoresponsive nanocarriers further discussed in this review. The usual modifications to PNIPAAm include: (i) copolymerization with a hydrophilic monomer, such as acrylamide, to increase the LCST beyond $32{ }^{\circ} \mathrm{C}$; (ii) addition of a hydrophobic block, such as polycaprolactone ( $P C L)$, to yield core-shell nanoparticles and (iii) grafting to a natural biopolymer to confer LCST properties to it.

Apart from PNIPAAm, several other polymers exhibit LCST-type thermoresponsiveness in aqueous media. Most of them leverage hydrogen bonding to achieve thermoresponsiveness, which is an advantage for application in a biological setting, where biological fluids are made of complex solutions containing different ions and at different $\mathrm{pHs}$. Given hydrogen bonds are less susceptible to be broken with increased ionic strength of the medium, these nanocarriers are indeed expected to maintain their thermoresponsiveness over a wide range of ionic strengths and $\mathrm{pHs}$. 
Table 1: PNIPAAm-based copolymers used in the formulations of thermoresponsive nanocarriers.

\begin{tabular}{|c|c|c|}
\hline Polymer & Synthesis technique & Modification objective \\
\hline & $\begin{array}{l}\text { Free-radical copolymerization and crosslinking } \\
\text { using } N, N^{\prime} \text {-methylenebisacrylamide }\end{array}$ & Hydrophilic comonomer to increase the LCST. \\
\hline & $\begin{array}{l}\text { Free-radical copolymerization to synthesize each } \\
\text { block separately and amide coupling to obtain the } \\
\text { block copolymer }\end{array}$ & $\begin{array}{l}\text { Hydrophilic comonomer to increase LCST of the } \\
\text { thermoresponsive corona block and hydrophobic } \\
\text { block for the core of the self-assembled micelle. }\end{array}$ \\
\hline P(NIPAA & $\begin{array}{l}\text { Free-radical copolymerization in presence of } \\
\text { mercaptoethanol as a chain transfer agent and } \\
\text { ROP of CL }\end{array}$ & $\begin{array}{l}\text { Hydrophilic comonomer to increase LCST of the } \\
\text { thermoresponsive corona block and hydrophobic } \\
\text { biodegradable block for the core of the self- } \\
\text { assembled micelle. }\end{array}$ \\
\hline & $\begin{array}{l}\text { Sequential RAFT polymerization of NIPAAM and } \\
\text { NVP to prepare the diblock copolymer }\end{array}$ & $\begin{array}{l}\text { PNVP block used to make a film by mixing the } \\
\text { polymer with tannic acid. }\end{array}$ \\
\hline
\end{tabular}




\begin{tabular}{|c|c|c|}
\hline poly(N-isopropylacrylamide)- $b$-polycaprolactone & $\begin{array}{l}\text { Divergent ROP and ATRP to prepare the } \\
\text { corresponding diblock copolymer }\end{array}$ & $\begin{array}{l}\text { Thermoresponsive corona block and } \\
\text { hydrophobic biodegradable block for the core of } \\
\text { the self-assembled micelle. }\end{array}$ \\
\hline $\begin{array}{c}\text { 1: PNIPAAm- } b \text {-PNP } \\
\text { PNIPAAm- } b \text {-poly(N-acryloyl-5-methoxy-2-pyrrolidone) } \\
\text { 3: PNIPAAm- } b \text {-PBNP } \\
\text { PNIPAAm- } b \text {-poly(N-acryloyl-5-butoxy-2-pyrrolidone) }\end{array}$ & Sequential RAFT polymerization & $\begin{array}{l}\text { Thermoresponsive corona block and diverse } \\
\text { hydrophobic blocks for the core of the self- } \\
\text { assembled micelle, to investigate the impact of } \\
\text { hydrophobicity on the drug encapsulation. }\end{array}$ \\
\hline 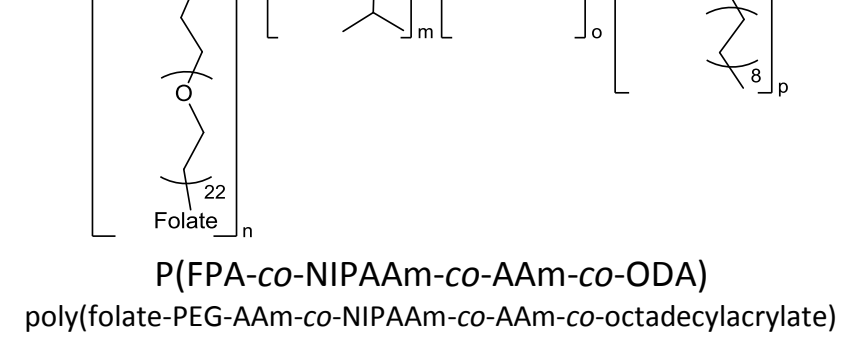 & Free-radical copolymerization & $\begin{array}{l}\text { Random quaterpolymer. ODA serves as a } \\
\text { hydrophobic monomer to form the core of the } \\
\text { micelles. NIPAAm and AAm tune the LCST above } \\
32{ }^{\circ} \mathrm{C} \text { and PEG-Folate is used for specific cell } \\
\text { targeting. }\end{array}$ \\
\hline $\begin{array}{c}\beta \text {-cyclodextrin-g-(PEG-v-PNIPAAm })_{7} \\
\beta \text {-cyclodextrin- } g \text {-(PEG-v-PNIPAAm) star polymer }\end{array}$ & RAFT polymerization on a modified cyclodextrin & $\begin{array}{l}\text { Cyclodextrin serves as a hydrophobic cavity to } \\
\text { create inclusion complex with a hydrophobic } \\
\text { drug. }\end{array}$ \\
\hline
\end{tabular}




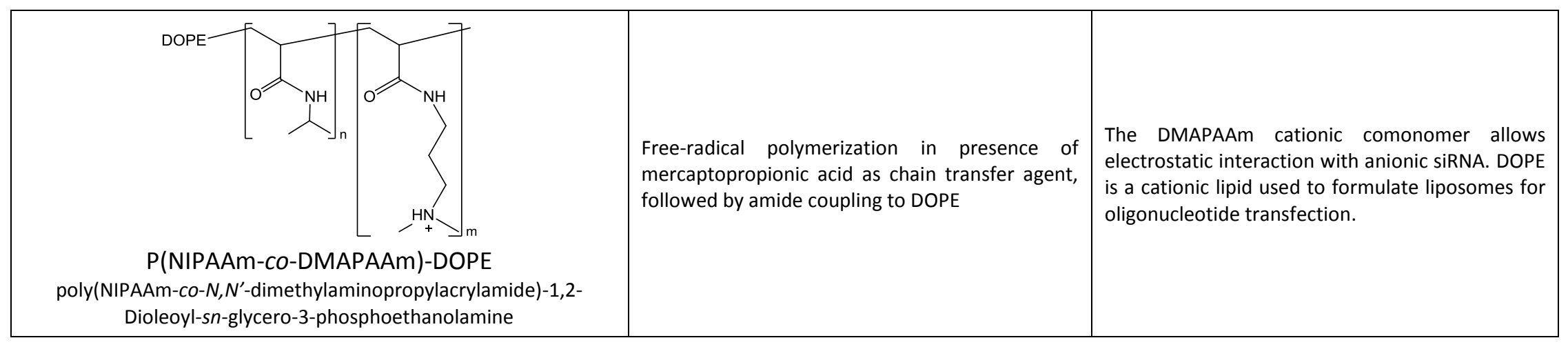

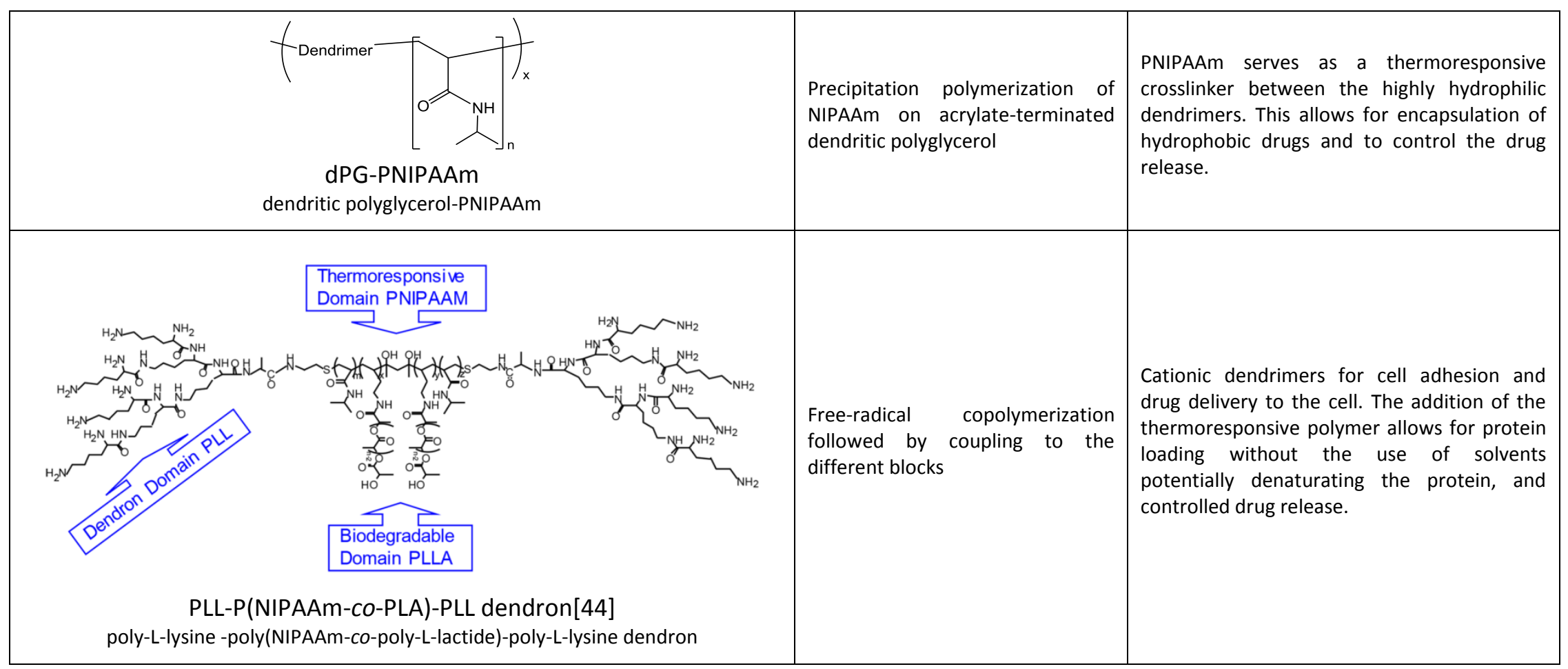




azide $\begin{aligned} & \text { HA is a biomacromolecule that can be used to } \\ & \text { treat osteoarthritis but needs to be injected } \\ & \text { directly into the joint. It is very hydrophilic } \\ & \text { and can diffuse easily. PNIPAAm serves as a } \\ & \text { viscosity modulator. }\end{aligned}$
terminated PNIPAAm coupled baluronic acid-g-poly(NIPAAm)
click chemistry to alkyne-containg
ing HA




\section{II.2. Elastin-like polypeptides (ELP)}

Elastin-like polypeptides (ELPS) were designed after their natural counterpart elastin and more specifically its precursor tropoelastin. Tropoelastins are a set of 50-70 kDa water-soluble proteins that are cross-linked together to form the insoluble elastin found in the extracellular matrix. Elastin, as its name suggests, is an elastic material that recovers its initial shape after being subjected to a mechanical stress. The different bioactive motifs of elastin are also responsible for cell adhesion, proliferation or differentiation. The detailed study of the tropoelastins' amino acid sequence revealed repeated motifs among which the VPGXG pentapeptide, with $X$ a guest residue being any amino acid except proline. These ELPs present LCST behavior that can be tuned with the size of the polypeptides and the nature of the guest residues. In the case of ELPs, the LCST is known as the inverse transition temperature $T_{t}$. Extensive characterization work has been carried out by the Chilkoti's group, as they have come up with a way to simulate the properties of ELPs based on their chemical design[45] (Figure 5).
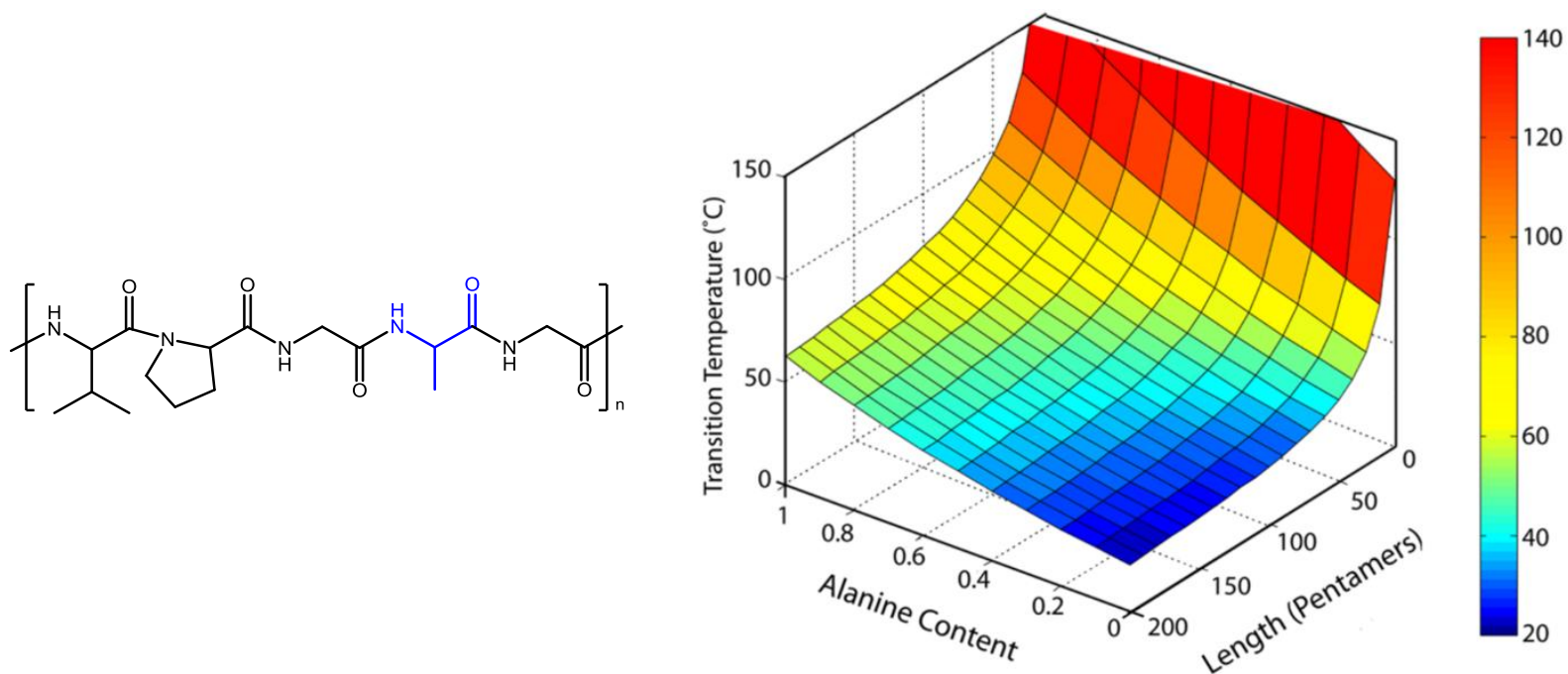

Figure 5: Left: Chemical structure of the pentapeptide Valine-Proline-Glycine-Alanine-Glycine [VPGAG] that is repeated to obtain the elastin-like polypeptides, with alanine (in blue) being a guest residue that can be changed to modulate the physico-chemical properties of the ELPs. Right: A 3-dimensional plot of the predicted inverse transition temperature $T_{t}$ landscape for the alanine and valine superfamily of ELPs at $25 \mu M$ in PBS (taken from McDaniel et al.)[45].

By mapping out the possible ELPs that can be synthesized, it is possible to choose a specific ELP sequence that fits specific requirements in terms of $T_{t}$ and to use it as a building block for a drug delivery system. Another advantage of ELPs relies on their synthesis. As they are long polypeptides, conventional peptide synthesis would be too long and costly to yield ELPs in sufficient amount. A better synthetic route consists in modifying bacterial DNA by using plasmids coding for the desired ELP sequence and performing bacterial fermentation to get the desired proteins. The advantages of this technique are numerous, among which: having extremely well-defined polypeptides (as opposed to a polymer distribution with conventional polymerization techniques), possibility to have complex functionalization through post-translation modifications, and, in comparison with chemical peptide synthesis, ease of synthesis as only two steps are required (i.e., plasmid transfection into bacteria followed by bacterial fermentation for production of the peptides). The synthesis is also mostly environmentally friendly as no organic solvents are used and most reagents are natural. The major drawback of this synthetic method however comes from the purification process that is more 
complex than a simple polymer precipitation. As formulation research groups traditionally work with chemistry equipment, the facilities/equipment to synthesize ELPs are not always present. To overcome this hurdle, the group of van Hest has synthesized a methacrylate derivative of the VPGVG pentapeptide which was polymerized to obtain an elastin-based side-chain polymer by ATRP $[46,47]$. This strategy was further exemplified with the RAFT polymerization technique by Fernandez-Trillo et al[48]. Nevertheless, the side chains possess a free carboxylic acid moiety that is sensitive to $\mathrm{pH}$, thus $\mathrm{T}_{\mathrm{t}}$ is $\mathrm{pH}$-dependent unlike traditional ELPs.

ELPs have been used in a variety of different biomaterials: as depots and hydrogels to reduce systemic toxicity and improve therapeutic efficacy[49], as nanocarriers for drug delivery purposes and as drug-polypeptide conjugates[50]. In this review we will focus on a recent example of ELP used as nanocarrier building block.

II.3. Other frequently used LCST polymers

a.<smiles>CC(C)(C)CCOC(C)(C)C</smiles>

b.<smiles>CC(C)OC(C)CC(C)(C)C</smiles>

c.

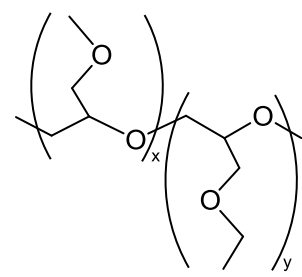

d.

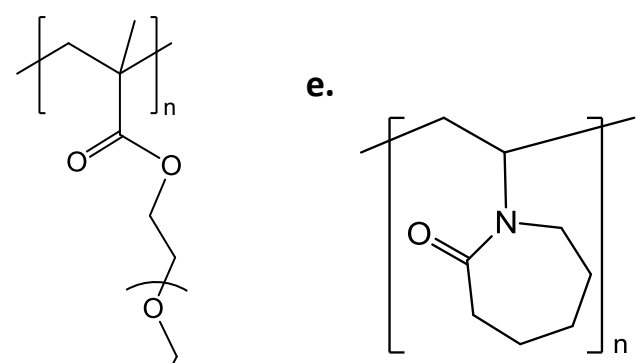

Figure 6: Chemical structure of other LCST polymers used for nanocarrier fabrication. a: poly(ethylene glycol) (PEG), b: poly(propylene glycol) (PPG), c: poly(glycidyl methyl ether-co-glycidyl ethyl ether) $(P(G M E-c o-G E E))$, d: poly(oligoethylene glycol) methyl ether methacrylate (POEGMA), e: poly(Nvinylcaprolactam) (PNVCL).

Polyethylene glycol (PEG) and its derivatives are an important family of thermoresponsive polymers used in the fabrication of nanocarriers. PEG was initially used to shield hydrophobic nanoparticles from opsonization and to allow for a prolonged circulation time in the bloodstream[51]. In its linear form (Figure 6 a.), PEG exhibits an LCST greater than $90{ }^{\circ} \mathrm{C}$ in water. The addition of salt in the aqueous medium can result in a decrease of the LCST. For instance, the LCST can reach $35{ }^{\circ} \mathrm{C}$ in the presence of $450 \mathrm{mM}$ of $\mathrm{K}_{2} \mathrm{SO}_{4}$ [52]. This is cumbersome, and no reports detail the use of linear PEG on its own to build a nanocarrier. Nevertheless, when incorporated into a multi-block copolymer, linear PEG can exhibit a more relevant LCST without additional salts. For instance, a methacrylate-bearing pendant PEG (Figure $6 \mathrm{~d}$.) was used to easily prepare a comb-like structure by radical polymerization. PEG is linked to the polymer backbone through an ester bond that presents only relative stability in biological fluids. The number of ethylene glycol repeating units (noted $x$ in figure $6 \mathrm{~d}$.) heavily influences the LCST: LCST is 28,50 and $90^{\circ} \mathrm{C}$ for $\mathrm{x}=2,3$ and 8-9, respectively[53,54]. In addition, the LCST decreases as the molar mass increases. This can be attributed to the methyl substituted carbon polymer backbone, which brings more hydrophobicity, thus resulting in a lower LCST. As for 
concentration, the phase diagram exhibits a flat plateau similar to that of PNIPAAm. These properties are modified if the PEG comb is coupled to another hydrophobic or hydrophilic polymer block. By choosing the number of repeating units and the molar mass, the desired LCST can easily be obtained. Polymers having a structure close to PEG include poly(propylene glycol) (PPG) (Figure 6 b), which has an extra methyl substitution group, and poly(glycidyl methyl ether-co-glycidyl ethyl ether) (P(GMEco-GEE)) (Figure 6c). PPG is fully soluble in water when its $M_{n}$ is below $400 \mathrm{~g} / \mathrm{mol}$ and exhibits useful LCST from $400 \mathrm{~g} / \mathrm{mol}$ up to $3000 \mathrm{~g} / \mathrm{mol}$ on a concentration range that narrows down as $M_{n}$ increases[55].

Poly(N-vinylcaprolactam) (PNVCL) (Figure 6e) is also used to some extent to prepare thermoresponsive nanocarriers. The transition temperature is only slightly impacted by the molar mass and the concentration, and LCST thus remains between 32 and $36{ }^{\circ} \mathrm{C}[56]$. The ease of preparation of the polymer and the constant value of the obtained LCST make it a great candidate for facile thermoresponsive polymer synthesis[57].

For a more exhaustive list of non-ionic LCST polymers, the reader is invited to consult the excellent review by Aseyev et al.[58].

\section{II.4. LCST-based nanocarriers}

\section{II.4.1 Nanocarrier formulation techniques}

Polymeric nanocarriers encapsulating drugs are mainly prepared in three different ways: emulsionsolvent evaporation, nanoprecipitation (also termed solvent-displacement method), or direct micellar self-assembly in water[59]. These methods require a polymer containing a hydrophobic block, an organic solvent miscible (nanoprecipitation) or non-miscible (emulsion-solvent evaporation) with water and the drug to be encapsulated. The drug can be either physically encapsulated or chemically linked to the polymer chain to obtain a polymer prodrug. Upon formulation, the drug is entrapped in the polymer matrix that form the core of the nanoparticles. In the case of physical encapsulation, the drug can diffuse through the polymer matrix to reach the surface of the nanoparticle and eventually be released from it. However, this natural release is characterized by fast, uncontrolled "burst release" of a significant fraction of drugs only surface-adsorbed, followed by slow release of drug from the nanoparticle core. In the case of chemical linkage, the drug-polymer linker must be cleaved to release the parent drug from the nanocarrier. The general idea of having a thermoresponsive block in the polymer matrix is meant to control and drastically accelerate the release of the active ingredient by sharply changing the conformation of the polymer chains with temperature. For LCST polymers, the polymer chains shrink upon heating thus pushing outwards the drug from the nanocarrier, as seen on figure 7. This translates in either a decrease in size of the nanocarriers if the particles are colloidally stable, or an increase in size if they start aggregating. The obtained nanoparticles can be further functionalized to add a ligand for cell targeting purposes. 


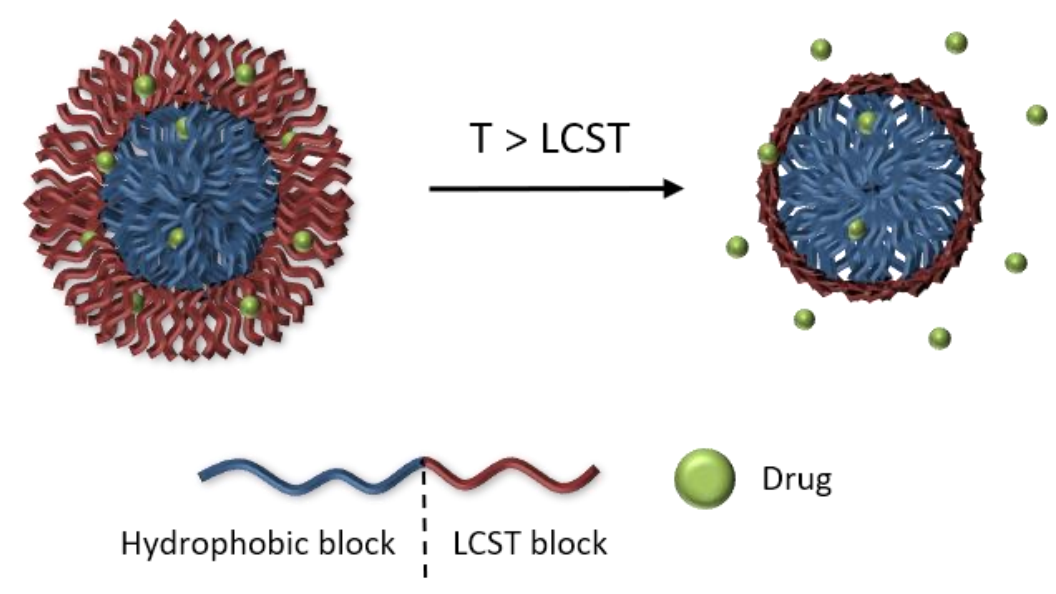

Figure 7: Scheme of a thermoresponsive nanoparticle encapsulating a drug, formulated from a diblock copolymer containing a hydrophobic block that serves as a scaffold, and a LCST block that responds to temperature. Upon heating, the LCST block shrinks as it is no longer hydrated and hydrophobic interactions prevail between the different polymer chains. As the polymer chains shrink, the drug is ejected from the nanoparticle.

\section{II.4.2 LCST nanocarriers}

A selection of relatively recent nanocarriers using LCST polymers is presented here. The characteristics of each system are summarized in the following tables. The first systems are based on a simple encapsulation of drug into a diblock copolymer matrix, followed by: prodrugs, functionalized nanocarriers, natural biomacromolecule modification to generate thermoresponsiveness and a vaccine. These systems are solely based on polymeric material presenting LCST behavior, nevertheless a selection of dual responsive nanocarriers for both $\mathrm{pH}$ and temperature is also presented, as well as thermoresponsive nanoparticles encapsulating metallic constructs.

\section{II.4.2.a. LCST polymer-based nanocarriers for physical drug encapsulation}

Table 2 summarizes the different nanocarriers exploiting LCST thermoresponsiveness for drug delivery. In terms of polymer synthesis, the thermoresponsive block usually makes up for most of the molar mass of the whole materials except in two cases: $725 \mathrm{~g} / \mathrm{mol}$ for a total of 4,550 g/mol and $16,100 \mathrm{~g} / \mathrm{mol}$ for a total of $35,800 \mathrm{~g} / \mathrm{mol}$. This shows that a long thermoresponsive polymer block is not necessary to convey proper thermoresponsiveness. According to the different preparation methods used, the formulations obtained primarily consist in micelles, nanogels and nanoparticles. The difference in terms of definition is not always clear. Micelles should always exhibit a critical micellar concentration (CMC) and are thermodynamically stable with polymer chains in the micelles in equilibrium with the surrounding polymer chains in the medium at the CMC. As they are diluted below the $\mathrm{CMC}$, micelles disassemble into unimolecular amphiphiles. On the other hand, nanogels and nanoparticles are not involved in any equilibrium state with the surrounding medium, meaning that they are not modified upon dilution. The difference between nanogels and nanoparticles is the higher hydration state for nanogels. As for the choice of the encapsulated molecules, they mainly consist in cytotoxic drugs used in cancer treatment. Doxorubicin is a molecule of choice because of its fluorescence properties enabling facile tracing and titration, and its wide use to treat many different types of cancers (e.g., breast, lung, bladder, ovarian, stomach, bone sarcoma, Hodgkin's lymphoma, acute leukemia, etc.). However, doxorubicin must reach the cells' nucleus to exert its therapeutic activity by intercalation and inhibition of DNA biological processes such as replication or 
transcription[60]. Docetaxel and paclitaxel are taxane derivatives which promote tubulin selfassembly, thus blocking the cell's division cycle[61]. These molecules are effective in the cytosol, and do not need to reach the nucleus. Methotrexate is an antimetabolite also active in the cytosol[62]. 
Table 2: Overview of the physico-chemical parameters of LCST nanocarriers with documented in vivo or in vitro results. $M_{n}$ total $=M_{n}$ of the whole polymer; $M_{n}$ thermo $=M_{n}$ of the thermoresponsive block; Drug Loading is the ratio between the mass of encapsulated drug and the total mass of the system.

\begin{tabular}{|c|c|c|c|c|c|c|c|c|c|}
\hline Ref. & Polymer & $\begin{array}{l}M_{\mathrm{n}} \text { total } \\
(\mathrm{g} / \mathrm{mol})\end{array}$ & $\begin{array}{c}M_{\mathrm{n}} \text { thermo. } \\
(\mathrm{g} / \mathrm{mol})\end{array}$ & Nanocarrier & Molecule & $\begin{array}{l}\text { Drug } \\
\text { Loading } \\
\text { (wt.\%) }\end{array}$ & $\begin{array}{l}\text { LCST } \\
\left({ }^{\circ} \mathrm{C}\right)\end{array}$ & Size $(\mathrm{nm})$ & Stimulus purpose \\
\hline$[63]$ & $\begin{array}{l}\text { P(NIPAAm-co- } \\
\text { AAm) }\end{array}$ & n.a. & n.a. & Nanogel & Docetaxel & 7.4 & 40 & 50 (r.t.) & $\begin{array}{l}\text { Stimulus to accumulate the nanohydrogels at the } \\
\text { targeted heated tissue of } \mathrm{S} 180 \text { tumor bearing mice. } \\
\text { Water sack at } 42{ }^{\circ} \mathrm{C} \text { on tumor, heating during the whole } \\
\text { treatment. } 78 \% \text { tumor growth inhibition compared to } \\
41 \% \text { free drug and } 49 \% \text { without hyperthermia. }\end{array}$ \\
\hline$[64]$ & $\begin{array}{l}\text { P(NIPAAm-Co- } \\
\text { AAm)- } b-P B M A\end{array}$ & 10,200 & 7,500 & Micelle & Methotrexate & 15 & 40 & 175 (r.t.) & $\begin{array}{l}\text { Trigger drug release, in vitro LLC cells had less viability } \\
\text { with drug loaded micelles and hyperthermia at } 42^{\circ} \mathrm{C} \text {, } \\
\text { than drug loaded micelles alone. }\end{array}$ \\
\hline$[65]$ & $\begin{array}{l}\text { P(NIPAAm-co- } \\
\text { NHMAAm)-b-PCL }\end{array}$ & n.a. & n.a. & Micelle & Doxorubicin & 6.3 & 38 & 97 (r.t.) & $\begin{array}{l}\text { In vitro, drug release kinetics increased at } 43^{\circ} \mathrm{C} \text { vs. } 38^{\circ} \mathrm{C} \text {. } \\
\text { On cells and in vivo, no hyperthermia was applied or } \\
\text { control at other temperature. No free drug control given } \\
\text { either. }\end{array}$ \\
\hline$[66]$ & $\begin{array}{l}\text { PNIPAAm- } b \text {-PBNP } \\
\text { PNIPAAm- } b \text {-PMNP } \\
\text { PNIPAAm- } b \text {-PNP }\end{array}$ & $\begin{array}{l}14,000 \\
13,000 \\
12,000\end{array}$ & 8,400 & Micelle & Doxorubicin & $\begin{array}{l}26 \\
24 \\
20\end{array}$ & $\begin{array}{l}41 \\
38 \\
32\end{array}$ & $\begin{array}{l}52 \text { (r.t.) } \\
67 \text { (r.t.) } \\
120 \text { (r.t.) }\end{array}$ & $\begin{array}{l}\text { No release at } 20^{\circ} \mathrm{C}(<6 \%) \text {, release at } 37^{\circ} \mathrm{C}(\mathrm{PBNP} 25 \% \text {, } \\
\text { PMNP } 30 \% \text {, PNP } 40 \%) \text {. MCF- } 7 \text { cells were incubated at } \\
37^{\circ} \mathrm{C} \text {, then treated with the diverse micelles at } 20^{\circ} \mathrm{C} \text { or } \\
37^{\circ} \mathrm{C} \text { for } 3 \mathrm{~h} \text { before washing the wells with fresh } \\
\text { medium and carrying on the experiment for another } 48 \\
\text { h. At } 20^{\circ} \mathrm{C} \text {, all micelles were less toxic than free Dox, at } \\
37^{\circ} \mathrm{C} \text { they were equally toxic. }\end{array}$ \\
\hline$[67]$ & $\begin{array}{l}\text { PNIPAAm-U-DPy } \\
\text { PNIPAAm-DAP }\end{array}$ & $\begin{array}{l}18,000 \\
10,500\end{array}$ & 10,300 & Micelle & Doxorubicin & 16 & 34 & 530 (r.t.) & $\begin{array}{l}\text { HepG2 cells were treated at } 25^{\circ} \mathrm{C} \text { and } 37^{\circ} \mathrm{C} \text { with Dox } \\
\text { loaded micelles for } 24 \mathrm{~h} \text {. At } 25^{\circ} \mathrm{C} \text {, no toxicity was seen, } \\
\text { whereas at } 37^{\circ} \mathrm{C} \text {, the } \mathrm{IC} \mathrm{C}_{50} \text { was similar to that of free Dox } \\
\text { (respectively } 1.42 \mu \mathrm{g} / \mathrm{mL} \text { vs. } 1.05 \mu \mathrm{g} / \mathrm{mL} \text { ). }\end{array}$ \\
\hline$[68]$ & Cytosine-PPG & 800 & 800 & Nanogel & Doxorubicin & 24.8 & 35 & $\begin{array}{l}376 \text { (r.t.) } \\
\text { Aggregates and } \\
78 \text { particles } \\
\left(43^{\circ} \mathrm{C}\right) \\
\end{array}$ & $\begin{array}{l}\text { Dox loaded nanogels had a lower } \mathrm{IC}_{50} \text { than free Dox for } \\
\text { small cell lung cancer cell lines } \mathrm{H} 146 \text { and } \mathrm{H} 1688 \text { when } \\
\text { incubated at } 40{ }^{\circ} \mathrm{C} \text {. At } 25^{\circ} \mathrm{C} \text { the loaded nanogels did not } \\
\text { exhibit any cytotoxicity. }\end{array}$ \\
\hline [69] & $\begin{array}{l}\beta \text {-cyclodextrin- } g \text { - } \\
(\text { PEG-v-PNIPAAm)7 }\end{array}$ & 50,000 & $7 \times 7,140$ & Nanoparticle & Paclitaxel & 3 & 35 & $\begin{array}{c}21 \text { (r.t.) } \\
222\left(37^{\circ} \mathrm{C}\right)\end{array}$ & $\begin{array}{l}\text { HepG2 and } \mathrm{H} 460 \text { (non-small lung cancer) cells having } \\
\text { developed resistance to paclitaxel were cultivated at } \\
25^{\circ} \mathrm{C} \text { and } 37^{\circ} \mathrm{C} \text { in the presence of the nanoparticles. Cell } \\
\text { viability was lower for the free drug than the } \\
\text { nanoparticles at } 37^{\circ} \mathrm{C} \text {, at } 25^{\circ} \mathrm{C} \text { they were comparable. In } \\
\text { vivo, with mice bearing HepG2 drug resistant tumor, the } \\
\text { nanoparticles completely inhibited tumor growth } \\
\text { compared with free PTX which showed no inhibition } \\
\text { (same growth for the saline control). }\end{array}$ \\
\hline
\end{tabular}


Table 2 continued.

\begin{tabular}{|c|c|c|c|c|c|c|c|c|c|}
\hline Ref. & Polymer & $\begin{array}{l}\text { Mn total } \\
\text { (g/mol) }\end{array}$ & $\begin{array}{c}\text { Mn thermo. } \\
\text { (g/mol) }\end{array}$ & Nanocarrier & Molecule & $\begin{array}{l}\text { Drug } \\
\text { Loading } \\
\text { (wt. \%) }\end{array}$ & $\begin{array}{l}\text { LCST } \\
\left({ }^{\circ} \mathrm{C}\right)\end{array}$ & Size (nm) & Stimulus purpose \\
\hline$[70]$ & $\begin{array}{l}\text { dPG-PNIPAAm } \\
\text { (dPG1) } \\
\text { dPG-P(GME-co- } \\
\text { EGE) } \\
\text { (dPG2) }\end{array}$ & n.a. & n.a. & Nanogel & $\begin{array}{l}\text { Dexamethasone } \\
\text { (DX) } \\
\text { Tacrolimus } \\
\text { (TAC) }\end{array}$ & $\begin{array}{c}\text { dPG1 } \\
\text { DX } 6.8 \\
\text { TAC } 0.9 \\
\text { dPG } 2 \\
\text { DX } 5.8 \\
\text { TAC } 2.5\end{array}$ & $\begin{array}{l}\mathrm{dPG} 1 \\
34 \\
\mathrm{dPG} 2 \\
29\end{array}$ & $\begin{array}{c}\text { dPG1 } \\
110 \text { (r.t.) } \\
88\left(37^{\circ} \mathrm{C}\right) \\
\mathrm{dPG} 2 \\
133 \text { (r.t.) } \\
113\left(37^{\circ} \mathrm{C}\right)\end{array}$ & $\begin{array}{l}\text { Body temperature serves as the trigger for the } \\
\text { effective skin delivery of DX and TAC. Comprehensive } \\
\text { toxicity study. Both polymers display good results, no } \\
\text { efficacy displayed. }\end{array}$ \\
\hline$[44]$ & $\begin{array}{l}\text { PLL-P(NIPAAm-co- } \\
\text { PLA)- } b \text {-PLA-PLL } \\
\text { dendron }\end{array}$ & 4,550 & 725 & Nanoparticle & $\begin{array}{l}\text { Mouse Nerve } \\
\text { Growth Factor } \\
\quad \text { (NGF) }\end{array}$ & $\begin{array}{l}\text { (efficiency } \\
\text { at 9) }\end{array}$ & 31 & $\begin{array}{l}600\left(25^{\circ} \mathrm{C}\right) \\
150\left(37^{\circ} \mathrm{C}\right)\end{array}$ & $\begin{array}{l}\text { Monitoring uptake of nanoparticles in PC12 cells at } \\
25^{\circ} \mathrm{C} \text { and } 37^{\circ} \mathrm{C} \text {. Up to a } 7.5 \text {-fold increase in uptake at } \\
\text { higher temperature. Cells treated for } 3 \text { days with the } \\
\text { nanoparticles exhibited neurite growth. No free NGF } \\
\text { control is reported. }\end{array}$ \\
\hline$[71]$ & $\begin{array}{l}\text { PNIPAAm- } b- \\
\text { PVPON }\end{array}$ & 35,800 & 16,100 & Micelles in film & Doxorubicin & $\begin{array}{c}9.3 \\
\text { (in film) }\end{array}$ & 32 & $\begin{array}{c}10 \text { (r.t.) } \\
90\left(34^{\circ} \mathrm{C}\right)\end{array}$ & $\begin{array}{l}\text { Cooling to release Dox from micelles in film. Cooling to } \\
20^{\circ} \mathrm{C} \text { releases Dox, heating to } 37{ }^{\circ} \mathrm{C} \text { stops the release. } \\
\text { Taking the surrounding medium of the film after a } \\
\text { cooling cycle inhibits MCF- } 7 \text { cell proliferation. Multiple } \\
\text { cycles allow control of drug release on demand from } \\
\text { the film which acts as a sponge. }\end{array}$ \\
\hline$[72]$ & $\begin{array}{l}\mathrm{dPG} 1 \\
\mathrm{dPG} 2\end{array}$ & n.a. & n.a. & Nanogel & $\begin{array}{l}\text { Etanercept } \\
\quad \text { (ETR) }\end{array}$ & 10 & $\begin{array}{l}\mathrm{dPG} 1 \\
35 \\
\mathrm{dPG} 2 \\
33\end{array}$ & $\begin{array}{c}\mathrm{dPG} 1 \\
84 \mathrm{dPG} 2 \\
185\end{array}$ & $\begin{array}{l}\text { Primary skin cells (keratinocytes and fibroblasts) } \\
\text { derived from normal human skin were first treated } \\
\text { with TNF } \alpha \text { to induce skin inflammation. The } \\
\text { formulation was added on top of the skin and a } \\
\text { gradient of } 32^{\circ} \mathrm{C} \text { to } 37^{\circ} \mathrm{C} \text { was applied for } 3 \mathrm{~h} \text { to mimic } \\
\text { the gradient upon application on a real patient. ETR } \\
\text { was found in the viable epiderms (below the stratum } \\
\text { corneum SC) for the thermoresponsive formulations, } \\
\text { unlike the free ETR in PBS. The carriers did not go past } \\
\text { the SC, the mechanism that allows a farther diffusion is } \\
\text { not yet fully elucidated. }\end{array}$ \\
\hline$[73]$ & $\begin{array}{c}\text { P(NIPAAm-co- } \\
\text { DMAPAAm)-DOPE }\end{array}$ & 6,200 & 5,500 & Liposome & Luc siRNA & $5 / 1(+/-)$ & 37 & $\begin{array}{c}105 \text { (r.t.) } \\
150\left(40^{\circ} \mathrm{C}\right)\end{array}$ & $\begin{array}{l}\text { HeLa-Luc cells treated with the liposomes at } 30^{\circ} \mathrm{C} \text {, } \\
37^{\circ} \mathrm{C} \text { and } 40^{\circ} \mathrm{C} \text {. Lipofectamine (positive control) } \\
\text { worked equally at all temperatures, unmodified } \\
\text { liposomes were less effective but same response at all } \\
\text { temperatures whereas the thermoresponsive } \\
\text { liposomes showed little silencing at } 30^{\circ} \mathrm{C} \text {, and high } \\
\text { silencing (similar to lipofectamine) at } 37^{\circ} \mathrm{C} \text { and } 40^{\circ} \mathrm{C} \text {. }\end{array}$ \\
\hline
\end{tabular}


Beyond standard chemotherapies, other pathologies such as inflammatory skin diseases are investigated. For this type of diseases, the group of Calderón has worked on specific drugs such as dexamethasone and tacrolimus for topical administration. They pushed the concept even further by encapsulating etanercept, a protein, and successfully delivered it to the viable epidermis of a mildly barrier deficient skin, an unprecedented feature discussed further below. In terms of drug loading, these thermoresponsive nanocarriers can encapsulate the same amounts of drug as traditional polymeric nanocarriers with values between 1 and $26 \mathrm{wt} . \%$. The LCST ranged from $31{ }^{\circ} \mathrm{C}$, that is higher than room temperature but lower than body temperature, to $41^{\circ} \mathrm{C}$, that is slightly higher than body temperature and corresponds to mild hyperthermia.

Apart from the system reported by Gu's group[63], all other nanocarriers have an increased drug release kinetics at higher temperature than their LCST compared to the free drug release at a lower temperature. The aim of the system designed by Gu's group is to accumulate at the tumor site under mild hyperthermia. Indeed, at temperature above the LCST, PNIPAAm chains become hydrophobic and nanocarriers interact with one another to form larger aggregates. This physical targeting is achieved by putting a heated water bag on top of the tumor.

The impact of the nature of the hydrophobic block on the physico-chemical properties of drugloaded nanocarriers has been systematically studied by Pietrangelo's group. They synthesized a PNIPAAm block and used it as a basis to synthesize three different hydrophobic blocks of the same molar mass with increasing levels of hydrophobicity: PNP, PMNP and PBNP (defined in Table 1)[66]. They showed that the more hydrophobic the block, the better the doxorubicin encapsulation and the worse the drug release even at temperatures higher than the LCST. The LCST of the diblock copolymer also increased with hydrophobicity for these kinds of polymers, an interesting parameter that can be tuned for future systems. While this work is promising, the formulated unloaded micelles exhibited toxicity at concentrations as low as $130 \mu \mathrm{g} / \mathrm{mL}$, making it difficult to translate to the clinic under the present form.

Working with a thermoresponsive polymer to form uncrosslinked, yet stable micelles is possible [67][68]. To ensure that the thermoresponsive polymer chains interact strongly with one another even below LCST, pendant or end groups exhibiting high hydrogen bonding affinities, similar to what can be seen in DNA, were added. These moieties form strong hydrogen bonded dimers (Figure 8), that provide anchors upon which the polymers interact to form stable nanogels. Upon heating, the thermoresponsive polymers change their conformation and the nanogels shrink which results in efficient drug release. 

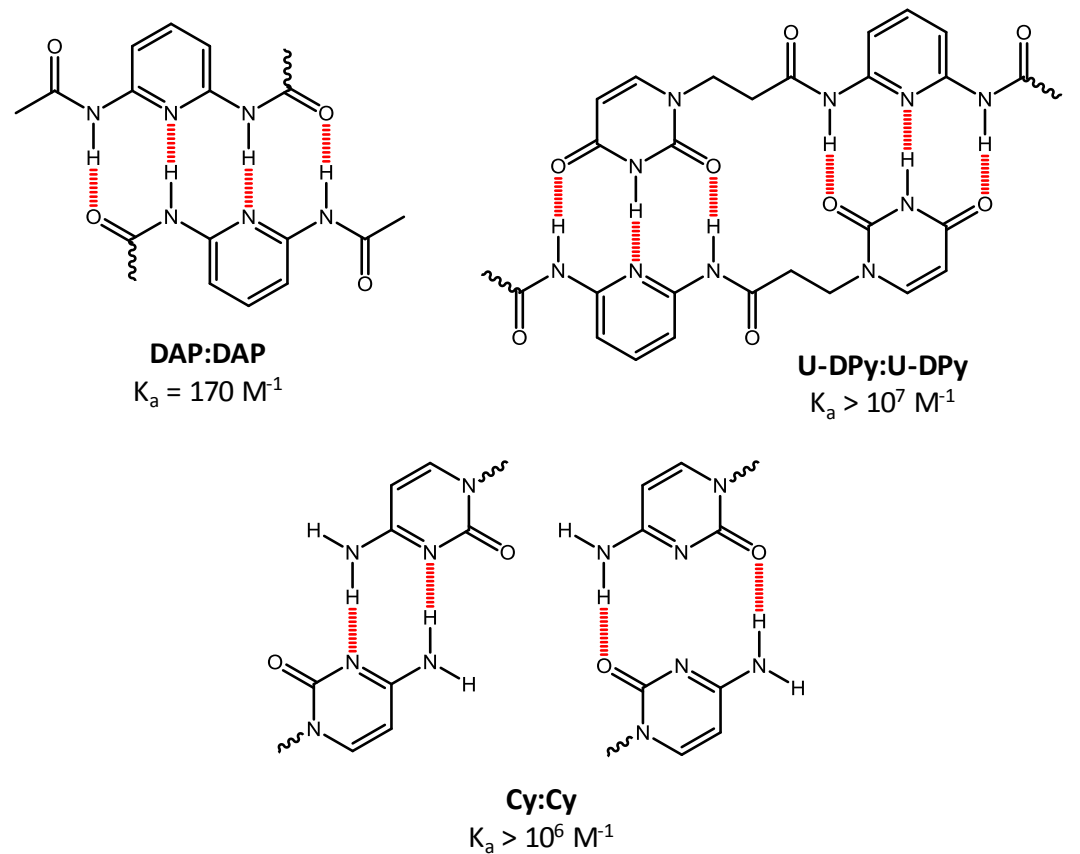

Figure 8: Chemical representation of potential hydrogen bond dimers studied. Hydrogen bonds represented in red, wavy bonds represent links to polymer, $K_{a}$ is the association constant. DAP: diacylamido pyridine. U-DPy: N-(6-(3-(2,4-dioxo-3,4-dihydropyrimidin-1(2H)-yl)propanamido)pyridin2-yl)undec-10-enamide. Cy: cytosine. Adapted from [67][68].

In the case of cytosine-PPG (Cy-PPG), an $800 \mathrm{~g} / \mathrm{mol}$ thermoresponsive PPG end-capped with cytosine, an impressive control of Dox release with temperature was obtained. The loaded nanogels showed no toxicity at $25{ }^{\circ} \mathrm{C}$ on two cell lines but had a lower $I \mathrm{C}_{50}$ than free Dox at $40{ }^{\circ} \mathrm{C}$, with a reduction of up to 4 times the free drug's $\mathrm{IC}_{50}$ at $40^{\circ} \mathrm{C}$. These results highlight the ability of the thermoresponsive carrier to improve the delivery of the drug to the cell's nucleus and increase its efficacy in vitro. Another example of enhanced therapeutic activity of the drug due to the thermoresponsive carrier was also reported by modifying $\beta$-cyclodextrins with a V-shaped PEG-PNIPAAm polymer [69]. The resulting material was used to build inclusion complexes with hydrophobic drugs such as Dox or paclitaxel. The encapsulation was made below the LCST of the system. Upon heating, PNIPAAm chains retract and the inclusion complexes interact with one another forming larger nanoparticles (from $21 \mathrm{~nm}$ at room temperature to $220 \mathrm{~nm}$ at $37^{\circ} \mathrm{C}$ ). Surprisingly, these larger nanoparticles circumvent the tumor's multi drug resistance mechanism as shown by in vivo studies on micebearing paclitaxel resistant tumors. In this case there is no need for additional heating to get the desired effect, as the LCST is at $35{ }^{\circ} \mathrm{C}$; that is close to the mice body temperature. Thermoresponsiveness is used here to allow facile drug encapsulation. However, no experiment was performed with a control non-thermoresponsive polymer to clearly establish the benefit of the thermoresponsiveness. Nevertheless, the absence of tumor targeting by heating raises questions regarding the safety of the formulation, as the whole body of the mouse is at a temperature higher than the LCST of the polymer. First results of toxicity were reported by measuring the mice body weight and histological studies, showing that paclitaxel-loaded nanocarriers were well-tolerated in mice.

Moving forward from traditional small molecule encapsulation for cancer therapy, recent reports showcase a clever use of thermoresponsiveness for diverse applications. As mentioned earlier, Calderón's group has successfully encapsulated and delivered small molecules and proteins 
(etanercept, ETR) to the viable epidermis from a topical administration[70,72]. The system consisted in thermoresponsive polymers, PNIPAAm or P(GEE-co-GME), crosslinked by dendritic polyglycerol that form nanogels. The thermoresponsiveness was used to encapsulate ETR in the nanogels by making them swell in a solution of ETR at $32{ }^{\circ} \mathrm{C}$ (below their LCST), without the use of organic solvent. The release happened when the formulation was placed on reconstructed human skin and subjected to a temperature gradient from 32 to $37^{\circ} \mathrm{C}$. The authors showed that the nanogels do not penetrate the stratum corneum, whereas ETR manages to delve deeper into the viable epidermis. The mechanism underlying this unique diffusion ability is not fully elucidated and no control (e.g., standard emulsion or cream used for topical drug delivery) was performed. Nevertheless, this pioneering work could lead to further research in the topical administration of proteins. Another example of drug loading without the use of organic solvent is provided by Kim et al.[44], where they encapsulated mouse nerve growth factor in thermoresponsive dendrimers based on PNIPAAm, PLA and poly-L-lysine. The advantage of the latter two polyester blocks is to provide biodegradability to the system for easier excretion from the body, as only the PNIPAAm backbone will remain intact. They showcased good neurite growth at $37{ }^{\circ} \mathrm{C}$ compared to $25^{\circ} \mathrm{C}$ but provided no comparison with free mouse nerve growth factor. While showing two different results at two different temperatures is important, a change from $25^{\circ} \mathrm{C}$ to $37^{\circ} \mathrm{C}$ is not clinically relevant and they announced that further research is carried out to develop a system with a LCST close to $42{ }^{\circ} \mathrm{C}$.

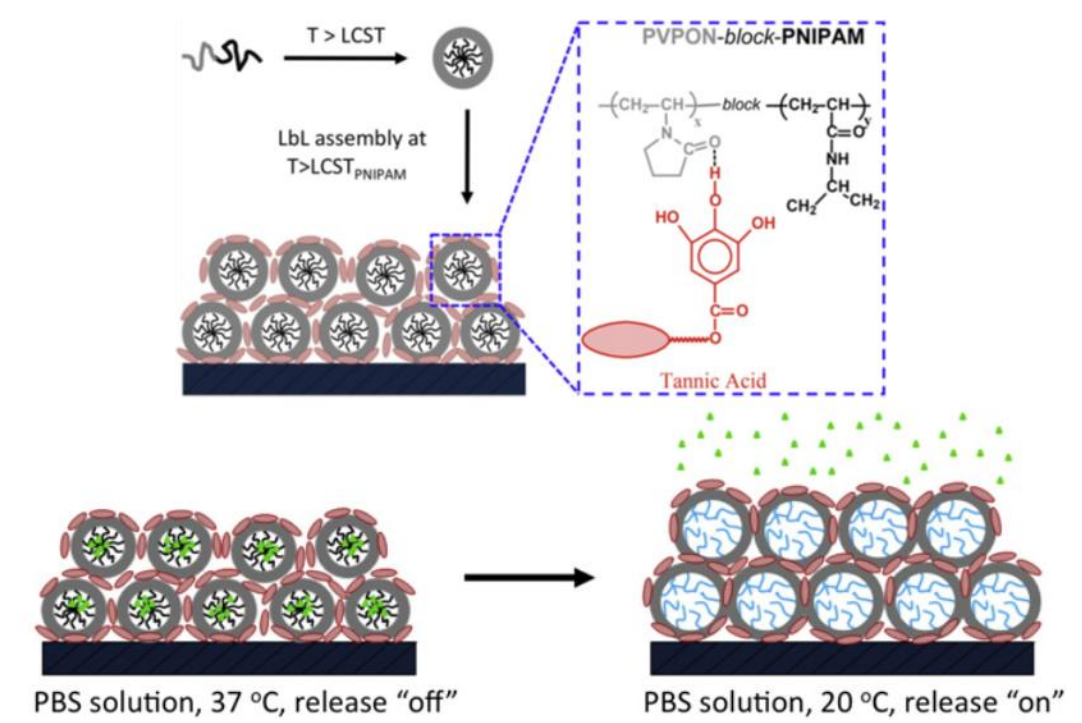

Figure 9: Schematic representation of a layer-by-layer film of thermoresponsive micelles loaded with doxorubicin at temperature higher than the $L C S T, 37^{\circ} \mathrm{C}$ and the response after cooling at $20^{\circ} \mathrm{C}$. The inset shows the possible hydrogen bonding between tannic acid and the hydrophobic block PVPON.

Films containing thermoresponsive block copolymer micelles were built by the layer-by-layer technique on top of silicon wafers[71]. The layers stick with one another thanks to a tannic acid coating that provides additional hydrogen bonds between the different micelles. At a temperature higher than the LCST, the micelles are in a compact state, whereas at a lower temperature, PNIPAAm hydration results in a swelling of the micelles and the release of the drug (Figure 9). They managed to repeat drug loading / unloading cycles up to 15 times with the same film that retained its physical integrity. This novel system combining a thermoresponsive nanocarrier with a layer-by-layer film construction technique could be used for local on-demand treatment of cancer or other applications such as wound healing. 
A study on thermoresponsive polymer-modified lipids to build thermoresponsive liposomes has also been carried out [73]. To enable surface encapsulation of anionic luciferase siRNA, the authors copolymerized NIPAAm with a cationic monomer DMAPAAm (see Table 1 ) before coupling the copolymer to a lipid 1,2-Dioleoyl-sn-glycero-3-phosphoethanolamine (DOPE). They formulated liposomes by mixing the polymer-modified lipid with unmodified lipid and another cationic lipid. This approach is different from the one used by Celsion for their ThermoDox ${ }^{\circledR}$ formulation as they used a mixture of three different unmodified lipids to obtain low temperature sensitive liposomes (LTSL). The underlying mechanisms of drug release are different as the LTSL do not use LCST properties to allow the release of the drug. In this work, they also compared their liposomes with lipofectamine (a positive control) and with PEGylated non-thermoresponsive liposomes. Changes in temperature did not impact the controls' size whereas thermoresponsive liposomes size increased from 105 to 150 $\mathrm{nm}$.

\section{II.4.2.b. LCST polymer prodrug-based nanocarriers}

Here, the thermoresponsive polymers used to build these systems are covalently linked to the drugs. Chemical modification of a drug produces a prodrug that needs to be cleaved to allow the drug to be released to recover its therapeutic activity. There are many advantages compared with traditional physical encapsulation, such as no drug burst release from the system, and the ability to tune drug loading by grafting the polymer with more and more active molecules. The number of reports using the prodrug approach is considerably lower than for traditional physical encapsulation. This may be due to the added difficulty of performing one or more chemical modifications to allow chemical linkage between the thermoresponsive polymer and the drug. As presented in Table 3, oligoethylene glycol dendrons were used as a scaffold to build Dox prodrugs[74]. Dox is linked through an amide bond to the core of the dendrimer, yielding one Dox molecule per dendrimer. Additionally, this dendrimer prodrug was also used to encapsulate free Dox to further increase the drug loading. Favorable Dox/Dox interactions allow high physical drug loading of nearly $25 \mathrm{wt} . \%$. They used the formulation in vitro on HepG2 liver cancer cells at $37^{\circ} \mathrm{C}$ without additional hyperthermia and showed better inhibition with their nanocarrier than with free Dox. The proposed explanation is a preferential endocytosis of the nanocarriers in comparison to passive free drug diffusion through the cell's membrane. This result can be compared to those obtained for paclitaxel inclusion complexes[69] and Cy-PPG encapsulating doxorubicin[68]. Well-designed thermoresponsive formulations may be a key to tackle drug resistance mechanisms in tumor cells as tumor temperatures are generally higher that of the rest of the human body.

Chilkoti's group has reported a thermoresponsive doxorubicin ELP prodrug formulation that consisted in grafting up to 8 Dox molecules on the side chain of a well-defined ELP [75]. The link between Dox and ELP was an acid-labile hydrazine function. To properly release the drug from the $\mathrm{ELP}$, the prodrug must reach late endosomes where the $\mathrm{pH}$ is low enough to trigger drug release. The study showed that the LCST of the formulated micelles remained constant over an ELP concentration range of $2 \mu \mathrm{M}$ to $100 \mu \mathrm{M}$. Heating induced aggregation of the micelles for preferential accumulation at the tumor vasculature. 
Table 3: Overview of the physico-chemical parameters of thermoresponsive polymer prodrug based nanocarriers with documented in vivo or in vitro results. $M_{n}$ total $=M_{n}$ of the whole polymer; $M_{n}$ thermo $=M_{n}$ of the thermoresponsive block; Drug Loading is the ratio between the mass of encapsulated drug and the total mass of the system.

\begin{tabular}{|c|c|c|c|c|c|c|c|c|c|}
\hline Ref. & Polymer & $\begin{array}{l}M_{\mathrm{n}} \text { total } \\
\text { (g/mol) }\end{array}$ & $\begin{array}{c}M_{\mathrm{n}} \text { thermo. } \\
(\mathrm{g} / \mathrm{mol})\end{array}$ & Nanocarrier & Molecule & $\begin{array}{l}\text { Drug Loading } \\
\text { (wt.\%) }\end{array}$ & $\begin{array}{l}\text { LCST } \\
\left({ }^{\circ} \mathrm{C}\right)\end{array}$ & Size (nm) & Stimulus purpose \\
\hline [74] & $\begin{array}{l}\text { Oligoethylene } \\
\text { glycol } \\
\text { dendrons }\end{array}$ & 3,000 & 3,000 & Nanoparticle & Doxorubicin & $\begin{array}{c}17.3(w / w) \\
\text { coupled to the } \\
\text { dendrimer }+24.7 \\
\text { entrapped }\end{array}$ & 39 & $\begin{array}{c}241 \text { (r.t.) } \\
2800\left(42^{\circ} \mathrm{C}\right)\end{array}$ & $\begin{array}{l}\text { Drug release much faster at } 40^{\circ} \mathrm{C} \text { than at } 37^{\circ} \mathrm{C} \text { in vitro. } \\
\text { No use of thermoresponsiveness on HepG } 2 \text { liver cancer cells. } \\
\text { However, the Dox loaded nanoparticles had an } \mathrm{IC}_{50} \text { of } 8 \\
\mu \mathrm{g} / \mathrm{mL} \text { instead of } 27 \mu \mathrm{g} / \mathrm{mL} \text { for the free DOX. }\end{array}$ \\
\hline [75] & $\begin{array}{l}\text { ELP } \\
{[(A G V P G) 9-} \\
(V G V P G)] 16\end{array}$ & 64,000 & 60,000 & Micelle & Doxorubicin & 6.8 & 39 & $\begin{array}{l}27 \text { (r.t.) } \\
\text { Micron } \\
\text { aggregates } \\
42^{\circ} \mathrm{C}\end{array}$ & $\begin{array}{l}\text { Mice bearing murine C } 26 \text { colon tumor. Heating using an in- } \\
\text { house water-bath heater where the tumor was submerged } \\
\text { into. Heating for } 1 \text { hour shows enhanced uptake of both } \\
\text { non-thermoresponsive micelles and thermoresponsive } \\
\text { micelles: effect of hyperthermia. Heating } 10 \text { minutes every } \\
20 \text { minutes (overall } 1 \text { hour of heating) has an impact on } \\
\text { accumulation: } 2.6 \text { fold increased uptake for } \\
\text { thermoresponsive micelles and only } 1.6 \text { fold increase for } \\
\text { non-reponsive micelles compared with unheated tumors. }\end{array}$ \\
\hline
\end{tabular}


However, as seen on Figure 10, depending on the heating schedule applied, Dox encapsulated in non-thermoresponsive nanocarriers could also accumulate at the same level as with thermoresponsive nanocarriers. Mild hyperthermia indeed induced better permeation of epithelial cells surrounding the tumor, which led to a double beneficial effect of combining mild hyperthermia with chemotherapy[27]. The better accumulation of Dox in the tumor using schedule 2 might be due to the unique thermoresponsive properties of the formulated prodrugs. The micelles are soluble when injected, as they reach the heated tumor vasculature they aggregate to form micron-sized particles and adhere to the vasculature. As hyperthermia is stopped after 10 minutes, the aggregates solubilize, and diffuse inside the tumor due to a concentration gradient between the vasculature and the tumor[76]. This process was repeated 6 times over the whole treatment schedule. Other reports do not often go as far as studying different heating schedules when performing in vivo studies, yet these are essential for successful translation to the clinic.

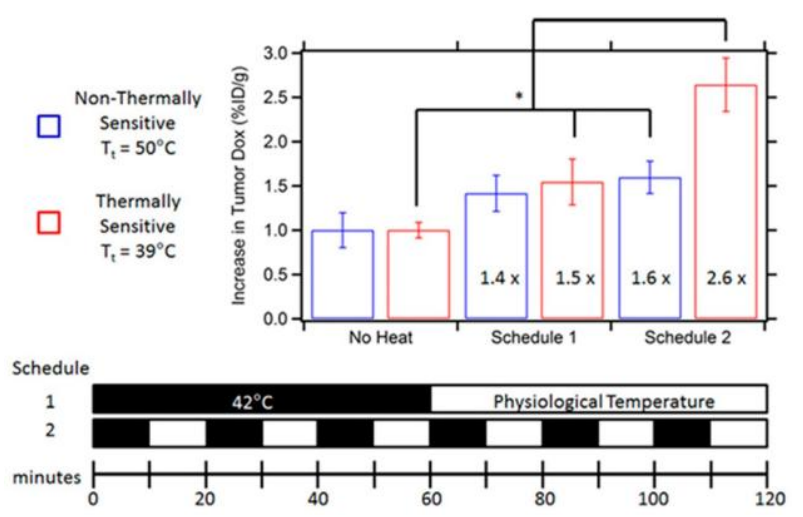

Figure 10: Tumor biodistribution of a thermally responsive and a control ELP-Dox nanoparticle formulation following two heating schedules. ${ }^{*} p<0.05$. Taken from [75].

\section{II.4.2.c. Functionalized LCST nanocarriers for targeted drug delivery}

While thermoresponsive nanocarriers allow physical targeting of the diseased site upon local mild hyperthermia, it is interesting to add a targeting functionality based on ligand-receptor interactions to further enhance the therapeutic efficacy of the nanocarrier. Cancer cells often overexpress specific type of membrane receptors that interacts with specific ligands. The idea is to position such ligands at the surface of the nanocarriers to enable biological targeting of cancer cells[77]. Figure 11 (left), extracted from [78] depicts the use of biotin as a targeting ligand on a LCST nanocarrier. 

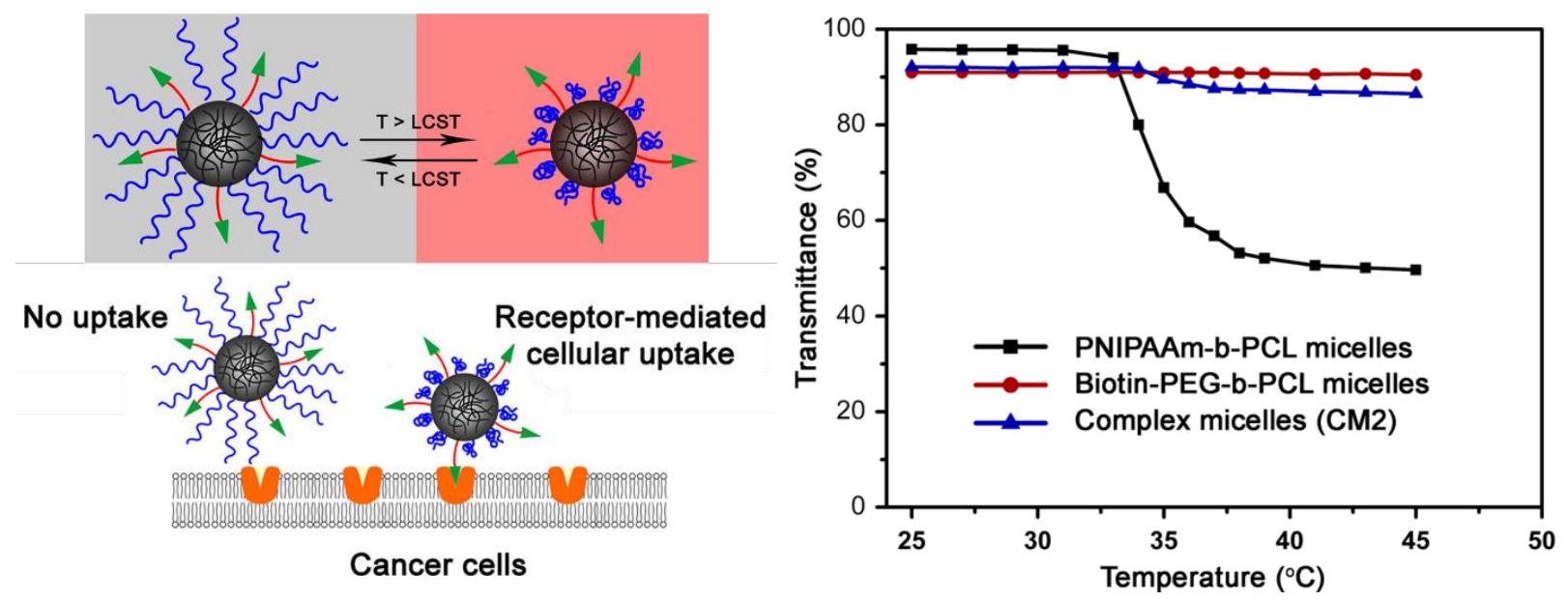

Figure 11: Left: Schematic representation of a LCST nanocarrier modified with biotin as a targeting ligand. Blue lines: LCST blocks; black lines: hydrophobic blocks; red lines: linear PEG; green triangle: biotin; orange: targeting receptor. Right: Light transmittance of the different micelles. Adapted from [78]. 
Table 4: Overview of the physico-chemical parameters of targeted LCST nanocarriers with documented in vivo or in vitro results. $M_{n}$ total $=M_{n}$ of the whole polymer; $M_{n}$ thermo $=M_{n}$ of the thermoresponsive block; Drug Loading is the ratio between the mass of encapsulated drug and the total mass of the system.

\begin{tabular}{|c|c|c|c|c|c|c|c|c|c|}
\hline Ref. & Polymer & $\begin{array}{l}\text { Mn total } \\
\text { (g/mol) }\end{array}$ & $\begin{array}{c}\text { Mn thermo. } \\
\text { (g/mol) }\end{array}$ & Nanocarrier & Molecule & $\begin{array}{l}\text { Drug } \\
\text { Loading } \\
\text { (wt. \%) }\end{array}$ & $\begin{array}{l}\text { LCST } \\
\left({ }^{\circ} \mathrm{C}\right)\end{array}$ & $\begin{array}{l}\text { Size } \\
(\mathrm{nm})\end{array}$ & Stimulus purpose \\
\hline [78] & $\begin{array}{l}\text { PNIPAAm- } b \text {-PCL mixed } \\
\text { with Biotin-PEG- } b \text {-PCL }\end{array}$ & 26,000 & 14,000 & Micelle & $\begin{array}{l}\text { Fluorophore } \\
\text { Nile Red }\end{array}$ & - & 41 & 210 & $\begin{array}{l}\text { Higher cellular uptake in } \mathrm{HepG} 2 \text { cells at } 42^{\circ} \mathrm{C} \text { than at } 25^{\circ} \mathrm{C} \text {, } \\
1.67 \text {-fold increase. }\end{array}$ \\
\hline [79] & $\begin{array}{l}\text { P(FPA-NIPA-Co-AAm- } \\
\text { Co-ODA) }\end{array}$ & n.a. & n.a. & Micelle & Paclitaxel & n.a. & 42 & 80 (r.t.) & $\begin{array}{l}\text { Heating mice at } \mathrm{S} 180 \text { tumor site at } 43^{\circ} \mathrm{C} \text { with PTX loaded } \\
\text { thermoresponsive micelles. Tumor inhibition best with } \\
\text { micelles and hyperthermia }(72.85 \%) \text { compared to micelles } \\
\text { without hyperthermia }(56.83 \%) \text { and free drug }(43.59 \%) \text {. }\end{array}$ \\
\hline$[80]$ & PE-PCL- $b$-PNVCL-FA & 25,000 & 13,600 & Micelle & Doxorubicin & 24.3 & 39 & $\begin{array}{c}185 \\
\text { (r.t.) } \\
80 \\
\left(45^{\circ} \mathrm{C}\right)\end{array}$ & $\begin{array}{l}\text { In vivo rats bearing C6 glioma tumors were treated with the } \\
\text { micelles. } 1 \mathrm{~h} \text { post injection, a warm water bath was put on } \\
\text { top of the tumor for } 30 \text { min. The folic acid coupled micelles } \\
\text { allowed for } 84 \% \text { tumor growth inhibition compared to } 20 \% \\
\text { for free Dox and Dox micelles without the ligand. Free Dox } \\
\text { also exhibited systemic toxicity towards the rats as their } \\
\text { body weight decreased. Dissection of the tumors showed } \\
\text { there was a much greater accumulation of Dox in the tumors } \\
\text { compared with the micelles without ligand. }\end{array}$ \\
\hline
\end{tabular}


In this work, micelles were made from a mixture of two different block copolymers: PNIPAAm- $b-\mathrm{PCL}$, and Biotin-PEG- $b$-PCL where the PEG chain is smaller than the PNIPAAm block. PCL composed the core of the micelles whereas the PNIPAAm and Biotin-PEG blocks were positioned at the surface. Given micelles were a 1:1 (mol:mol) mixture of thermoresponsive and amphiphilic block copolymers, the system exhibited a less pronounced LCST by light transmittance (Figure 11, right). The ligand is shielded at temperature below LCST, while at higher temperature, the PNIPAAm block retracts and reveals the biotin moieties. By specifically heating the diseased cells, there is therefore less risk that the micelles can interact with healthy cells presenting the receptor. In their work, the authors encapsulated a fluorophore as a proof-of-concept and measured cell internalization with or without hyperthermia. Folic acid was also used as a targeting moiety in similar nanocarriers[79]. It was used both for diagnostic and therapy by allowing better fluorophore / drug delivery to the tumor thanks to the targeting property of the formulated micelles. In Figure 12, the encapsulation of a cypate fluorophore inside the micelles allowed imaging of the tumor without the need for heating, showing that the ligand was always available for cell targeting. Nevertheless, to make sure that the micelles did not accumulate in healthy tissue, they performed a folic acid receptor blockade by injecting free folic acid prior to administration of the targeting micelles on mice bearing two different types of tumors. Once the micelles were administrated, they heated one of the two tumors and witnessed preferential accumulation at the heated tumor (Figure 12, right).
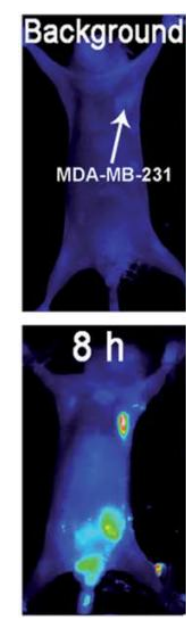
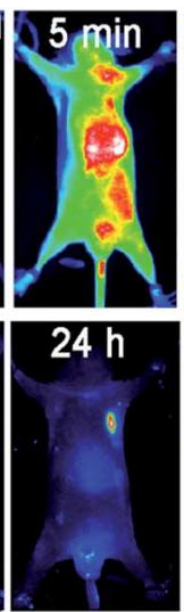
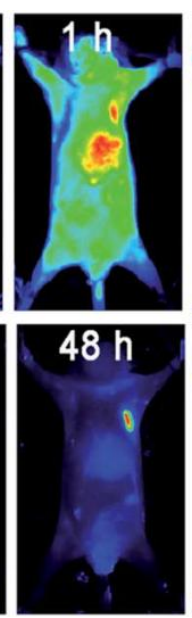
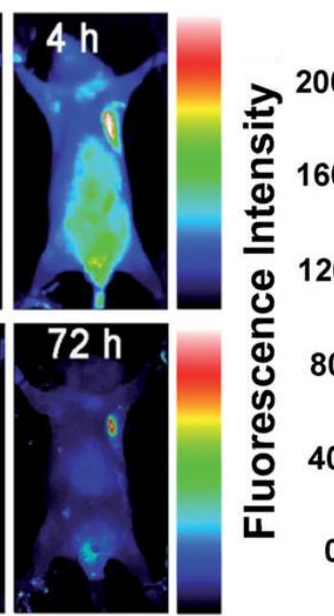

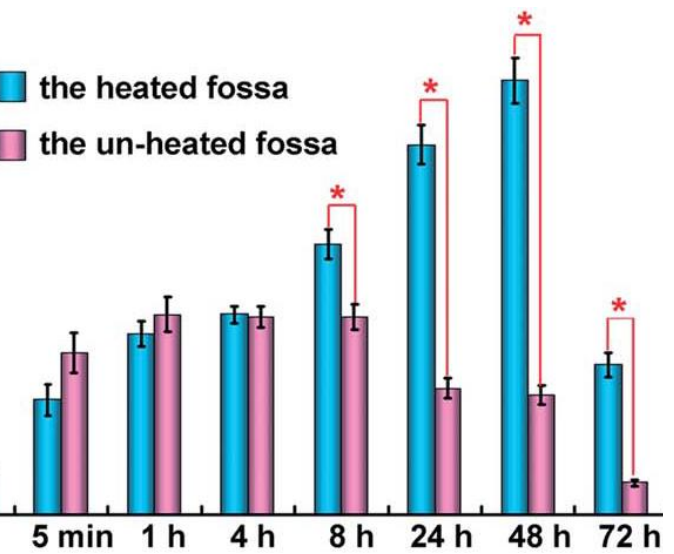

Figure 12: Left, in vivo imaging of a mouse bearing an MDA-MB-231 tumor after injection of a cypate loaded thermoresponsive micelle without hyperthermia. Right: folate blockade experiment on mice bearing two tumors (fossa), injection of free folic acid to block the receptors followed by administration of the cypate loaded thermoresponsive micelles and heating of only one fossa. From [79].

These imaging results were followed by a therapeutic study successfully showing that thermoresponsive paclitaxel-loaded micelles administered to mice with hyperthermia provided the best results in terms of tumor inhibition. The use of folic acid as a targeting ligand gave good in vivo results on C6 glioma tumor-bearing rats [80]. However, the in vivo study was performed without external heating. In vitro, the $\mathrm{IC}_{50}$ of Dox-loaded micelles with folic acid targeting was lower than that of free Dox, showcasing once again a better cellular uptake of Dox from the thermoresponsive micelles. The effect of hyperthermia was only studied for drug release and not in vivo or in vitro, which makes the use a thermoresponsive polymer questionable. In terms of structure, they 
compared two LCST polymers: PNIPAAm and poly( $N$-vinylcaprolactam) (PNVCL) and demonstrated the superiority of the PNVCL based block in terms of thermoresponsiveness.

\section{II.4.2.d. Thermoresponsive nanocarriers based on modified natural biomacromolecules}

The idea behind these systems is to use commercially available natural biomacromolecules as a scaffold to build more biocompatible and biodegradable thermoresponsive nanocarriers the three following reports are based on three different biomacromolecules: (i) fibrinogen, a $340 \mathrm{kDa}$ glycoprotein found in vertebrates that is converted to fibrin by thrombin to trigger blood clotting in case of wound; (ii) chitosan, a variable sized linear polysaccharide containing some $N$-acetylated units, derived from chitin found in the shell of seafood such as shrimps and (iii) hyaluronic acid, a glycosaminoglycan found throughout the whole body as part of the extracellular matrix. In Figure 13 is presented the different modifications of these biomacromolecules.
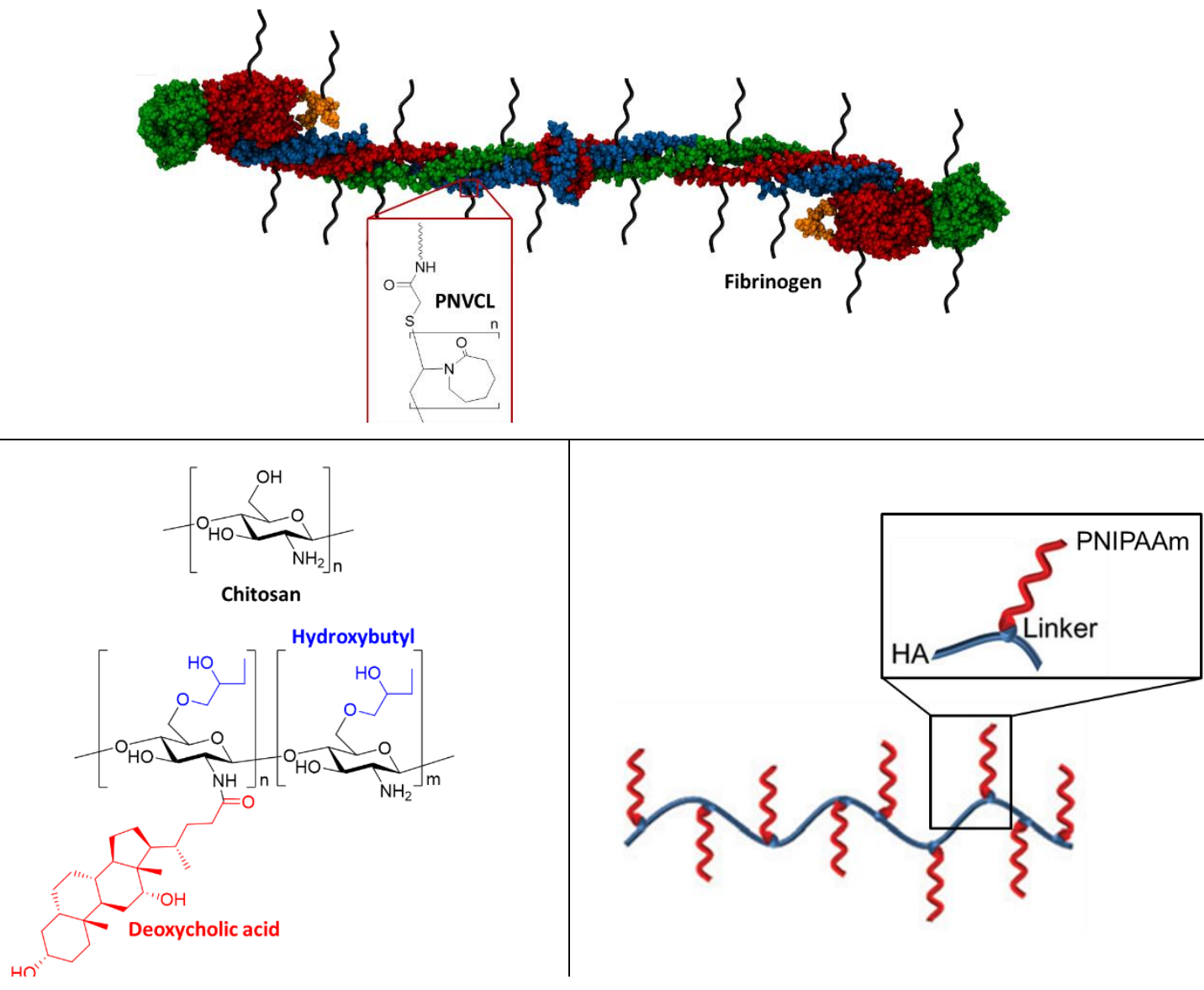

Figure 13: Schematic representations of the modified natural biomacromolecules presented in this review. Top: fibrinogen grafted with PNVCL. Bottom-left: chitosan and deoxycholic acid modified hydroxybutyl chitosan. Bottom-right: hyaluronic acid grafted with PNIPAAm through a small oligoethylene glycol linker. Adapted from [81-83].

PNVCL was synthesized by the RAFT polymerization technique from a chain transfer agent bearing a free carboxylic acid group that was further used for coupling to free amines from fibrinogen's lysine moieties[84]. Fibrinogen was selected not only as a natural biomacromolecule scaffold but also as a targeting ligand, because it can interact with $\alpha_{5} \beta_{1}$ integrin receptors over expressed by several types of cancer cells (e.g., breast, colon, ovarian, lung, glioma, and melanoma[85]). PNVCL has a LCST of 
$32{ }^{\circ} \mathrm{C}$, but when linked to hydrophilic fibrinogen, the resulting LCST varies from 35 up to $54{ }^{\circ} \mathrm{C}$ as the amount of grafted PNVCL decreases. 
Table 5: Overview of the physico-chemical parameters of LCST nanocarriers based on modified natural biomacromolecules with documented in vivo or in vitro results. $M_{n}$ total $=M_{n}$ of the whole polymer; $M_{n}$ thermo $=M_{n}$ of the thermoresponsive block; Drug Loading is the ratio between the mass of encapsulated drug and the total mass of the system. 5-FU: 5-fluorouracil.

\begin{tabular}{|c|c|c|c|c|c|c|c|c|c|}
\hline Ref. & Polymer & $\begin{array}{l}\text { Mn total } \\
\text { (g/mol) }\end{array}$ & $\begin{array}{l}\text { Mn thermo. } \\
\text { (g/mol) }\end{array}$ & Nanocarrier & Molecule & $\begin{array}{l}\text { Drug } \\
\text { Loading } \\
\text { (wt.\%) }\end{array}$ & $\begin{array}{l}\text { LCST } \\
\left({ }^{\circ} \mathrm{C}\right)\end{array}$ & $\begin{array}{l}\text { Size } \\
(\mathrm{nm})\end{array}$ & Stimulus purpose \\
\hline$[84]$ & fib-g-PNVCL & $3.4 \times 10^{5}$ & n.a. & Nanogel & $\begin{array}{l}\text { 5-FU and } \\
\text { Megestrol } \\
\text { (Meg) }\end{array}$ & $\begin{array}{l}10 \mathrm{Meg} \\
16.65-\mathrm{FU}\end{array}$ & 35 & 160 & $\begin{array}{l}\text { L929 fibroblasts and MCF-7 breast cancer cells were } \\
\text { incubated with the loaded nanogels. At temperature above } \\
\text { LCST, there was less cell viability for the MCF-7 cells whereas } \\
\text { L929 fibroblasts viability remained stable. }\end{array}$ \\
\hline$[82]$ & $\begin{array}{l}\text { Deoxycholate- } \\
\text { chitosan-hydroxybutyl }\end{array}$ & $1.05 \times 10^{6}$ & $1.05 \times 10^{6}$ & Nanoparticle & Curcumin & 10 & 40 & $\begin{array}{c}141 \\
\text { (r.t.) } \\
30 \\
\left(43^{\circ} \mathrm{C}\right)\end{array}$ & $\begin{array}{l}\text { Nanoparticles loaded with curcumin reduced colon } \\
\text { colorectal cancer cells Caco- } 2 \text { viability nearly } 2 \text {-fold with } \\
\text { hyperthermia at } 43^{\circ} \mathrm{C} \text { compared to without hyperthermia at } \\
37^{\circ} \mathrm{C} \text {. }\end{array}$ \\
\hline$[83]$ & HA-PNIPAAm & $1.86 \times 10^{6}$ & 15,000 & Nanoparticle & $\begin{array}{l}\text { Hyaluronic } \\
\text { acid }\end{array}$ & $\begin{array}{c}\text { not } \\
\text { applicable }\end{array}$ & 32 & $\begin{array}{l}240(\text { at } \\
\left.37^{\circ} \mathrm{C}\right)\end{array}$ & $\begin{array}{l}\text { The body temperature serves as a trigger to aggregate the } \\
\text { HA conjugates into nanoparticles and slow down the } \\
\text { diffusion of HA. Residence time was superior to } 21 \text { days for } \\
\text { the HA conjugates whereas regular HA was completely } \\
\text { cleared after the same amount of time. }\end{array}$ \\
\hline
\end{tabular}

Table 6: Overview of the physico-chemical parameters of a LCST nanocarrier-based vaccine. $M_{n}$ total $=M_{n}$ of the whole polymer; $M_{n}$ thermo $=M_{n}$ of the thermoresponsive block; Drug Loading is the ratio between the mass of encapsulated drug and the total mass of the system.

\begin{tabular}{|c|c|c|c|c|c|c|c|c|c|}
\hline Ref. & Polymer & $\begin{array}{l}\text { Mn total } \\
\text { (g/mol) }\end{array}$ & $\begin{array}{c}\text { Mn thermo. } \\
\text { (g/mol) }\end{array}$ & Nanocarrier & Molecule & $\begin{array}{c}\text { Drug } \\
\text { Loading } \\
\text { (wt.\%) }\end{array}$ & $\begin{array}{l}\text { LCST } \\
\left({ }^{\circ} \mathrm{C}\right)\end{array}$ & $\begin{array}{l}\text { Size } \\
(\mathrm{nm})\end{array}$ & Stimulus purpose \\
\hline$[86]$ & $\begin{array}{l}\text { P(HPMA-co-PgMA)- } b \text { - } \\
\text { P(DEGMA) } \\
\text { PgMA modified to } \\
\text { incorporate a coil } \\
\text { peptide }\end{array}$ & 16,800 & 7,600 & Nanoparticle & $\begin{array}{l}\text { TLRa (SM } \\
20 \times 7 / 8 a)\end{array}$ & $3 \mathrm{~mol} . \%$ & 33 & $\begin{array}{c}\text { few nm } \\
\text { (r.t.) } \\
2000 \\
\left(37^{\circ} \mathrm{C}\right)\end{array}$ & $\begin{array}{l}\text { Antigen interacts with a coil peptide grafted onto the } \\
\text { hydrophilic block of the polymer. The antigen serves as a } \\
\text { nucleus for particle aggregation above the transition } \\
\text { temperature of } 33^{\circ} \mathrm{C} \text {, at body temperature. The report } \\
\text { shows that particle presentation of both the TLRa and the } \\
\text { antigen at the same time stimulates immunity. The } \\
\text { thermoresponsiveness allows for keeping the formulation as } \\
\text { a clear solution in storage and having in situ particle } \\
\text { formation upon administration. }\end{array}$ \\
\hline
\end{tabular}


This result shows that a certain amount of thermoresponsive polymer must be grafted to fully transfer its thermoresponsive properties. The nanogel structure was obtained by cross-linking the modified proteins with $\mathrm{CaCl}_{2}$. Two drugs for the treatment of breast cancer were encapsulated in such a system: megestrol acetate, a hormone analogue to provide hormonal therapy and 5fluorouracil (5-FU) for traditional cytotoxic therapy.

Thermoresponsiveness was also conferred by achieving modification of chitosan with a small molecule [82]. The underlying mechanism of the LCST property stems from the structural similarity between the repeating hydroxybutyl moiety and PEG (see section II.3). To finely tune the LCST, deoxycholic acid (DA) was added as a hydrophobic pendant group, and a lower LCST was obtained as the amount of grafted DA was increased. The nanoparticle size decreased with the additional grafting of DA: from $180 \mathrm{~nm}$ at $2.5 \%$ grafting down to $105 \mathrm{~nm}$ at $5.8 \%$ grafting. Chitosan is a cationic polymer at $\mathrm{pH}$ 7.4, and cationic polymers can easily interact with anionic cell membranes and exhibit toxicity[87]. Despite the positive surface charge, unloaded nanocarriers did not reduce cellular viability below $80 \%$ up to $500 \mu \mathrm{g} / \mathrm{mL}$. In this study the authors encapsulated curcumin, a natural compound notorious for being difficult to formulate due to its chemical instability: it has a half-life of $10 \mathrm{~min}$ in PBS at $37{ }^{\circ} \mathrm{C}$., but leading to very significant in vitro cytotoxicity against cancer cells $[88,89]$. The study confirmed this activity on colorectal cancer Caco-2 cells when using a thermoresponsive nanocarrier and hyperthermia.

In the case of osteoarthritis, hyaluronic acid (HA) content decreases in joints resulting in less protective cartilage. Bone is exposed, and chronic inflammation occurs locally. Intra-arterial injections of exogenous HA can be used to relieve the pain, but HA degrades rapidly therefore the patient needs to be injected frequently for a long-term effect. A potential solution proposed by Allémann's group was to synthesize thermoresponsive HA so that at body temperature (above the LCST), it formed nanoparticles to protect HA from degradation and could ultimately lead to less frequent injections to the patient[83]. While PNIPAAm grafted with HA systems have already been described, they were rapidly degraded and excreted in vivo. This study revealed the importance of having the PEG linker between HA and the PNIPAAm chains to readily obtain nanoparticles at body temperature and protect HA from early degradation. As shown in Figure 14, the modified HA did not diffuse as far from the injection site as regular HA did, which means a higher residence time and thus a lesser need to inject a consecutive HA dose. Dexamethasone, an anti-inflammatory drug used to treat several immune diseases, was encapsulated and its release from the nanoparticles was controlled with temperature. It would be a significant improvement for osteoarthritis therapy if it could be given in conjunction with a long-lasting HA. 

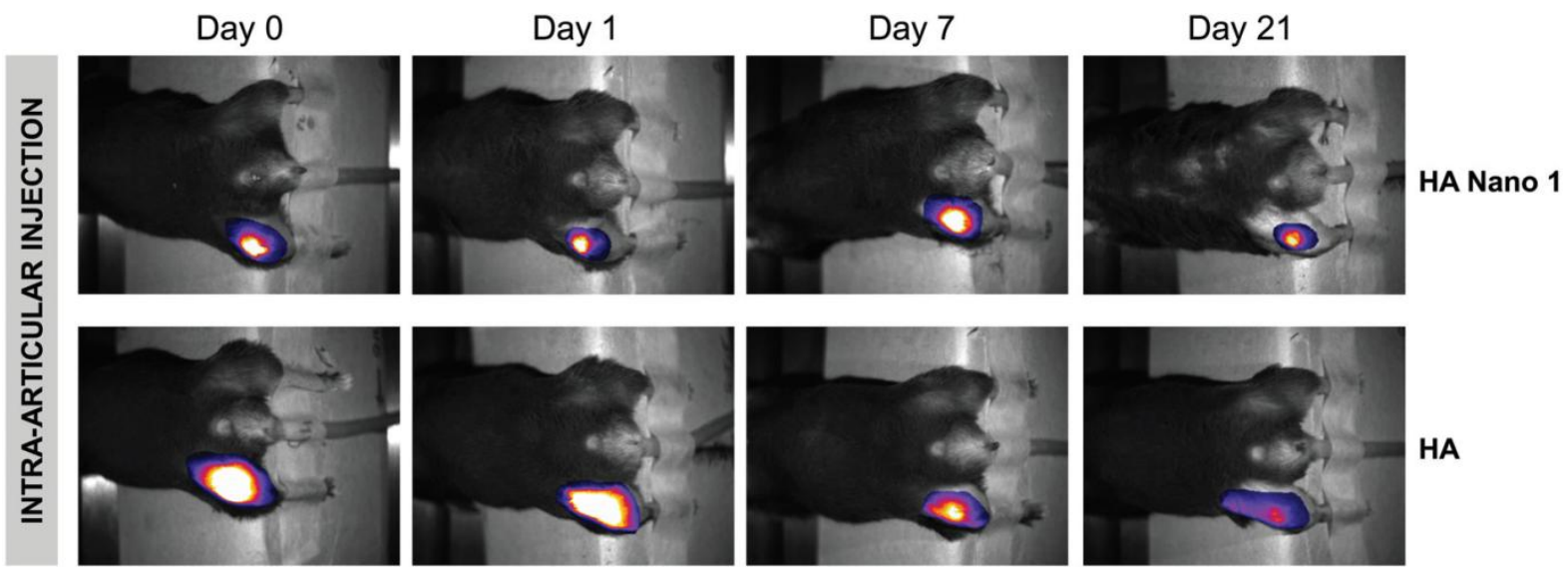

Figure 14: In vivo imaging of mice intra-articulately injected with modified hyaluronic acid (HA Nano 1) and regular HA. The thermoresponsive HA stays in the joint zone, while regular HA diffuses farther from the articulation, resulting in a worse protection. Taken from [83].

\section{II.4.2.e. LCST nanocarriers for vaccination}

TRPP-7/8a-coil

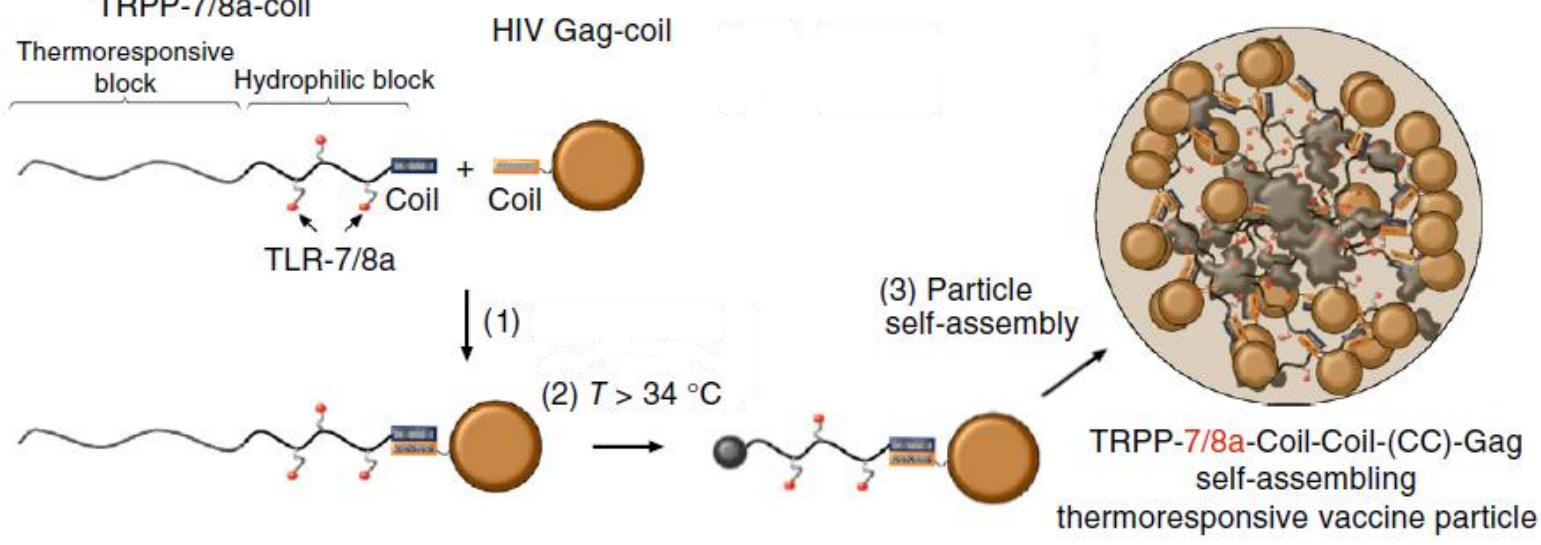

Figure 15: Cartoon schematic of a temperature-responsive polymer particle (TRPP) modified with a coil peptide that forms heterodimers with a recombinant HIV Gag-coil fusion protein to form TRPP7/8a-(CC)-Gag. Heterodimerization occurs at room temperature and particle formation results at temperatures greater than $33^{\circ} \mathrm{C}$. TLR-7/8a: Toll Like Receptor 7 and 8 agonist, small molecule. Adapted from [86].

Lynn et al. reported a study on the in vivo immune response after administration of a nanoparticulate formulation of a toll receptor like agonist (TLRa)[86]. They worked on a small molecule agonist of both TLR-7 and TLR-8, named SM 20x7/8a, as it has shown to activate major immune response pathways. Several agonists were first coupled to a non-thermoresponsive polymer chain, forming an agonist prodrug, which was in turn formulated into large nanoparticles (around $600 \mathrm{~nm}$ ). This TLRa prodrug showed great immune response in comparison with free agonist, as there was a selective uptake in the lymph of the nanoparticles where they eventually reached the lymph node for maximum exposure to immune cells. While this first nanoparticle formulation exhibited good immune response, the authors pointed out that the nanoparticle formulation may degrade over time in storage and sought to employ a LCST polymer to circumvent potential nanoparticle degradation. Indeed, at temperature below the polymer's LCST $\left(33^{\circ} \mathrm{C}\right)$, the prodrug was soluble in water without forming nanoparticles that could degrade. Upon subcutaneous injection, the 
local temperature is above the LCST, forcing the prodrug to form aggregates in situ. As the injection was subcutaneous, the prodrug stayed locally concentrated long enough for the thermoresponsiveness to have its effect. The employed LCST block consisted in poly[di(ethylene glycol) methyl ether methacrylate] (PDEGMA), a comb-like PEG derivative. Tuning of the LCST was possible by varying the amount of grafted SM 20x7/8a, a hydrophobic molecule. To exert maximum immune response, they managed to co-deliver an antigen with the agonist by exploiting coil-coil interaction between a modified antigen and a peptide modified prodrug (Figure 15). Thermoresponsiveness here addresses the important issue of formulation degradation/stability and allows in situ vaccine nanoparticulate formation.

\section{II.4.2.f. LCST and pH responsive nanocarriers for dual-responsive drug delivery}

The aim of having dual-responsive systems for drug delivery is to leverage an external stimulus to target a specific site for nanocarrier accumulation, and to benefit from an endogenous stimulus for more efficient drug delivery[90,91]. As demonstrated in the reports of section II.4.2.a., LCST-based nanocarriers can accumulate locally where hyperthermia is applied. Once the nanoparticles have been taken up by cells, they are located in endosomes where the $\mathrm{pH}$ gradually becomes more acidic, down to $\mathrm{pH} 6.5$ in what is known as a late endosome. Eventually late endosomes can fuse with lysosomes leading to a further decrease of the $\mathrm{pH}$ down to $\mathrm{pH}$ 5[92]. For the drug to be active, it must exit the endosome and reach its target, either the cytosol (albendazole in Table 7) or the cell's nucleus (Dox). The idea of using a pH-responsive polymer is thus to allow faster degradation of the nanoparticle structure inside the acidic endosome and promote endosomal escape of the drug for a more efficient drug delivery[93]. The rationale in combining both temperature and $\mathrm{pH}$-responsive materials to build a drug delivery nanocarrier is to enhance the ability of the nanocarrier to accumulate at the desired site and to efficiently release the drug when the $\mathrm{pH}$ conditions allow it, for improved efficiency of the drug delivery system.

Except for the system described by Qin et al.[94], all the reported systems in Table 7 employ a $\mathrm{pH}-$ responsive polymer block linked to the thermoresponsive one. Loh et al. opted for poly[(R)-3hydroxybutyrate] (PHB), a hydrophobic polyester that degrades into D-3-hydroxybutyrate, a component of human blood[95], whereas Hong et al. reported a nanocarrier made from a poly(histidine) (PHis) block[96]. Histidine is a natural occurring amino acid with a pKa around 6, due to the protonation state of the nitrogen in the imidazole ring. Poly(methacrylic acid) (PMAA) is easy to synthesize and responds to $\mathrm{pH}$ due to its several free carboxylic acid groups[97]. In comparison with the previous two polymers, PMAA is not biodegradable. Another example of a nonbiodegradable $\mathrm{pH}$-responsive polymer used in conjunction with a LCST polymer block is poly[2(diisopropylamino)ethylmethacrylate] (PDPA)[98] whose tertiary amines can be protonated at slightly acidic pH. The work by Qin et al. put forward the in-situ formation of Schiff base bonds between the primary amine groups of chitosan and the ketone groups of Dox[94]. Their complex system integrated chitosan-coated carbon nanotubes encapsulated with Dox in a cross-linked PNIPAAm matrix, as seen in Figure 16. They managed to encapsulate a very high amount of Dox (ca. > 40 wt.\%), which is rarely seen for traditional drug-loaded nanoparticulate systems. The purpose was to use near infrared (NIR) illumination on carbon nanotubes that in turn transformed this energy into heat for local hyperthermia. The Schiff base bonds between Dox and chitosan were cleaved inside late endosomes for better drug release. In comparison with the other presented reports, they used a heating technique that could be easily used in a clinical setting. 
As for the work by Khine et al., a pH temperature dual responsive formulation of albendazole, an anthelmintic drug used to treat parasitic infections, was studied. It has been extensively reported that albendazole can be used to treat cancer but because of its very low water-solubility, designing a suitable formulation still remains challenging[99]. By tuning the amount of MAA units in the copolymer, the burst release was limited, and $\mathrm{pH}$ response of the system was finely tuned. Indeed, with $12 \%$ MAA content in the copolymer, it took 10 hours to get $50 \%$ of the drug released, whereas with no MAA it took less than an hour to reach the same release. The copolymer's LCST at pH 7 was measured at $50{ }^{\circ} \mathrm{C}$, but the copolymer readily precipitated at $\mathrm{pH} 5$ allowing for efficient drug release in the late endosomes. 
Table 7: Overview of the physico-chemical parameters of temperature and $p H$ dual-responsive nanocarriers with documented in vivo or in vitro results. $M_{n}$ total $=$ $M_{n}$ of the whole polymer; $M_{n}$ thermo $=M_{n}$ of the thermoresponsive block; Drug Loading is the ratio between the mass of encapsulated drug and the total mass of the system.

\begin{tabular}{|c|c|c|c|c|c|c|c|c|c|}
\hline $\begin{array}{c}\text { Ref } \\
\text { - }\end{array}$ & Polymer & $\begin{array}{l}\text { Mn } \\
\text { total } \\
\text { (g/mol } \\
\quad)\end{array}$ & $\begin{array}{l}\text { Mn } \\
\text { thermo } \\
\text { (g/mol) }\end{array}$ & Nanocarrier & Molecule & $\begin{array}{l}\text { Drug } \\
\text { Loading } \\
\text { (wt.\%) }\end{array}$ & $\begin{array}{l}\text { LCS } \\
\mathrm{T} \\
\left({ }^{\circ} \mathrm{C}\right)\end{array}$ & Size (nm) & Stimulus purpose \\
\hline [95] & $\begin{array}{l}\text { PDMAEMA- } \\
\text { PHB- } \\
\text { PDMAEMA }\end{array}$ & 6,320 & 4,200 & Micelle & Doxorubicin & 31 & 36.2 & $\begin{array}{l}\text { Bimodal distribution at } \\
10 \text { to } 20 \mathrm{~nm} \text { and } 500 \text { to } \\
600 \mathrm{~nm}\left(20^{\circ} \mathrm{C}\right) \\
\text { Micron aggregates } \\
\left(40^{\circ} \mathrm{C}\right) \text { except at } \mathrm{pH} 2 \\
\end{array}$ & $\begin{array}{l}\text { Encapsulated drug has } I C_{50} 58 \text { times higher than free Dox on } \\
\text { HeLa cells. With hypothermia to } 20^{\circ} \mathrm{C} \text {, the } I_{50} \text { is only } 3 \\
\text { times higher, increased efficacy. However, a control with } \\
\text { pluronic Dox loaded micelles shows equivalent response to } \\
\text { temperature. }\end{array}$ \\
\hline [96] & $\begin{array}{l}\text { PHis-PLGA- } \\
\text { PEG-PLGA- } \\
\text { PHis }\end{array}$ & 8,215 & 2,000 & Micelle & Doxorubicin & 10.4 & 45 & $\begin{array}{c}79 \text { (r.t.) } \\
30\left(50^{\circ} \mathrm{C}\right)\end{array}$ & $\begin{array}{l}\text { Thermoresponsiveness is not exploited in the studies } \\
\text { conducted on MCF- } 7 \text { cells, but the micelles were more } \\
\text { cytotoxic at lower pH. }\end{array}$ \\
\hline [97] & $\begin{array}{l}\text { PMMA-b- } \\
\text { P(MAA-co- } \\
\text { DEGMA) }\end{array}$ & 15,600 & 7,150 & Micelle & Albendazole & $\begin{array}{c}\text { n.a. } \\
(69 \\
\text { efficiency) }\end{array}$ & 50 & 92 (r.t.) & $\begin{array}{l}\text { Lower } \mathrm{pH} \text { in the endosomes also lowers the LCST resulting } \\
\text { in a collapse of the micelles and the proper release of the } \\
\text { drugs inside the } \mathrm{A} 2780 \text { ovarian cancer cells. }\end{array}$ \\
\hline [94] & $\begin{array}{l}\text { PNIPAAm } \\
\text { on chitosan } \\
\text { adsorbed } \\
\text { carbon } \\
\text { nanotubes } \\
\text { (PEG- } \\
\text { diacrylate } \\
\text { as } \\
\text { crosslinkers } \\
\text { ) }\end{array}$ & n.a. & n.a. & Nanoparticle & Doxorubicin & 43 & 38 & $\begin{array}{c}240 \text { (r.t.) } \\
100\left(39^{\circ} \mathrm{C}\right)\end{array}$ & $\begin{array}{l}\text { NIR used to heat the desired tissue. HeLa cervical cancer } \\
\text { cells were more viable when exposed to Dox loaded } \\
\text { nanoparticles than with free Dox. With NIR irradiation, cell } \\
\text { inhibition of the nanoparticles was higher than that of free } \\
\text { Dox. }\end{array}$ \\
\hline [98] & $\begin{array}{l}\text { PDPA- } b- \\
\text { P(NIPAAm- } \\
\text { co-DMAAm) }\end{array}$ & 17,000 & 11,700 & Micelle & Doxorubicin & 3.8 & 39 & $\begin{array}{c}\mathrm{pH} 7.4 \\
50 \text { (r.t.) } \\
\text { Micron aggregates } \\
\left(42^{\circ} \mathrm{C}\right) \\
\mathrm{pH} 5.4 \\
\left.9 \text { (r.t. and } 42^{\circ} \mathrm{C}\right)\end{array}$ & $\begin{array}{l}\text { HeLa cells were incubated with Dox loaded micelles for } 2 \mathrm{~h} \\
\text { at } 37^{\circ} \mathrm{C} \text { or } 42^{\circ} \mathrm{C} \text {. At } 42^{\circ} \mathrm{C} \text { cell viability was reduced } 3 \text {-fold } \\
\text { compared to } 37^{\circ} \mathrm{C} \text {. }\end{array}$ \\
\hline
\end{tabular}




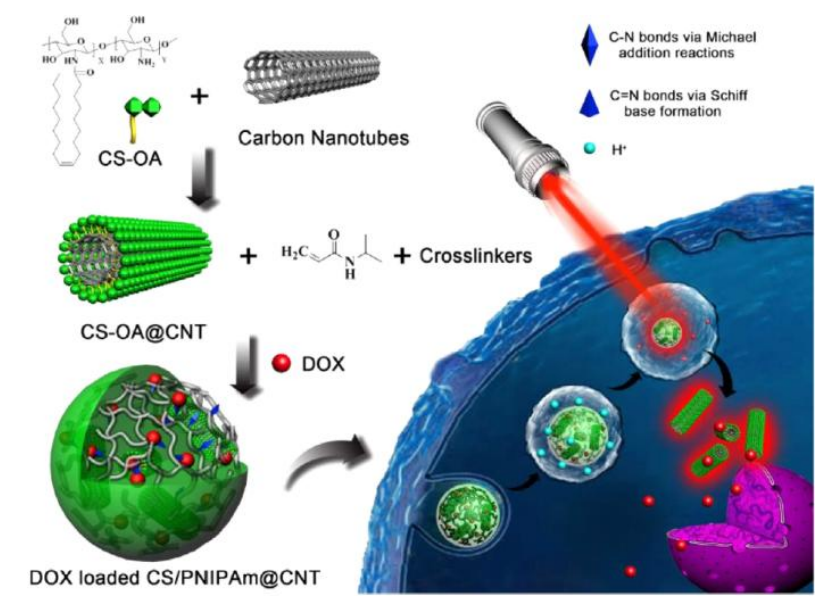

Figure 16: Schematic representation of a NIR-and pH-responsive nanoparticles as described by Chai et al.[94].

The impact of $\mathrm{pH}$ on the thermoresponsiveness of the LCST block was further investigated (Figure 17). At a regular $\mathrm{pH}$ of 7.4 , the LCST was at $39{ }^{\circ} \mathrm{C}$, which allowed micelle aggregation with mild hyperthermia at the tumor site. At acidic pH 5.4, the LCST shifted to $50{ }^{\circ} \mathrm{C}$, allowing the copolymer chains to fully solubilize and release the encapsulated Dox. Cytotoxicity tests with a copolymer having a hydrophobic block instead of the thermoresponsive block did not give better results upon hyperthermia. Therefore, it appears the $\mathrm{pH}$ sensitivity was here mandatory for an efficient drug delivery.
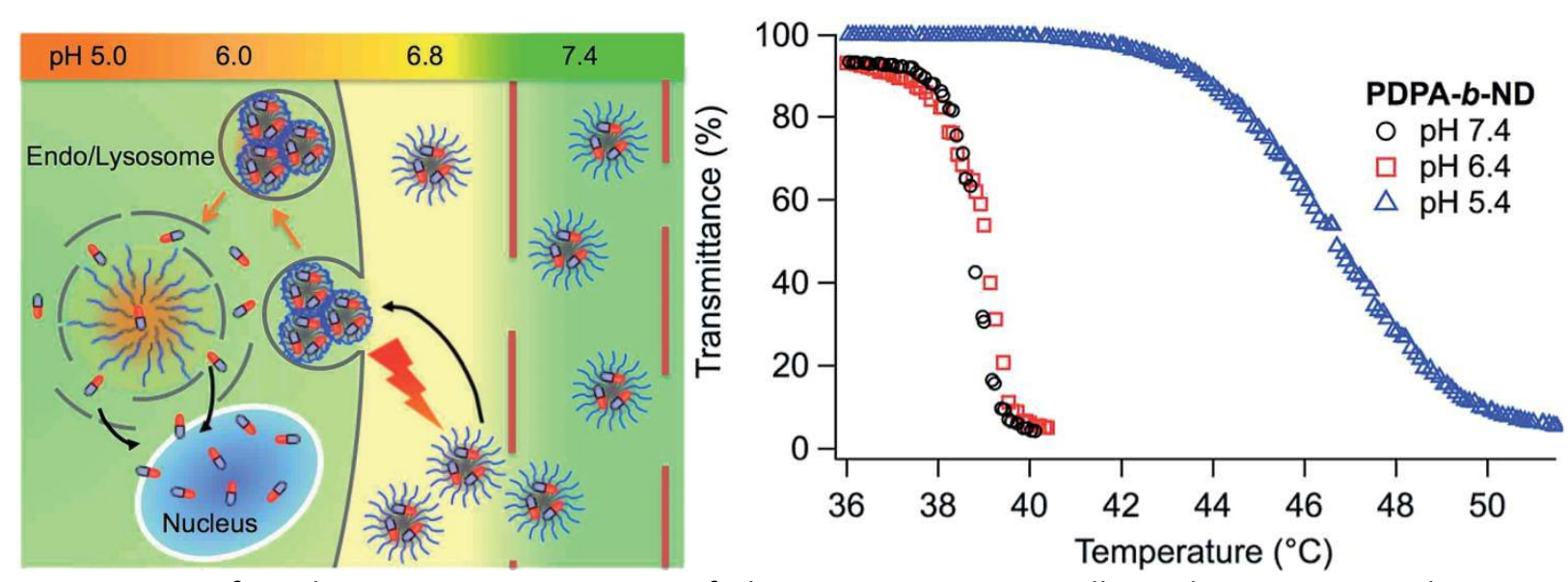

Figure 17: Left: Schematic representation of thermoresponsive micelle endocytosis upon heating (thunder) to induce micellar aggregation, followed by micelle disruption at acidic $\mathrm{pH}$ in late endosomes. Right: Transmittance curves as a function of temperature and $\mathrm{pH}$ of the dual responsive micelles. Adapted from [98].

\section{II.4.2.g. LCST and metal-based nanocarriers for drug delivery}

Metal core nanoparticles made of gold, iron, or copper are currently being developed for their magnetic (iron) or optical properties (gold), as well as a scaffold for grafting ligands and performing biological studies (gold nanoparticles)[100]. In the case of iron nanoparticles, these can accomplish two important actions: magnetic guidance towards the diseased tissue by physically guiding the suspension[101,102] and local hyperthermia by applying a specific alternating magnetic 
field[103,104]. This type of nanocarrier has been shown to be relatively biocompatible[105]. Usually these nanoparticles are in the $10 \mathrm{~nm}$ size range and cannot encapsulate a drug without surface modification. Gold nanoparticles are used as their surface can be easily modified to attach ligands and study the nanoparticle's fate once taken up by a cell.

The work by Deng et al. focused on Mn and Zn doped ferrite (MZF) magnetic nanoparticles coencapsulated with Dox inside a LCST copolymer matrix[106]. They used a diblock copolymer with a PCL biodegradable hydrophobic block and a poly(2-(2-methoxyethoxy)ethyl methacrylate-cooligo(ethylene glycol)methacrylate) ( $\mathrm{P}\left(\mathrm{MEO}_{2} \mathrm{MA}-\mathrm{co}-\mathrm{OEGMA}\right)$ ) thermoresponsive block, based on PEG derivatives. As seen in Figure 18, they managed to formulate $200 \mathrm{~nm}$ micelles encapsulating both MZF and Dox. The authors tested their system with regular hyperthermia and magnetically induced hyperthermia through alternating magnetic field (AMF). The results showed an increased response with hyperthermia and even better response with the AMF stimulus. MZF nanoparticles were thus able to enhance the release of the drug and its therapeutic effect.
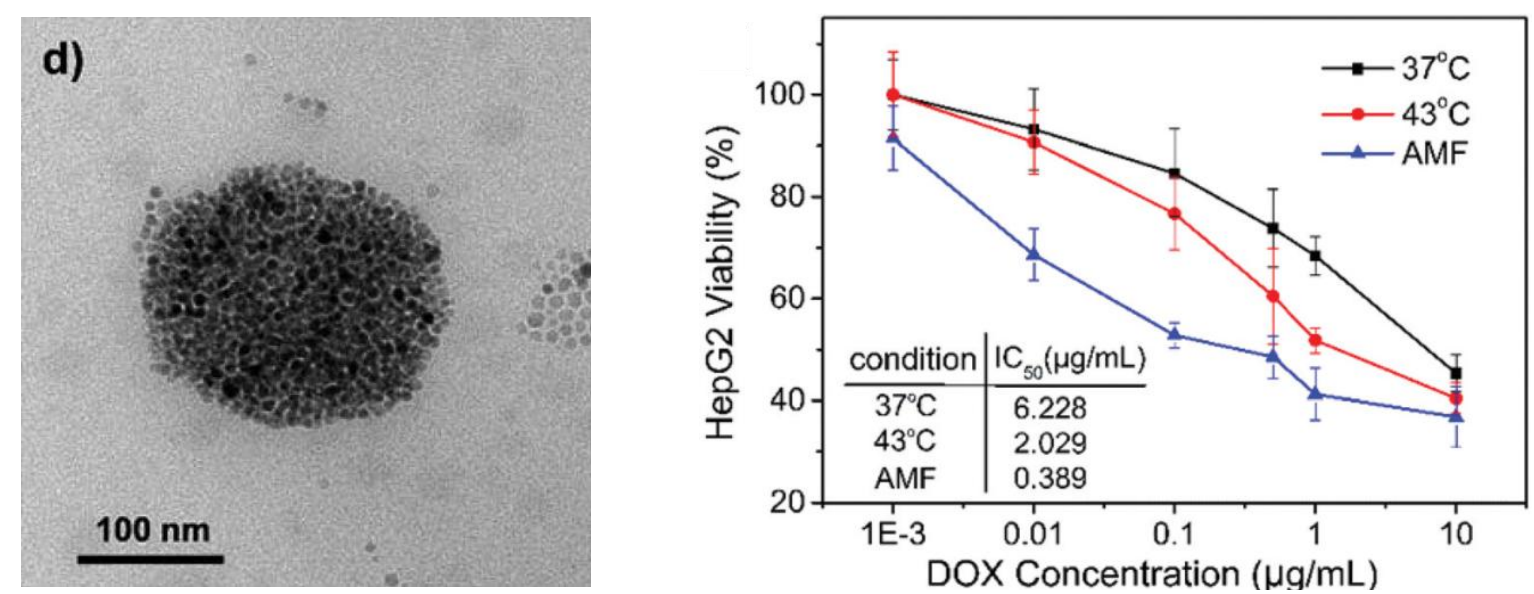

Figure 18: Left: transmission electron microscopy image of an MZF nanoparticle and doxorubicin loaded thermoresponsive micelle. The visible opaque disks are the MZF nanoparticles. Right: HepG2 cell viability upon exposure to the loaded micelles under different conditions, AMF: alternating magnetic field. From [106].

The ability of thermoresponsive polymers to hide and reveal the transferrin protein grafted on top of gold nanoparticles was also reported [107]. Similar to the work of Wu et al. discussed in section II.4.2.c., there was a higher nanoparticle uptake at higher temperature, when the OEGMA chains retract, allowing the transferrin protein to interact with the cell membrane's transferrin receptors (TfR). There was a balance between the number of grafted proteins on the gold nanoparticle and the number of thermoresponsive copolymer chains: an optimum of 3 grafted proteins for 2 grafted copolymer chains was determined. 
Table 8: Overview of the physico-chemical parameters of LCST and metal based nanocarriers with documented in vivo or in vitro results. $M_{n}$ total $=M_{n}$ of the whole polymer; $M_{n}$ thermo $=M_{n}$ of the thermoresponsive block; Drug Loading is the ratio between the mass of encapsulated drug and the total mass of the system.

\begin{tabular}{|c|c|c|c|c|c|c|c|c|c|}
\hline Ref. & Polymer & $\begin{array}{l}\text { Mn total } \\
\text { (g/mol) }\end{array}$ & $\begin{array}{l}\text { Mn thermo. } \\
\text { (g/mol) }\end{array}$ & Nanocarrier & Molecule & $\begin{array}{l}\text { Drug } \\
\text { Loading } \\
\text { (wt.\%) }\end{array}$ & $\begin{array}{l}\text { LCST } \\
\left({ }^{\circ} \mathrm{C}\right)\end{array}$ & $\begin{array}{l}\text { Size } \\
(\mathrm{nm})\end{array}$ & Stimulus purpose \\
\hline [106] & $\begin{array}{c}\text { 6sPCL- } b-\mathrm{P}\left(\mathrm{MEO}_{2} \mathrm{MA}-\right. \\
\text { co-OEGMA) and MZF } \\
\text { nanoparticles }\end{array}$ & 61,270 & 43,130 & Micelle & Doxorubicin & 5 & 43 & $\begin{array}{l}190 \\
\text { (r.t.) }\end{array}$ & $\begin{array}{l}\text { Alternating magnetic field (AMF) allows for heating the } \\
\text { magnetic nanoparticles inside the micelles. Dox micelles' IC } C_{50} \\
\text { on HepG } 2 \text { cells decreases } 13 \text { times in presence of AMF ( } 5 \\
\text { min per } 24 \mathrm{~h} \text {, over } 72 \mathrm{~h} \text { ) compared to cells incubated only at } \\
37^{\circ} \mathrm{C} \text {. }\end{array}$ \\
\hline [107] & $\begin{array}{l}\text { AuNPs-P(MPC-co- } \\
\text { PEGMA-co-Tf) }\end{array}$ & 59,000 & 28,000 & $\begin{array}{c}\text { Metal } \\
\text { nanoparticle }\end{array}$ & Transferrin & $\begin{array}{l}3 \text { proteins } \\
\text { per AuNP }\end{array}$ & 39 & $\begin{array}{l}59 \text { (r.t.) } \\
63 \text { and } \\
450 \\
\left(41^{\circ} \mathrm{C}\right)\end{array}$ & $\begin{array}{l}\text { Endocytosis in HeLa cells, known for expressing TfR, was } \\
\text { monitored by confocal microscopy. Incubation for } 2 \mathrm{~h} \text { at } \\
\text { different temperatures, with AuNPs grafted or not with the } \\
\text { thermoresponsive part. There are } 4 \text { times more AuNPs at } \\
41^{\circ} \mathrm{C} \text { than at } 33^{\circ} \mathrm{C} \text {. The study reveals endocytosis is TfR } \\
\text { mediated, as when incubated with an excess of free Tf, the } \\
\text { nanoparticles are not taken up as much anymore. }\end{array}$ \\
\hline
\end{tabular}




\section{UCST polymers}

UCST polymers are insoluble below the critical temperature and soluble above (Figure $1 \mathrm{~b}$ ). In comparison with LCST polymers, there are much less reports regarding UCST polymers in aqueous medium but they arouse great interest in the last decade. This is rather surprising provided that UCST-type thermoresponsiveness seems more intuitive as it implies polymer solubilization above the critical temperature as opposed to their LCST-type counterparts. Aqueous UCST polymers can be divided in two categories according to the involved mechanism conferring the thermoresponsiveness: hydrogen bonds or electrostatic interactions. The latter property is primarily represented by zwitterionic polymers, even if polyelectrolytes in the presence of multivalent counterions can also exhibit UCST behavior[108]. Only the first two UCST polymers based on hydrogen bonds presented here were used for the design of drug delivery nanocarriers through in vitro or in vivo studies. The reader is invited to consult the review by Seuring and Agarwal for a more exhaustive list of UCST polymers in aqueous solution and their synthesis [109].

\section{III.1. UCST polymers based on hydrogen bonding}

For this type of polymers, the polymer-polymer interactions rely on reversible hydrogen bonding. Below the UCST, these interactions are stronger than polymer-water hydrogen bonding, leading to the polymer chains to phase out. Apart from the three examples presented here, other systems exist but are less studied.

\section{III.1.1 Poly( $N$-acryloylglycinamide) (PNAGA) and copolymers}

The most widely studied UCST homopolymer is poly ( $N$-acryloylglycinamide) (PNAGA), that serves as the UCST counterpart of PNIPAAm. While it was first reported in 1964 by Haas and Schuler as a polymer capable of forming a thermally reversible gel[110], the UCST behavior in dilute conditions was not observed at that time. A comprehensive study of PNAGA as a UCST polymer was only recently reported [111]. The NAGA monomer is not widely commercially available, thus the monomer was synthesized prior to polymerization, which adds a difficulty in the use of PNAGA. The unveiling of the UCST properties of the homopolymer was made possible by using very pure monomer from a specific synthetic pathway and using a non-ionic radical initiator. In a subsequent study, NAGA was polymerized in a controlled manner by RAFT polymerization from a non-ionic RAFT agent[112]. UCST of PNAGA is only observed if a purely non-ionic polymer is obtained without any traces of charged impurities[112]. This has prevented previous reports from witnessing the UCST behavior of PNAGA[112]. Each NAGA repeating unit contains two hydrogen donor sites on the nitrogen atoms and two hydrogen acceptor sites on the oxygen atoms, allowing intra- and interpolymer chain hydrogen bonding (Figure 19). 


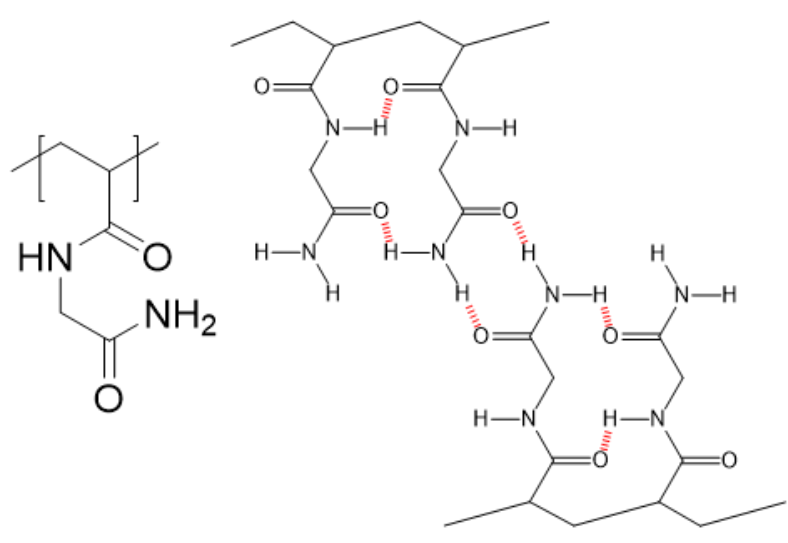

Figure 19: Left: chemical structure of poly(N-acryloylglycinamide) (PNAGA). Right: schematic representation of two PNAGA chains with possible hydrogen bonds shown in red.

The UCST behavior of PNAGA presents a broad hysteresis of up to $20^{\circ} \mathrm{C}$ between the heating and cooling cycle. Polymer concentration in solution has a slight impact on UCST. For PNAGA of molar mass between 15,000 and $35,000 \mathrm{~g} / \mathrm{mol}$, the UCST remains at a constant value around $27^{\circ} \mathrm{C}[113]$. As the molar mass decreases below $15,000 \mathrm{~g} / \mathrm{mol}$, the nature of the polymer end group has an increasing impact on the UCST. In the report by Agarwal et al., a hydrophobic dodecyl RAFT agent was used and the UCST was higher at $7,000 \mathrm{~g} / \mathrm{mol}\left(38^{\circ} \mathrm{C}\right)$ than at $15,000 \mathrm{~g} / \mathrm{mol}\left(28^{\circ} \mathrm{C}\right)$. The ionic strength of the solution tended to decrease the UCST[113], yet PNAGA retained its thermoresponsiveness in human serum[112]. As for PNIPAAm, copolymerizing NAGA with a hydrophilic monomer decreased its UCST[111]. Hence, with a hydrophobic monomer, such as styrene, the UCST increased[114]. Recently, NAGA has also been copolymerized with acrylonitrile (AN) to increase the UCST (shown up to $45{ }^{\circ} \mathrm{C}$ ), to keep it constant irrespectively of the copolymer concentration in solution, and to remove the hysteresis[115]. In the nanocarrier presented below, the UCST copolymer used is poly( $N$-acryloyl glycinamide-co-butyl acrylate), P(NAGA-co-BA), where butyl acrylate acts as a hydrophobic monomer to tune the UCST up to $60^{\circ} \mathrm{C}$.

\section{III.1.2. P(AAm-co-AN) and other acrylamide copolymers}

Moving forward from PNAGA, general guidelines for the synthesis of UCST polymer based on hydrogen bonding from the lessons learned with PNAGA were determined. There is a need for monomers capable of making reversible hydrogen bonds, having low content in ionic groups and a certain hydrophilic / hydrophobic balance. Plus, easy to polymerize systems based on ready-to-use commercially available monomers were presented. In that sense, poly(acrylamide-co-acrylonitrile), P(AAm-Co-AN), a copolymer exhibiting a UCST behavior in water and in PBS with a narrower hysteresis than PNAGA, was synthesized [114]. The UCST was tuned by controlling the amount of AN in the copolymer: the higher the AN content, the higher the UCST, with values ranging from $5{ }^{\circ} \mathrm{C}$ to beyond $60{ }^{\circ} \mathrm{C}$ (Figure 20, right). They also showed that the UCST increased when increasing the copolymer concentration: $6{ }^{\circ} \mathrm{C}$ at $1 \mathrm{wt} . \%$ to $26^{\circ} \mathrm{C}$ at $15.3 \mathrm{wt} . \%$ (with a fixed AN content). 


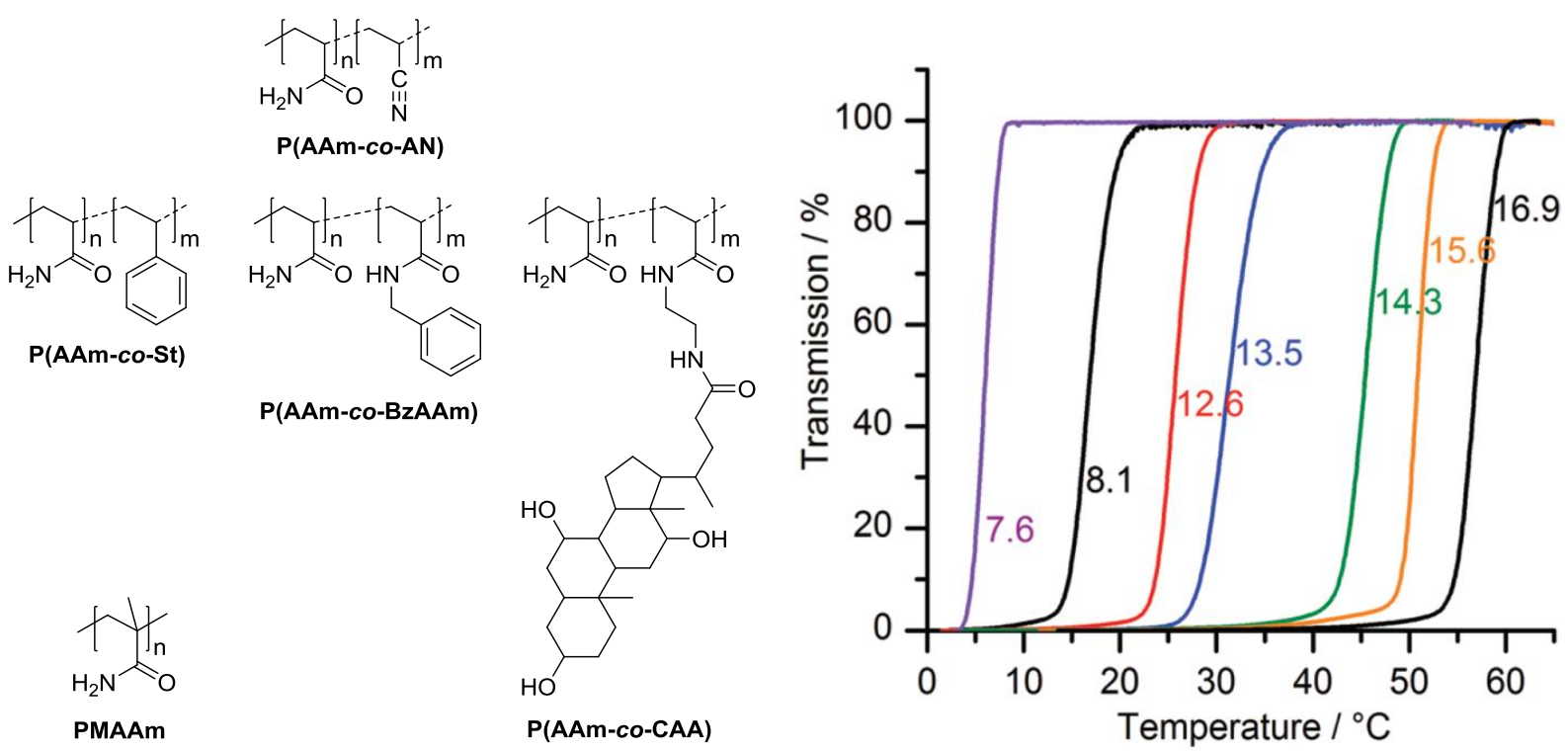

Figure 20: Left: chemical structure of acrylamide copolymers reported to have a UCST behavior in water. $P(A A m-c o-A N)$ : poly(acrylamide-co-acrylonitrile); $P(A A m-c o-S t)$ : poly(acrylamide-co-styrene); $P(A A m-c o-B z A A m)$ : poly(acrylamide-co-N-benzylacrylamide); $P(A A m-c o-C A A)$ : poly(acrylamide-cocholic acid acrylamide); PMAAm: poly(methacrylamide). Right: UV-vis transmittance cooling curves of $P(A A m-c o-A N)$ copolymers with different mol.\% amounts of acrylonitrile, given by the numbers, from [114].

The $\mathrm{P}(\mathrm{AAm}-\mathrm{co}-\mathrm{AN})$ copolymer has been used as the thermoresponsive block in multiblock copolymers to design thermoresponsive micelles and other nanocarriers[116-120].

Some groups have investigated the influence of the nature of the hydrophobic comonomer on the UCST of acrylamide-based copolymers. For instance, poly(acrylamide-co-styrene), P(AAm-co-St), exhibited UCST only when the copolymer chains had an homogenous composition obtained by RDRP methods such as RAFT. Indeed, whereas P(AAm-co-St) obtained by free-radical copolymerization did not exhibit UCST whatever the amount of St, a similar copolymer obtained by RAFT gave a UCST between $50{ }^{\circ} \mathrm{C}$ and $65{ }^{\circ} \mathrm{C}[121]$. The obtained UCST decreases upon dilution, from $65{ }^{\circ} \mathrm{C}$ at $10 \mathrm{mg} / \mathrm{mL}$ down to $40{ }^{\circ} \mathrm{C}$ at $0.9 \mathrm{mg} / \mathrm{mL}$. On another example, poly(acrylamide-co-benzylacrylamide), P(AAm-coBzAAm), was obtained by post-modifying a poly(pentafluorophenyl acrylate) polymer with a mixture of ammonia and benzylamine[122]. The amines reacted with the pentafluorophenyl pendant groups to yield P(AAm-co-BzAAm). The copolymer exhibited a UCST behavior only with 13 mol.\% of BzAAm in the copolymer, leading to a UCST of $15{ }^{\circ} \mathrm{C}$ at $5 \mathrm{mg} / \mathrm{mL}$ in water. Copolymers with a lower amount of BzAAm were fully soluble in water, and those with a higher amount of BzAAm were insoluble. Both $\mathrm{P}(\mathrm{AAm}-\mathrm{Co}-\mathrm{St})$ and $\mathrm{P}(\mathrm{AAm}-\mathrm{Co}-\mathrm{BzAAm})$ must be synthesized in precise conditions to obtain UCST behavior in water. For the latter, it would be of interest to synthesize it from vinyl monomers instead of modifying a pre-existing polymer and comparing the two synthetic routes in terms of UCST tuning. Poly(acrylamide-co-cholic acid acrylamide), P(AAm-co-CAA), was copolymerized from a modified acrylamide monomer and yielded a copolymer exhibiting a concentration dependent UCST: $48{ }^{\circ} \mathrm{C}$ at $10 \mathrm{mg} / \mathrm{mL}$ down to $24{ }^{\circ} \mathrm{C}$ at $1 \mathrm{mg} / \mathrm{mL}$ in water[123]. Rather than having a copolymer, Seuring and Agarwal also showed that polymethacrylamide (PMAAm) has a UCST in water but only reported one example with the critical temperature at $57^{\circ} \mathrm{C}$ at $10 \mathrm{mg} / \mathrm{mL}$ with a broad hysteresis[114]. PMAAm has the right hydrophilic / hydrophobic balance due to the added methyl group on the polymer backbone compared to PAAm. 


\section{III.1.3. Polymers bearing ureido pendant groups}

Urea possesses a high number of $\mathrm{H}$-donor and $\mathrm{H}$-acceptor sites and was shown to be able to make dimers in water[124], making it a good candidate for a UCST polymer pendant group. Shimada et al. modified a commercially available polyallylamine to yield poly(allylurea-co-allylamine), $\mathrm{P}(\mathrm{aU}-\mathrm{co}-\mathrm{aA})$, exhibiting a UCST behavior in a $150 \mathrm{mM} \mathrm{NaCl}$ solution at physiological pH, and not in pure water[125]. The presence of the salt was important as it shielded the cationic charge on the nitrogen, (Figure 21, top left), allowing enhanced polymer-polymer interactions. The UCST can be tuned by changing the amount of aU in the copolymer: the higher the aU content, the higher the UCST with the highest reported value at $65{ }^{\circ} \mathrm{C}$. The UCST was constant at physiological pH between 5.5 and 8 but was impacted by dilution and salt concentration. In the same study, the same synthetic route was applied to a polyornithine. This polymer consisted in a polypeptide made from a non-proteinogenic amino acid and was modified to yield poly(citrulline-co-ornithine), $\mathrm{P}$ (Ci-co-Or), (Figure 21, top right). This copolymer is therefore biodegradable and UCST could be tune in the same manner as for $\mathrm{P}(\mathrm{aU}-\mathrm{co}-\mathrm{aA})$, however the maximum reported UCST value was at $30{ }^{\circ} \mathrm{C}$. In terms of toxicity, while they showed that the fully cationic PaA affected cellular activity starting at $100 \mu \mathrm{g} / \mathrm{mL}$, the copolymer $\mathrm{P}(\mathrm{aU}-\mathrm{co}-\mathrm{aA})$ appeared to be well tolerated, leading to $\sim 80 \%$ cell viability up to $1 \mathrm{mg} / \mathrm{mL}[126]$. Indeed, the copolymer carried less than 15 mol.\% of cationic monomers, thus preventing cell membrane toxicity. As such, $\mathrm{P}(\mathrm{aU}-\mathrm{co}-\mathrm{aA})$ and $\mathrm{P}(\mathrm{Ci}-\mathrm{co}-\mathrm{Or})$ are good candidates for thermoresponsive drug delivery.

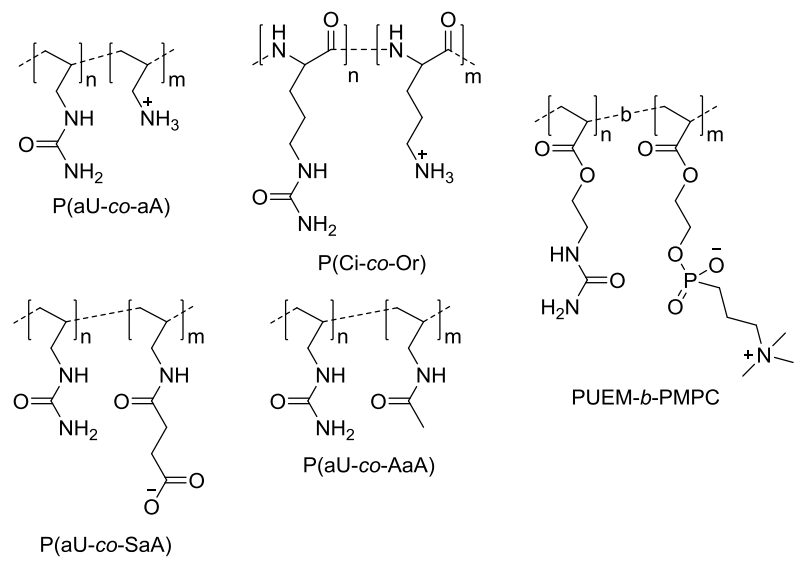

Figure 21: Chemical structure of ureido-bearing polymers reported to have a UCST behavior in aqueous solution. $P(a U$-co-aA): poly(allylurea-co-allylamine); $P(C i-c o-O r):$ poly(citrulline-co-ornithine); P(aU-co-SaA): poly(allylurea-co-succinylated allylamine); $P(a U$-co-AaA): poly(allylurea-co-acetylated allylamine); PUEM-b-PMPC: poly(2-ureidoethylmethacrylate)-b-poly(2-methacryloyloxyethyl phosphorylcholine).

Further studies have shown that a copolymer containing aU and succinylated allylamine also exhibited a UCST behavior[127]. The difference with $\mathrm{P}(\mathrm{aU}-\mathrm{co}-\mathrm{aA})$ is mainly the negative charge on the succinylated allylamine instead of the positive charge on the nitrogen of allylamine (Figure 21). In the same report, the hydrophobic comonomer acetylated allylamine also yielded a UCST copolymer that could potentially exhibit its thermoresponsiveness also in pure water as opposed to only in a $150 \mathrm{mM}$ $\mathrm{NaCl}$ solution. A recent study showed that homopolymerization of 2-ureidoethylmethacrylate (UEM) yielded a polymer exhibiting a UCST behavior both in pure water and in PBS[128]. In another report, micelles from a block copolymer of PUEM with a hydrophilic biocompatible block of poly(2- 
methacryloyloxyethylphosphorylcholine), PMPC (Figure 21), were obtained and retained thermoresponsiveness[129].

\section{III.2. Zwitterionic polymers exhibiting UCST behavior}

Zwitterionic polymers presenting both cationic and ionic charges can exhibit a UCST behavior in water. This behavior stems from the strong coulombic interactions present between the charged groups that can be either intra- or intermolecular. Because of the nature of the interactions, they are much more influenced by the ionic strength of the solution. As biological fluids are made of complex ions and strong ionic strength, it proves to be challenging to use these materials for drug delivery systems. For instance, poly(3-dimethyl(methacryloyloxyethyl) ammonium propane sulfonate) and poly(3-[N-(3-methacrylamidopropyl)- $\mathrm{N}, \mathrm{N}$-dimethyl]ammoniopropane sulfonate) exhibited UCST behavior in pure water[130]. These could nevertheless provide thermoresponsiveness to nanoparticulate systems either by copolymerization[131] or surface modification[132].

\section{III.3. Polypeptide-based UCST polymers}

While Shimada et al. have synthesized a polypeptide exhibiting a UCST, P(Ci-co-Or), the Chilkoti's group has transposed their ELP design approach for the synthesis of UCST polypeptides[133]. There is no report describing this new family of polypeptides for drug delivery systems but the extensive use of ELPs seems promising for further studies based on these polypeptides. The work is based on resilins, that are biopolymers found in insects which provide soft rubber-elasticity to mechanically active organs and tissues such as legs and wings. By studying the structure of resilin, they discovered repeating amino acid motifs containing both arginine and aspartic acid moieties. Arginine residues in a polypeptide are positively charged at physiological $\mathrm{pH}$, whereas aspartic acid residues are negatively charged. Figure 22 gives one example of an amino acid sequence providing a UCST polypeptide. By adding an aromatic amino acid and tuning the length of the polypeptides, they managed to synthesize thermoresponsive polypeptides exhibiting a UCST relevant for biological applications (i.e., in the $20-43{ }^{\circ} \mathrm{C}$ range). This work showed the importance of the guanidinyl group of the arginine residue to yield thermoresponsiveness. Both the guanidinyl group of an arginine residue and the free amine of a lysine residue are protonated at $\mathrm{pH} 7.4$ but the synthesized polypeptide did not exhibit a UCST behavior in the presence of lysine residues whereas it did when these were replaced with arginine residues. Thus, the guanidinyl group governed the UCST behavior, while the opposite charges between the aspartic acid and the arginine residues reinforced the polymer chains interactions so that the polypeptide could phase out below the UCST. 


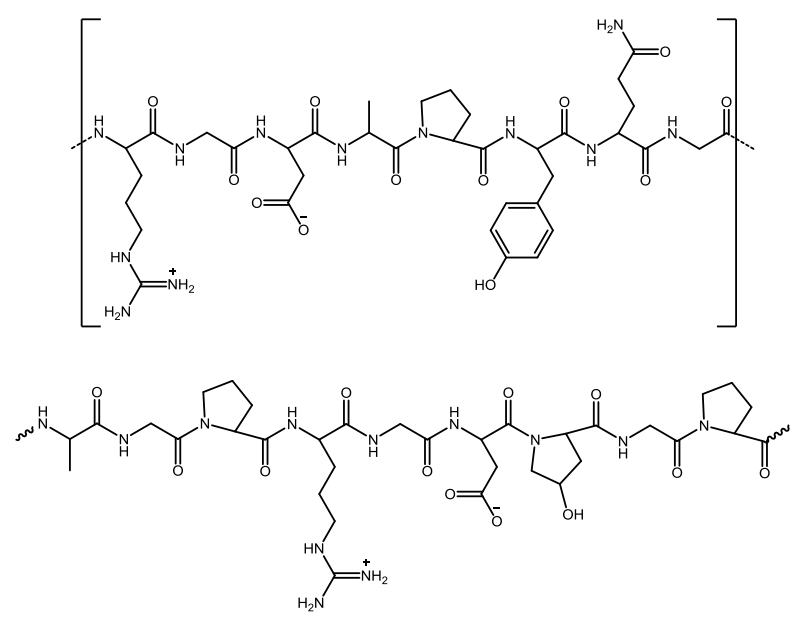

Figure 22: Top: one example of a repeated motif of an UCST polypeptide as designed by Chilkoti's group. The amino acid sequence is RGDAPYQG, repeated 28 times it gives a polypeptide with a critical temperature of $50^{\circ} \mathrm{C}$ in PBS. Bottom: basic structure of the gelatin protein.

As for ELPs, this kind of polypeptide is not easy to synthesize in a regular chemistry laboratory, and for the time being no reports have been found providing a guide to synthesize an acrylate derivative of a UCST amino acid sequence for facile radical polymerization. Nevertheless, the structures elucidated by Chilkoti et al. can be compared to the general chemical structure of the gelatin protein (Figure 22, bottom). Indeed, Otsuka et al. have shown that a gelatin chitosan complex in certain mixture conditions exhibited a UCST behavior in water with a critical temperature at around $35{ }^{\circ} \mathrm{C}[134]$. These findings pave the way to obtaining biocompatible and biodegradable UCST polymers as starting materials to build future thermoresponsive nanocarriers.

\section{III.4. UCST-based nanocarriers}

In comparison with LCST-based nanocarriers, there are few reports of UCST-based drug delivery nanocarriers with in vitro or in vivo results. Table 9 summarizes the only systems that can be found in the literature. Three of these systems employ $\mathrm{P}(\mathrm{AAm}-\mathrm{CO}-\mathrm{AN})$ as the UCST building block owing to its ease of synthesis and the ability to fine tuning its UCST, and one is based on P(NAGA-Co-BA), with butyric acid acting as a hydrophobic monomer to yield a UCST of $60^{\circ} \mathrm{C}$. The first UCST-type drug delivery nanocarrier was reported by Li et al. [135]. Their approach was pretty straightforward and relied on the formulation of Dox inside PEGylated UCST copolymer micelles followed by in vitro and in vivo evaluation of the efficacy with or without microwave-mediated hyperthermia[135]. 
Table 9: Overview of the physico-chemical parameters of UCST based nanocarriers with documented in vivo or in vitro results. $M_{n}$ total = $M_{n}$ of the whole polymer; $M_{n}$ thermo $=M_{n}$ of the thermoresponsive block; Drug Loading is the ratio between the mass of encapsulated drug and the total mass of the system.

\begin{tabular}{|c|c|c|c|c|c|c|c|c|c|}
\hline Ref. & Polymer & $\begin{array}{l}\text { Mn total } \\
\text { (g/mol) }\end{array}$ & $\begin{array}{c}\text { Mn thermo. } \\
\text { (g/mol) }\end{array}$ & Nanocarrier & Molecule & $\begin{array}{l}\text { Drug } \\
\text { Loading } \\
\text { (wt. \%) }\end{array}$ & $\begin{array}{l}\text { UCST } \\
\left({ }^{\circ} \mathrm{C}\right)\end{array}$ & $\begin{array}{l}\text { Size } \\
(\mathrm{nm})\end{array}$ & Stimulus purpose \\
\hline [135] & $\begin{array}{c}\mathrm{P}(\mathrm{AAm}-\mathrm{co}-\mathrm{AN})-g- \\
\text { PEG }\end{array}$ & 56,600 & 32,500 & Micelle & Doxorubicin & 5.8 & 43 & $\begin{array}{c}120 \\
(\text { r.t. }) \\
100 \\
\left(43^{\circ} \mathrm{C}\right)\end{array}$ & $\begin{array}{l}\text { BEL-7402, hepatocellular carcinoma cells were treated with free } \\
\text { Dox and micellar Dox. IC } 50 \text { of free Dox was the same at } 37^{\circ} \mathrm{C} \text { and } \\
43^{\circ} \mathrm{C} \text {, whereas IC } \mathrm{C}_{50} \text { of micellar Dox was the same as free Dox at } \\
37^{\circ} \mathrm{C} \text { but was lower at } 43^{\circ} \mathrm{C}(4.91 \mu \mathrm{g} / \mathrm{mL} \text { vs. } 1.56 \mu \mathrm{g} / \mathrm{mL}) . \text { In vivo, } \\
\text { local hyperthermia applied with microwave. Hyperthermia itself } \\
\text { did not enhance free Dox tumor growth inhibition, best inhibition } \\
\text { with micellar Dox and hyperthermia. }\end{array}$ \\
\hline [136] & P(NAGA-Co-BA) & n.a. & n.a. & $\begin{array}{l}\text { Micelle } \\
\text { coated with red } \\
\text { blood cell } \\
\text { membrane }\end{array}$ & $\begin{array}{l}\text { Doxorubicin } \\
\text { Indocyanine } \\
\text { green }\end{array}$ & $\begin{array}{c}10 \\
5\end{array}$ & 60 & 85 (r.t.) & $\begin{array}{l}\text { Laser irradiation allows a } 9{ }^{\circ} \mathrm{C} \text { increase of the temperature in vitro. } \\
\text { On HeLa cells, no free Dox comparison with and without laser } \\
\text { irradiation. The micelles seem toxic even at low DOX } \\
\text { concentration }(2.62 \mu \mathrm{g} / \mathrm{mL}): 70 \% \text { cell viability. With laser } \\
\text { irradiation, there is a } 2 \text {-fold decrease in cell viability as it drops to } \\
\text { around } 35 \% \text {. Effect also seen at } 5.25 \mu \mathrm{g} / \mathrm{mL} \text { concentration. }\end{array}$ \\
\hline [137] & $\begin{array}{c}\text { P(AAm-co-AN)-g- } \\
\text { MSN }\end{array}$ & n.a. & 18,100 & $\begin{array}{l}\text { Mesoporous } \\
\text { nanoparticle }\end{array}$ & Doxorubicin & n.a. & 42 & $\begin{array}{l}275 \\
\text { (r.t.) }\end{array}$ & $\begin{array}{l}\text { SK-BR-3 breast cancer cells. No free Dox comparison. } 80 \% \text { cell } \\
\text { viability with loaded MSNs without hyperthermia, } 30 \% \text { viability } \\
\text { with hyperthermia at } 42{ }^{\circ} \mathrm{C}, 20 \% \text { with hyperthermia and } \\
\text { glutathione. }\end{array}$ \\
\hline [138] & $\begin{array}{l}\text { MNPs@A54-PEG- } \\
g \text {-P(AAm-co-AN) }\end{array}$ & 50,600 & 32,500 & Micelle & Doxorubicin & n.a. & 43 & $\begin{array}{c}450 \\
(\text { r.t. }) \\
100 \\
\left(37^{\circ} \mathrm{C}\right)\end{array}$ & $\begin{array}{l}\text { Microwave treatment of the formulation without the metallic } \\
\text { nanoparticles (MNPs) increases the temperature, the increase is } \\
\text { enhanced with MNPs. } 20 \% \text { burst release without microwave, up to } \\
60 \% \text { release with microwave in } 10 \text { hours. In vivo, mice bearing } \\
\text { BEL-7402 tumors were treated with the different formulations } \\
\text { (with and without targeting ligand, with and without MNPs, with } \\
\text { and without microwave treatment). Microwave applied } 24 \mathrm{~h} \text { post } \\
\text { injection as that is when the accumulation of iron inside the tumor } \\
\text { is maximum, higher with targeting ligand than without. With } \\
\mathrm{MNPs} \text {, hyperthermia up to } 45^{\circ} \mathrm{C} \text { in the tumor, without MNPs only } \\
39^{\circ} \mathrm{C} \text {. Best tumor inhibition with the complete system, followed } \\
\text { by without MNPs and with MNPs without microwave. }\end{array}$ \\
\hline
\end{tabular}


PEGylation was carried out after polymerization by chemically coupling succinimidyl carbonate ended PEG on the primary amides of the acrylamide monomers. They showed that their formulated micelles shrink upon heating, regardless of the initial micelle concentration. Dox-loaded UCST micelles with hyperthermia exhibited the best results in terms of tumor growth inhibition, making the system a good candidate for hyperthermia-triggered drug release. A similar system was also reported by Huang et al. but did not use hyperthermia in vitro to show the clear advantage of thermoresponsiveness[139].

To further improve their approach, Li et al. co-encapsulated metal nanoparticles (MNPs) made of iron oxide that were able to respond to microwaves and to produce more heat locally[138]. They also grafted a targeting ligand (A54) on the copolymer, specific to hepatic tumor cells, to have both biological and physical targeting of the tumor. When comparing the targeted vs. non-targeted drugloaded micelles in vivo, tumor growth inhibition remained identical. Likewise, the addition of MNPs only slightly improved tumor growth inhibition compared to micelles without MNPs. However, they did provide a new method for in vivo tumor imaging and therefore a greater anticancer activity.

Hui et al. co-encapsulated Dox with a photothermal agent, indocyanine green (ICG), that rapidly heated upon irradiation with a laser at a specific wavelength of $808 \mathrm{~nm}$ [136]. They also used a novel biocompatible coating made of red blood cell $(\mathrm{RBC})$ constituents to replace traditional PEG (Figure 23). Upon heating, the micelles swelled and the hydrodynamic diameter increased providing an onand-off release of the drug upon laser irradiation. The photothermal effect had an impact on cell viability on its own, that was not clearly quantified in the report. Nevertheless, in vitro results revealed promising. A question remains as whether laser irradiation can penetrate deeply into tissues for a controlled drug release in vivo.

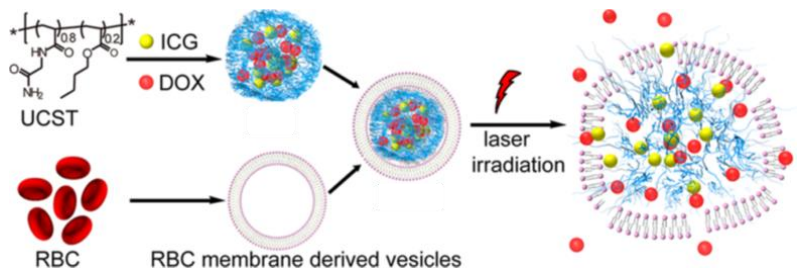

Figure 23: Schematic representation of the formulation of UCST micelles loaded with doxorubicin (DOX) and indocyanine green (ICG), coated with red blood cell (RBC) constituents and the consequence of laser irradiation on the prepared micelles. Adapted from [136].

Instead of using a polymeric matrix as the material to encapsulate the drug, Hei et al. synthesized mesoporous nanoparticles (MSN) coated with P(AAm-co-AN)[137]. MSNs are made of silica and their important specific surface area allows to encapsulate a large number of small molecules such as drugs. The UCST copolymer was grafted through a disulfide bond at the surface of the MSN. The idea was to use the UCST copolymer as a gate nearby the MSN pores to physically prevent drug leakage below the UCST. Upon hyperthermia the copolymer solubilized and opened up the gates, allowing the drug to be released (Figure 24). The disulfide bond can be cleaved by intracellular glutathione to further complete the drug release from the system. The drug release appeared to be very well controlled and the in vitro results were promising for this uncommon system. 

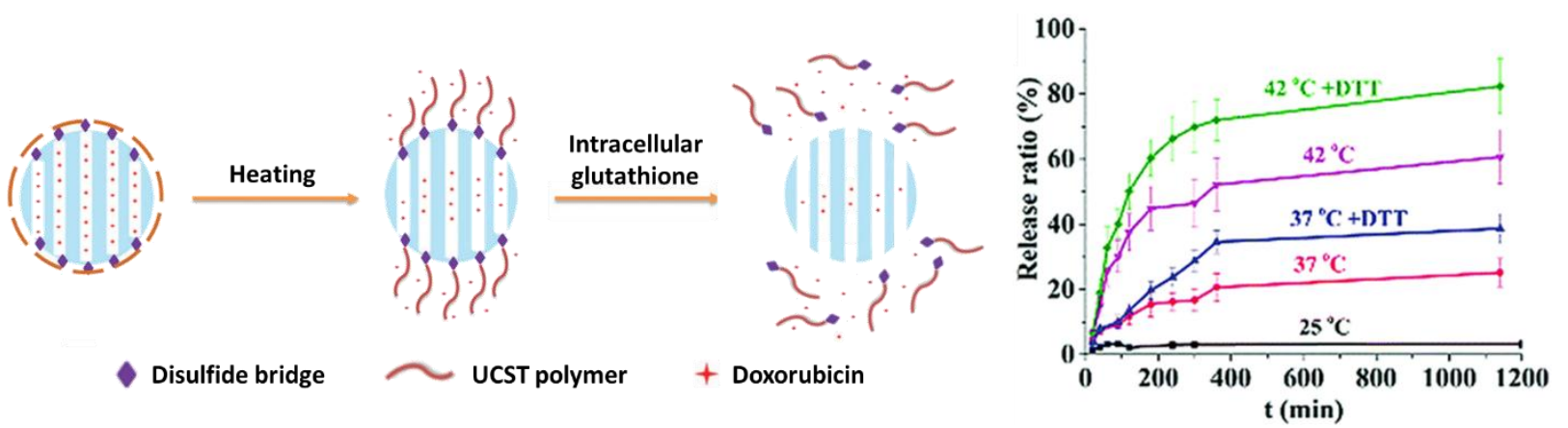

Figure 24: Left: Schematic representation of doxorubicin loaded UCST mesoporous nanoparticles and their evolution upon heating and exposure to glutathione. Right: Doxorubicin release curves at different temperatures and with the presence of dithiothreitol (DTT), a compound capable of breaking disulfide bridges. Adapted from [137].

\section{Conclusion}

Polymer-based thermoresponsive nanocarriers have been intensively investigated in past two decades. Historically, LCST-based nanocarriers were the first to be reported because LCST polymers have been studied for a longer time than UCST counterparts. They have recently been used to build nanocarriers leading to the emergence of a new class of polymer-based thermoresponsive nanocarriers. While there has been a considerable amount of work put into the design and the comprehension of these nanocarriers, some hurdles remain to be overcome to come up a clinically viable product. In the examples detailed in this review, the reports often show that the drug release is improved upon hyperthermia. However, very few reports use a non-thermoresponsive control formulation to see how temperature on its own impacts the drug diffusion from the polymer matrix and subsequent release. Some reports also put forward that temperature at the tumor site is higher than the average body temperature, which would let think that they can be used as an endogenous stimulus for drug release. While it may be true that tumor cells have a strong metabolism, it seems unlikely that there is a measurable difference between tumor and body temperature. In terms of critical temperature, some studies reported polymers with a LCST at $37{ }^{\circ} \mathrm{C}$ for a nanocarrier that should release its payload in a controlled manner. Yet at this temperature, there is no way of controlling the drug release in vivo and these studies usually suggest further work to tune the critical temperature for mild hyperthermia. Why not design the system with the proper critical temperature in the first place? For a thermoresponsive nanocarrier to be designed properly to maximize its clinical potential, research groups and clinicians should collaborate efficiently to better understand the requirements of a clinical setting. Indeed, clinical practices are changing every year and the benefits of hyperthermia in treating diseases such as cancer are now well-established[140]. Yet the modalities for applying hyperthermia are not harmonized and depend on the equipment available in the clinic. Nevertheless, hyperthermia devices exist in hospitals and using them on cutting-edge thermoresponsive nanocarriers could bring a therapeutic improvement for cancer treatment[141].

\section{Acknowledgements}

Authors acknowledge the support of la Ligue contre le Cancer for Alexandre Bordat's Ph.D. fellowship, Cancéropôle IDF Emergence and Fondation ARC for funding. Institut Galien Paris-Sud is a member of the Laboratory of Excellence LERMIT supported by a grant from ANR (ANR-10-LABX-33). 


\section{Bibliography}

[1] R.K. Jain, T. Stylianopoulos, Delivering nanomedicine to solid tumors, Nat. Rev. Clin. Oncol. 7 (2010) 653-664. doi:10.1038/nrclinonc.2010.139.

[2] S.M. Moghimi, A.C. Hunter, J.C. Murray, Nanomedicine: current status and future prospects, FASEB J. 19 (2005) 311-330. doi:10.1096/fj.04-2747rev.

[3] M.E. Davis, Z. Chen, D.M. Shin, Nanoparticle therapeutics: an emerging treatment modality for cancer, Nat. Rev. Drug Discov. 7 (2008) 771-782. doi:10.1038/nrd2614.

[4] K.K. Jain, Nanotechnology in clinical laboratory diagnostics, Clin. Chim. Acta. 358 (2005) 37-54. doi:10.1016/j.cccn.2005.03.014.

[5] V.P. Torchilin, Recent advances with liposomes as pharmaceutical carriers, Nat. Rev. Drug Discov. 4 (2005) 145-160. doi:10.1038/nrd1632.

[6] K. Kataoka, A. Harada, Y. Nagasaki, Block copolymer micelles for drug delivery: design, characterization and biological significance, Adv. Drug Deliv. Rev. 47 (2001) 113-131. doi:10.1016/S0169-409X(00)00124-1.

[7] K.E. Uhrich, S.M.C. and, R.S. Langer*, K.M. Shakesheff, Polymeric Systems for Controlled Drug Release, (1999). doi:10.1021/CR940351U.

[8] R. Gref, Y. Minamitake, M.T. Peracchia, V. Trubetskoy, V. Torchilin, R. Langer, Biodegradable long-circulating polymeric nanospheres., Science. 263 (1994) 1600-3.

doi:10.1126/SCIENCE.8128245.

[9] E. Miele, G.P. Spinelli, E. Miele, F. Tomao, S. Tomao, Albumin-bound formulation of paclitaxel (Abraxane ABI-007) in the treatment of breast cancer., Int. J. Nanomedicine. 4 (2009) 99-105. http://www.ncbi.nlm.nih.gov/pubmed/19516888 (accessed May 4, 2018).

[10] D.D. Von Hoff, T. Ervin, F.P. Arena, E.G. Chiorean, J. Infante, M. Moore, T. Seay, S.A. Tjulandin, W.W. Ma, M.N. Saleh, M. Harris, M. Reni, S. Dowden, D. Laheru, N. Bahary, R.K. Ramanathan, J. Tabernero, M. Hidalgo, D. Goldstein, E. Van Cutsem, X. Wei, J. Iglesias, M.F. Renschler, Increased Survival in Pancreatic Cancer with nab-Paclitaxel plus Gemcitabine, N. Engl. J. Med. 369 (2013) 1691-1703. doi:10.1056/NEJMoa1304369.

[11] P. Horcajada, T. Chalati, C. Serre, B. Gillet, C. Sebrie, T. Baati, J.F. Eubank, D. Heurtaux, P. Clayette, C. Kreuz, J.-S. Chang, Y.K. Hwang, V. Marsaud, P.-N. Bories, L. Cynober, S. Gil, G. Férey, P. Couvreur, R. Gref, Porous metal-organic-framework nanoscale carriers as a potential platform for drug delivery and imaging, Nat. Mater. 9 (2010) 172-178. doi:10.1038/nmat2608.

[12] S. Laurent, D. Forge, M. Port, A. Roch, C. Robic, L. Vander Elst, R.N. Muller, Magnetic Iron Oxide Nanoparticles: Synthesis, Stabilization, Vectorization, Physicochemical Characterizations, and Biological Applications, Chem. Rev. 108 (2008) 2064-2110. doi:10.1021/cr068445e.

[13] P.K. Jain, X. Huang, I.H. El-Sayed, M.A. El-Sayed, Review of Some Interesting Surface Plasmon Resonance-enhanced Properties of Noble Metal Nanoparticles and Their Applications to Biosystems, Plasmonics. 2 (2007) 107-118. doi:10.1007/s11468-007-9031-1.

[14] Y. (Chezy) Barenholz, Doxil ${ }^{\circledR}$ - The first FDA-approved nano-drug: Lessons learned, J. Control. Release. 160 (2012) 117-134. doi:10.1016/J.JCONREL.2012.03.020.

[15] A. Meyerhoff, U.S. Food and Drug Administration Approval of AmBisome (Liposomal Amphotericin B) for Treatment of Visceral Leishmaniasis, Clin. Infect. Dis. 28 (1999) 42-48. 
doi:10.1086/515085.

[16] S.C. Kim, D.W. Kim, Y.H. Shim, J.S. Bang, H.S. Oh, S.W. Kim, M.H. Seo, In vivo evaluation of polymeric micellar paclitaxel formulation: toxicity and efficacy, J. Control. Release. 72 (2001) 191-202. doi:10.1016/S0168-3659(01)00275-9.

[17] S. Wilhelm, A.J. Tavares, Q. Dai, S. Ohta, J. Audet, H.F. Dvorak, W.C.W. Chan, Analysis of nanoparticle delivery to tumours, Nat. Rev. Mater. 1 (2016) 1-12.

doi:10.1038/natrevmats.2016.14.

[18] U. Prabhakar, H. Maeda, R.K. Jain, E.M. Sevick-Muraca, W. Zamboni, O.C. Farokhzad, S.T. Barry, A. Gabizon, P. Grodzinski, D.C. Blakey, Challenges and Key Considerations of the Enhanced Permeability and Retention Effect for Nanomedicine Drug Delivery in Oncology, Cancer Res. 73 (2013) 2412-2417. doi:10.1158/0008-5472.CAN-12-4561.

[19] W.R. Sanhai, J.H. Sakamoto, R. Canady, M. Ferrari, Seven challenges for nanomedicine, Nat. Nanotechnol. 3 (2008) 242-244. doi:10.1038/nnano.2008.114.

[20] Y. Matsumura, H. Maeda, R.K. Jain, E.M. Sevick-Muraca, W. Zamboni, O.C. Farokhzad, S.T. Barry, A. Gabizon, P. Grodzinski, D.C. Blakey, A new concept for macromolecular therapeutics in cancer chemotherapy: mechanism of tumoritropic accumulation of proteins and the antitumor agent smancs., Cancer Res. 46 (1986) 6387-92. doi:10.1158/0008-5472.can-124561.

[21] H. Maeda, J. Wu, T. Sawa, Y. Matsumura, K. Hori, Tumor vascular permeability and the EPR effect in macromolecular therapeutics: a review, J. Control. Release. 65 (2000) 271-284. doi:10.1016/S0168-3659(99)00248-5.

[22] V. Torchilin, Tumor delivery of macromolecular drugs based on the EPR effect, Adv. Drug Deliv. Rev. 63 (2011) 131-135. doi:10.1016/j.addr.2010.03.011.

[23] J.W. Nichols, Y.H. Bae, EPR: Evidence and fallacy, J. Control. Release. 190 (2014) 451-464. doi:10.1016/J.JCONREL.2014.03.057.

[24] E. Huynh, G. Zheng, Cancer nanomedicine: addressing the dark side of the enhanced permeability and retention effect, Nanomedicine. 10 (2015) 1993-1995.

doi:10.2217/nnm.15.86.

[25] S. Mura, J. Nicolas, P. Couvreur, Stimuli-responsive nanocarriers for drug delivery, Nat. Mater. 12 (2013) 991-1003. doi:10.1038/nmat3776.

[26] R. Colombo, L.F. Da Pozzo, A. Salonia, P. Rigatti, Z. Leib, J. Baniel, E. Caldarera, M. PavoneMacaluso, Multicentric study comparing intravesical chemotherapy alone and with local microwave hyperthermia for prophylaxis of recurrence of superficial transitional cell carcinoma., J. Clin. Oncol. 21 (2003) 4270-6. doi:10.1200/JCO.2003.01.089.

[27] T. Boissenot, A. Bordat, E. Fattal, N. Tsapis, Ultrasound-triggered drug delivery for cancer treatment using drug delivery systems: From theoretical considerations to practical applications, J. Control. Release. 241 (2016) 144-163. doi:10.1016/j.jconrel.2016.09.026.

[28] P. Wust, M. Seebass, J. Nadobny, P. Deuflhard, G. Mönich, R. Felix, Simulation studies promote technological development of radiofrequency phased array hyperthermia, Int. J. Hyperth. 12 (1996) 477-494. doi:10.3109/02656739609023525.

[29] T. Brockow, A. Wagner, A. Franke, M. Offenbächer, K.L. Resch, A Randomized Controlled Trial on the Effectiveness of Mild Water-filtered Near Infrared Whole-body Hyperthermia as an 
Adjunct to a Standard Multimodal Rehabilitation in the Treatment of Fibromyalgia, Clin. J. Pain. 23 (2007) 67-75. doi:10.1097/AJP.0b013e31802b4f80.

[30] A. Jordan, R. Scholz, P. Wust, H. Fähling, Roland Felix, Magnetic fluid hyperthermia (MFH): Cancer treatment with AC magnetic field induced excitation of biocompatible superparamagnetic nanoparticles, J. Magn. Magn. Mater. 201 (1999) 413-419. doi:10.1016/S0304-8853(99)00088-8.

[31] R.T. Poon, N. Borys, Lyso-thermosensitive liposomal doxorubicin: a novel approach to enhance efficacy of thermal ablation of liver cancer, Expert Opin. Pharmacother. 10 (2009) 333-343. doi:10.1517/14656560802677874.

[32] M. Karimi, P. Sahandi Zangabad, A. Ghasemi, M. Amiri, M. Bahrami, H. Malekzad, H. Ghahramanzadeh Asl, Z. Mahdieh, M. Bozorgomid, A. Ghasemi, M.R. Rahmani Taji Boyuk, M.R. Hamblin, Temperature-Responsive Smart Nanocarriers for Delivery of Therapeutic Agents: Applications and Recent Advances, ACS Appl. Mater. Interfaces. 8 (2016) 21107-21133. doi:10.1021/acsami.6b00371.

[33] K. Matyjaszewski, J. Xia, Atom transfer radical polymerization., Chem. Rev. 101 (2001) 29212990. doi:10.1021/cr940534g.

[34] S. Perrier, P. Takolpuckdee, Macromolecular design via reversible addition-fragmentation chain transfer (RAFT)/xanthates (MADIX) polymerization, J. Polym. Sci. Part A Polym. Chem. 43 (2005) 5347-5393. doi:10.1002/pola.20986.

[35] Julien Nicolas, Yohann Guillaneuf, Catherine Lefay, Denis Bertin, Didier Gigmes, and B. Charleux, Nitroxide-mediated polymerisation, Prog. Polym. Sci. 38 (2013) 63-235. doi:10.1016/j.progpolymsci.2012.06.002.

[36] O. Dechy-Cabaret, B. Martin-Vaca, D. Bourissou, Controlled ring-opening polymerization of lactide and glycolide, Chem. Rev. 104 (2004) 6147-6176. doi:10.1021/cr040002s.

[37] Nahrain E. Kamber, and Wonhee Jeong, R.M. Waymouth*, Russell C. Pratt, and Bas G. G. Lohmeijer, J.L. Hedrick*, Organocatalytic Ring-Opening Polymerization, (2007). doi:10.1021/CR068415B.

[38] M. Heskins, J.E. Guillet, Solution Properties of Poly(N-isopropylacrylamide), J. Macromol. Sci. Part A - Chem. 8 (1968) 1441-1455. doi:10.1080/10601326808051910.

[39] Y. Lu, K. Zhou, Y. Ding, G. Zhang, C. Wu, Origin of hysteresis observed in association and dissociation of polymer chains in water, Phys. Chem. Chem. Phys. 12 (2010) 3188. doi:10.1039/b918969f.

[40] I. Bischofberger, V. Trappe, New aspects in the phase behaviour of poly- $\mathrm{N}$-isopropyl acrylamide: Systematic temperature dependent shrinking of PNiPAM assemblies well beyond the LCST, Sci. Rep. 5 (2015) 1-10. doi:10.1038/srep15520.

[41] S. Gammas, K. Suzuki, C. Sone, Y. Sakurai, K. Kataoka, T. Okano, Thermo-responsive polymer nanoparticles with a core-shell micelle structure as site-specific drug carriers, J. Control. Release. 48 (1997) 157-164. doi:10.1016/S0168-3659(97)00040-0.

[42] J.E. Chung, M. Yokoyama, M. Yamato, T. Aoyagi, Y. Sakurai, T. Okano, Thermo-responsive drug delivery from polymeric micelles constructed using block copolymers of poly $(\mathrm{N}$ isopropylacrylamide) and poly(butylmethacrylate), J. Control. Release. 62 (1999) 115-127. doi:10.1016/S0168-3659(99)00029-2. 
[43] F. Kohori, K. Sakai, T. Aoyagi, M. Yokoyama, M. Yamato, Y. Sakurai, T. Okano, Control of adriamycin cytotoxic activity using thermally responsive polymeric micelles composed of poly(N-isopropylacrylamide-co-N,N-dimethylacrylamide)-b-poly(-lactide), Colloids Surfaces B Biointerfaces. 16 (1999) 195-205. doi:10.1016/s0927-7765(99)00070-3.

[44] Y.S. Kim, M. Gulfam, T.L. Lowe, Thermoresponsive- co -Biodegradable Linear-Dendritic Nanoparticles for Sustained Release of Nerve Growth Factor to Promote Neurite Outgrowth, Mol. Pharm. 15 (2018) 1467-1475. doi:10.1021/acs.molpharmaceut.7b01044.

[45] J.R. Mcdaniel, D.C. Radford, A. Chilkoti, A Unified Model for De Novo Design of Elastin-like Polypeptides with Tunable Inverse Transition Temperatures, Biomacromolecules. 14 (2013) 2866-2872. doi:10.1021/bm4007166.

[46] L. Ayres, M.R.J. Vos, P.J. Hans, M. Adams, I.O. Shklyarevskiy, J.C.M. Van Hest, Elastin-Based Side-Chain Polymers Synthesized by ATRP, Macromolecules. 36 (2003) 5967-5973. doi:10.1021/ma025727h.

[47] L. Ayres, K. Koch, P. Hans, H.M. Adams, J.C.M. Van Hest, Stimulus Responsive Behavior of Elastin-Based Side Chain Polymers, Macromolecules. 38 (2005) 1699-1704.

doi:10.1021/ma047923p.

[48] F. Fernández-Trillo, A. Duréault, J.P.M. Bayley, J.C.M. Van Hest, J.C. Thies, T. Michon, R. Weberskirch, N.R. Cameron, Elastin-Based Side-Chain Polymers: Improved Synthesis via RAFT and Stimulus Responsive Behavior, Macromolecules. 40 (2007) 6094-6099. doi:10.1021/ma070527x.

[49] M. Amiram, K.M. Luginbuhl, X. Li, M.N. Feinglos, A. Chilkoti, A depot-forming glucagon-like peptide-1 fusion protein reduces blood glucose for five days with a single injection, J. Control. Release. 172 (2013) 144-151. doi:10.1016/J.JCONREL.2013.07.021.

[50] J.C. Rodríguez-Cabello, F.J. Arias, M.A. Rodrigo, A. Girotti, Elastin-like polypeptides in drug delivery, Adv. Drug Deliv. Rev. 97 (2016) 85-100. doi:10.1016/j.addr.2015.12.007.

[51] R. Gref, M. Lück, P. Quellec, M. Marchand, E. Dellacherie, S. Harnisch, T. Blunk, R. Müller, "Stealth" corona-core nanoparticles surface modified by polyethylene glycol (PEG): influences of the corona (PEG chain length and surface density) and of the core composition on phagocytic uptake and plasma protein adsorption., Colloids Surf. B. Biointerfaces. 18 (2000) 301-313. http://www.ncbi.nlm.nih.gov/pubmed/10915952.

[52] F.E. Bailey, R.W. Callard, Some properties of poly(ethylene oxide)1 in aqueous solution, J. Appl. Polym. Sci. 1 (1959) 56-62. doi:10.1002/app.1959.070010110.

[53] J.-F. Lutz, A. Hoth, Preparation of Ideal PEG Analogues with a Tunable Thermosensitivity by Controlled Radical Copolymerization of 2-(2-Methoxyethoxy)ethyl Methacrylate and Oligo(ethylene glycol) Methacrylate, Macromolecules. 39 (2006) 893-896. doi:10.1021/MA0517042.

[54] M. Mertoglu, S. Garnier, A. Laschewsky, K. Skrabania, J. Storsberg, Stimuli responsive amphiphilic block copolymers for aqueous media synthesised via reversible addition fragmentation chain transfer polymerisation (RAFT), Polymer (Guildf). 46 (2005) 7726-7740. doi:10.1016/J.POLYMER.2005.03.101.

[55] P. Molyneux, Water-Soluble Synthetic Polymers. Volume I Properties and Behavior, CRC Press, 1985. doi:10.1002/pi.4980160315.

[56] A.A. Tager, A.P. Safronov, S. V. Sharina, I.Y. Galaev, Thermodynamic study of poly(N-vinyl 
caprolactam) hydration at temperatures close to lower critical solution temperature, Colloid Polym. Sci. 271 (1993) 868-872. doi:10.1007/BF00652769.

[57] N.A. Cortez-Lemus, A. Licea-Claverie, Poly(N-vinylcaprolactam), a comprehensive review on a thermoresponsive polymer becoming popular, Prog. Polym. Sci. 53 (2016) 1-51.

doi:10.1016/J.PROGPOLYMSCI.2015.08.001.

[58] V. Aseyev, H. Tenhu, F.M. Winnik, Non-ionic Thermoresponsive Polymers in Water, Adv. Polym. Sci. 242 (2010) 29-89. doi:10.1007/12_2010_57.

[59] C. Vauthier, K. Bouchemal, Methods for the Preparation and Manufacture of Polymeric Nanoparticles, Pharm. Res. 26 (2009) 1025-1058. doi:10.1007/s11095-008-9800-3.

[60] F. Yang, S.S. Teves, C.J. Kemp, S. Henikoff, Doxorubicin, DNA torsion, and chromatin dynamics, Biochim. Biophys. Acta - Rev. Cancer. 1845 (2014) 84-89. doi:10.1016/J.BBCAN.2013.12.002.

[61] B.A. Weaver, How Taxol/paclitaxel kills cancer cells., Mol. Biol. Cell. 25 (2014) 2677-81. doi:10.1091/mbc.E14-04-0916.

[62] P.T.R. Rajagopalan, Z. Zhang, L. McCourt, M. Dwyer, S.J. Benkovic, G.G. Hammes, Interaction of dihydrofolate reductase with methotrexate: ensemble and single-molecule kinetics., Proc. Natl. Acad. Sci. U. S. A. 99 (2002) 13481-13486. doi:10.1073/pnas.172501499.

[63] J. Zhang, Z. Qian, Y. Gu, In vivo anti-tumor efficacy of docetaxel-loaded thermally responsive nanohydrogel, Nanotechnology. 20 (2009). doi:10.1088/0957-4484/20/32/325102.

[64] F. Sun, Y. Wang, Y. Wei, G. Cheng, G. Ma, Thermo-triggered drug delivery from polymeric micelles of poly( $\mathrm{N}$-isopropylacrylamide-co-acrylamide)-b-poly(n-butyl methacrylate) for tumor targeting, J. Bioact. Compat. Polym. 29 (2014) 301-317. doi:10.1177/0883911514535288.

[65] X. Wang, S. Li, Z. Wan, Z. Quan, Q. Tan, Investigation of thermo-sensitive amphiphilic micelles as drug carriers for chemotherapy in cholangiocarcinoma in vitro and in vivo, Int. J. Pharm. 463 (2014) 81-88. doi:10.1016/j.ijpharm.2013.12.046.

[66] X.-L. Sun, P.-C. Tsai, R. Bhat, E.M. Bonder, B. Michniak-Kohn, A. Pietrangelo, Thermoresponsive block copolymer micelles with tunable pyrrolidone-based polymer cores: structure/property correlations and application as drug carriers, J. Mater. Chem. B. 3 (2015) 814-823. doi:10.1039/C4TB01494D.

[67] C.C. Cheng, F.C. Chang, W.Y. Kao, S.M. Hwang, L.C. Liao, Y.J. Chang, M.C. Liang, J.K. Chen, D.J. Lee, Highly efficient drug delivery systems based on functional supramolecular polymers: In vitro evaluation, Acta Biomater. 33 (2016) 194-202. doi:10.1016/j.actbio.2016.01.018.

[68] C.C. Cheng, M.C. Liang, Z.S. Liao, J.J. Huang, D.J. Lee, Self-Assembled Supramolecular Nanogels as a Safe and Effective Drug Delivery Vector for Cancer Therapy, Macromol. Biosci. 17 (2017). doi:10.1002/mabi.201600370.

[69] X. Fan, H. Cheng, X. Wang, E. Ye, X.J. Loh, Y.L. Wu, Z. Li, Thermoresponsive Supramolecular Chemotherapy by " $\mathrm{V}$ "-Shaped Armed $\beta$-Cyclodextrin Star Polymer to Overcome Drug Resistance, Adv. Healthc. Mater. 1701143 (2017) 1-11. doi:10.1002/adhm.201701143.

[70] C. Gerecke, A. Edlich, M. Giulbudagian, F. Schumacher, N. Zhang, A. Said, G. Yealland, S.B. Lohan, F. Neumann, M.C. Meinke, N. Ma, M. Calderón, S. Hedtrich, M. Schäfer-Korting, B. Kleuser, Biocompatibility and characterization of polyglycerol-based thermoresponsive nanogels designed as novel drug-delivery systems and their intracellular localization in keratinocytes, Nanotoxicology. 11 (2017) 267-277. doi:10.1080/17435390.2017.1292371. 
[71] Z. Zhu, N. Gao, H. Wang, S.A. Sukhishvili, Temperature-triggered on-demand drug release enabled by hydrogen-bonded multilayers of block copolymer micelles, J. Control. Release. 171 (2013) 73-80. doi:10.1016/j.jconrel.2013.06.031.

[72] M. Giulbudagian, G. Yealland, S. Hönzke, A. Edlich, B. Geisendörfer, B. Kleuser, S. Hedtrich, M. Calderón, Breaking the barrier - Potent anti-inflammatory activity following efficient topical delivery of etanercept using thermoresponsive nanogels, Theranostics. 8 (2018) 450-463. doi:10.7150/thno.21668.

[73] J. Wang, E. Ayano, Y. Maitani, H. Kanazawa, Enhanced cellular uptake and gene silencing activity of siRNA using temperature-responsive polymer-modified liposome, Int. J. Pharm. 523 (2017) 217-228. doi:10.1016/j.ijpharm.2017.03.035.

[74] Y. Zhao, J. Zhao, C. Hao, M. Han, M. Wang, Y. Guo, X. Wang, Self-assembled thermosensitive nanoparticles based on oligoethylene glycol dendron conjugated doxorubicin: preparation, and efficient delivery of free doxorubicin, RSC Adv. 6 (2016) 2602-2610. doi:10.1039/C5RA22224A.

[75] J.R. McDaniel, S.R. Macewan, X. Li, D.C. Radford, C.D. Landon, M. Dewhirst, A. Chilkoti, Rational design of "heat seeking" drug loaded polypeptide nanoparticles that thermally target solid tumors, Nano Lett. 14 (2014) 2890-2895. doi:10.1021/nl5009376.

[76] M.R. Dreher, W. Liu, C.R. Michelich, M.W. Dewhirst, A. Chilkoti, Enhanced uptake of a thermally responsive polypeptide by tumor cells in response to its hyperthermia-mediated phase transition., Cancer Res. 67 (2007) 4418-4424. doi:10.1158/0008-5472.can-06-4444.

[77] J. Nicolas, S. Mura, D. Brambilla, N. Mackiewicz, P. Couvreur, Design, functionalization strategies and biomedical applications of targeted biodegradable/biocompatible polymerbased nanocarriers for drug delivery, Chem. Soc. Rev. 42 (2013) 1147-1235. doi:10.1039/C2CS35265F.

[78] Y. Wu, C. Yang, Q. Lai, Q. Zhang, W. Wang, Z. Yuan, Fabrication of thermo-sensitive complex micelles for reversible cell targeting, J. Mater. Sci. Mater. Med. 26 (2015) 1-13. doi:10.1007/s10856-015-5584-2.

[79] H. Chen, B. Li, J. Qiu, J. Li, J. Jin, S. Dai, Y. Ma, Y. Gu, Thermal responsive micelles for dual tumor-targeting imaging and therapy, Nanoscale. 5 (2013) 12409. doi:10.1039/c3nr04529c.

[80] S. Panja, G. Dey, R. Bharti, K. Kumari, T.K. Maiti, M. Mandal, S. Chattopadhyay, Tailor-Made Temperature-Sensitive Micelle for Targeted and On-Demand Release of Anticancer Drugs, ACS Appl. Mater. Interfaces. 8 (2016) 12063-12074. doi:10.1021/acsami.6b03820.

[81] S. Köhler, F. Schmid, G. Settanni, The Internal Dynamics of Fibrinogen and Its Implications for Coagulation and Adsorption, PLoS Comput. Biol. 11 (2015) 1-19. doi:10.1371/journal.pcbi.1004346.

[82] F. Wang, G. Xia, X. Lang, X. Wang, Z. Bao, Z. Shah, X. Cheng, M. Kong, C. Feng, Y. Liu, X. Chen, Influence of the graft density of hydrophobic groups on thermo-responsive nanoparticles for anti-cancer drugs delivery, Colloids Surfaces B Biointerfaces. 148 (2016) 147-156. doi:10.1016/j.colsurfb.2016.08.042.

[83] P. Maudens, S. Meyer, C.A. Seemayer, O. Jordan, E. Allémann, Self-assembled thermoresponsive nanostructures of hyaluronic acid conjugates for osteoarthritis therapy, Nanoscale. 10 (2018) 1845-1854. doi:10.1039/C7NR07614B.

[84] N.S. Rejinold, T. Baby, K.P. Chennazhi, R. Jayakumar, Multi drug loaded thermo-responsive 
fibrinogen-graft-poly( $\mathrm{N}$-vinyl caprolactam) nanogels for breast cancer drug delivery, J. Biomed. Nanotechnol. 11 (2015) 392-402. doi:10.1166/jbn.2015.1911.

[85] F. Schaffner, A.M. Ray, M. Dontenwill, Integrin $\alpha 5 \beta 1$, the Fibronectin Receptor, as a Pertinent Therapeutic Target in Solid Tumors., Cancers (Basel). 5 (2013) 27-47.

doi:10.3390/cancers5010027.

[86] G.M. Lynn, R. Laga, P.A. Darrah, A.S. Ishizuka, A.J. Balaci, A.E. Dulcey, M. Pechar, R. Pola, M.Y. Gerner, A. Yamamoto, C.R. Buechler, K.M. Quinn, M.G. Smelkinson, O. Vanek, R. Cawood, T. Hills, O. Vasalatiy, K. Kastenmüller, J.R. Francica, L. Stutts, J.K. Tom, K.A. Ryu, A.P. Esser-Kahn, T. Etrych, K.D. Fisher, L.W. Seymour, R.A. Seder, In vivo characterization of the physicochemical properties of polymer-linked TLR agonists that enhance vaccine immunogenicity, Nat. Biotechnol. 33 (2015) 1201-1210. doi:10.1038/nbt.3371.

[87] D. Fischer, Y. Li, B. Ahlemeyer, J. Krieglstein, T. Kissel, In vitro cytotoxicity testing of polycations: influence of polymer structure on cell viability and hemolysis, Biomaterials. 24 (2003) 1121-1131. doi:10.1016/S0142-9612(02)00445-3.

[88] K.M. Nelson, J.L. Dahlin, J. Bisson, J. Graham, G.F. Pauli, M.A. Walters, The Essential Medicinal Chemistry of Curcumin, J. Med. Chem. 60 (2017) 1620-1637. doi:10.1021/acs.jmedchem.6b00975.

[89] O. Naksuriya, M.J. van Steenbergen, J.S. Torano, S. Okonogi, W.E. Hennink, A Kinetic Degradation Study of Curcumin in Its Free Form and Loaded in Polymeric Micelles., AAPS J. 18 (2016) 777-87. doi:10.1208/s12248-015-9863-0.

[90] R. Cheng, F. Meng, C. Deng, H.-A. Klok, Z. Zhong, Dual and multi-stimuli responsive polymeric nanoparticles for programmed site-specific drug delivery, Biomaterials. 34 (2013) 3647-3657. doi:10.1016/J.BIOMATERIALS.2013.01.084.

[91] D. Schmaljohann, Thermo- and pH-responsive polymers in drug delivery, Adv. Drug Deliv. Rev. 58 (2006) 1655-1670. doi:10.1016/J.ADDR.2006.09.020.

[92] L.M. Bareford, P.W. Swaan, Endocytic mechanisms for targeted drug delivery, Adv. Drug Deliv. Rev. 59 (2007) 748-758. doi:10.1016/J.ADDR.2007.06.008.

[93] J. Panyam, W.-Z. Zhou, S. Prabha, S.K. Sahoo, V. Labhasetwar, Rapid endo-lysosomal escape of poly(dl-lactide-co-glycolide) nanoparticles: implications for drug and gene delivery, FASEB J. 16 (2002) 1217-1226. doi:10.1096/fj.02-0088com.

[94] Y. Qin, J. Chen, Y. Bi, X. Xu, H. Zhou, J. Gao, Y. Hu, Y. Zhao, Z. Chai, Near-infrared light remotecontrolled intracellular anti-cancer drug delivery using thermo/pH sensitive nanovehicle, Acta Biomater. 17 (2015) 201-209. doi:10.1016/j.actbio.2015.01.026.

[95] X.J. Loh, S.J. Ong, Y.T. Tung, H.T. Choo, Dual responsive micelles based on poly[(R)-3hydroxybutyrate] and poly(2-(di-methylamino)ethyl methacrylate) for effective doxorubicin delivery, Polym. Chem. 4 (2013) 2564. doi:10.1039/c3py00096f.

[96] W. Hong, D. Chen, L. Jia, J. Gu, H. Hu, X. Zhao, M. Qiao, Thermo- and pH-responsive copolymers based on PLGA-PEG-PLGA and poly(I-histidine): Synthesis and in vitro characterization of copolymer micelles, Acta Biomater. 10 (2014) 1259-1271. doi:10.1016/j.actbio.2013.12.033.

[97] Y.Y. Khine, Y. Jiang, A. Dag, H. Lu, M.H. Stenzel, Dual-Responsive pH and Temperature Sensitive Nanoparticles Based on Methacrylic Acid and Di(ethylene glycol) Methyl Ether Methacrylate for the Triggered Release of Drugs, Macromol. Biosci. 15 (2015) 1091-1104. 
doi:10.1002/mabi.201500057.

[98] Y. Hiruta, Y. Kanda, N. Katsuyama, H. Kanazawa, Dual temperature- and pH-responsive polymeric micelle for selective and efficient two-step doxorubicin delivery, RSC Adv. 7 (2017) 29540-29549. doi:10.1039/C7RA03579A.

[99] S.E. Marriner, D.L. Morris, B. Dickson, J.A. Bogan, Pharmacokinetics of albendazole in man, Eur. J. Clin. Pharmacol. 30 (1986) 705-708. doi:10.1007/BF00608219.

[100] S. Zeng, K.-T. Yong, I. Roy, X.-Q. Dinh, X. Yu, F. Luan, A Review on Functionalized Gold Nanoparticles for Biosensing Applications, Plasmonics. 6 (2011) 491-506. doi:10.1007/s11468-011-9228-1.

[101] J.-P. Fortin-Ripoche, M.S. Martina, F. Gazeau, C. Ménager, C. Wilhelm, J.-C. Bacri, S. Lesieur, O. Clément, Magnetic Targeting of Magnetoliposomes to Solid Tumors with MR Imaging Monitoring in Mice: Feasibility, Radiology. 239 (2006) 415-424.

doi:10.1148/radiol.2392042110.

[102] J. Estelrich, E. Escribano, J. Queralt, M.A. Busquets, Iron oxide nanoparticles for magneticallyguided and magnetically-responsive drug delivery., Int. J. Mol. Sci. 16 (2015) 8070-101. doi:10.3390/ijms16048070.

[103] J.-P. Fortin, C. Wilhelm, J. Servais, C. Ménager, J.-C. Bacri, F. Gazeau, Size-Sorted Anionic Iron Oxide Nanomagnets as Colloidal Mediators for Magnetic Hyperthermia, J. Am. Chem. Soc. 129 (2007) 2628-2635. doi:10.1021/JA067457E.

[104] F. Gazeau, M. Lévy, C. Wilhelm, Optimizing magnetic nanoparticle design for nanothermotherapy, Nanomedicine. 3 (2008) 831-844. doi:10.2217/17435889.3.6.831.

[105] M. Levy, N. Luciani, D. Alloyeau, D. Elgrabli, V. Deveaux, C. Pechoux, S. Chat, G. Wang, N. Vats, F. Gendron, C. Factor, S. Lotersztajn, A. Luciani, C. Wilhelm, F. Gazeau, Long term in vivo biotransformation of iron oxide nanoparticles, Biomaterials. 32 (2011) 3988-3999. doi:10.1016/J.BIOMATERIALS.2011.02.031.

[106] L. Deng, J. Ren, J. Li, J. Leng, Y. Qu, C. Lin, D. Shi, Magnetothermally responsive star-block copolymeric micelles for controlled drug delivery and enhanced thermo-chemotherapy, Nanoscale. 7 (2015) 9655-9663. doi:10.1039/C5NR00642B.

[107] E.J. Sayers, J.P. Magnusson, P.R. Moody, F. Mastrotto, C. Conte, C. Brazzale, P. Borri, P. Caliceti, P. Watson, G. Mantovani, J. Aylott, S. Salmaso, A.T. Jones, C. Alexander, Switching of Macromolecular Ligand Display by Thermoresponsive Polymers Mediates Endocytosis of Multiconjugate Nanoparticles, Bioconjug. Chem. (2018) acs.bioconjchem.7b00704. doi:10.1021/acs.bioconjchem.7b00704.

[108] J. Niskanen, H. Tenhu, How to manipulate the upper critical solution temperature (UCST)?, Polym. Chem. 8 (2017) 220-232. doi:10.1039/C6PY01612J.

[109] J. Seuring, S. Agarwal, Polymers with upper critical solution temperature in aqueous solution, Macromol. Rapid Commun. 33 (2012) 1898-1920. doi:10.1002/marc.201200433.

[110] H.C. Haas, N.W. Schuler, Thermally reversible homopolymer gel systems, J. Polym. Sci. Part B Polym. Lett. 2 (1964) 1095-1096. doi:10.1002/pol.1964.110021203.

[111] J. Seuring, S. Agarwal, Non-lonic Homo- and Copolymers with H-Donor and H-Acceptor Units with an UCST in Water, Macromol. Chem. Phys. 211 (2010) 2109-2117. doi:10.1002/macp.201000147. 
[112] J. Seuring, F.M. Bayer, K. Huber, S. Agarwal, Upper Critical Solution Temperature of Poly(Nacryloyl glycinamide) in Water: A Concealed Property, Macromolecules. 45 (2012) 374-384. doi:10.1021/ma202059t.

[113] F. Liu, J. Seuring, S. Agarwal, Controlled radical polymerization of $\mathrm{N}$-acryloylglycinamide and UCST-type phase transition of the polymers, J. Polym. Sci. Part A Polym. Chem. 50 (2012) 4920-4928. doi:10.1002/pola.26322.

[114] J. Seuring, S. Agarwal, First Example of a Universal and Cost-Effective Approach : Polymers with Tunable Upper Critical Solution Temperature in Water and Electrolyte Solution, Macromolecules. 45 (2012) 3910-3918.

[115] F. Käfer, A. Lerch, S. Agarwal, Tunable, concentration-independent, sharp, hysteresis-free UCST phase transition from poly( $\mathrm{N}$-acryloyl glycinamide-acrylonitrile) system, J. Polym. Sci. Part A Polym. Chem. 55 (2017) 274-279. doi:10.1002/pola.28374.

[116] H. Zhang, X. Tong, Y. Zhao, Diverse thermoresponsive behaviors of uncharged ucst block copolymer micelles in physiological medium, Langmuir. 30 (2014) 11433-11441. doi:10.1021/la5026334.

[117] S. Lin, J. Shang, P. Theato, CO2-Triggered UCST transition of amphiphilic triblock copolymers and their self-assemblies, Polym. Chem. 8 (2017) 2619-2629. doi:10.1039/C7PY00186J.

[118] H. Zhang, S. Guo, S. Fu, Y. Zhao, A Near-Infrared Light-Responsive Hybrid Hydrogel Based on UCST Triblock Copolymer and Gold Nanorods, Polymers (Basel). 9 (2017) 238. doi:10.3390/polym9060238.

[119] G. Tong, Z. Fang, G. Huang, Y. Jing, S. Dai, Q. Jiang, C. Zhang, S.-T. Feng, Z.-P. Li, Gadolinium/DOTA functionalized poly(ethylene glycol)-block-poly(acrylamide-co-acrylonitrile) micelles with synergistically enhanced cellular uptake for cancer theranostics, RSC Adv. 6 (2016) 50534-50542. doi:10.1039/C6RA04038A.

[120] F. Käfer, F. Liu, U. Stahlschmidt, V. Jérôme, R. Freitag, M. Karg, S. Agarwal, LCST and UCST in One: Double Thermoresponsive Behavior of Block Copolymers of Poly(ethylene glycol) and Poly(acrylamide-co-acrylonitrile), Langmuir. 31 (2015) 8940-8946. doi:10.1021/acs.langmuir.5b02006.

[121] B.A. Pineda-Contreras, F. Liu, S. Agarwal, Importance of compositional homogeneity of macromolecular chains for UCST-type transitions in water: Controlled versus conventional radical polymerization, J. Polym. Sci. Part A Polym. Chem. 52 (2014) 1878-1884. doi:10.1002/pola.27196.

[122] Y. Zhu, A.B. Lowe, P.J. Roth, Postpolymerization synthesis of (bis)amide (co)polymers: Thermoresponsive behavior and self-association, Polym. (United Kingdom). 55 (2014) 44254431. doi:10.1016/j.polymer.2014.07.003.

[123] Y.G. Jia, Q. Yu, Z. Ma, M. Zhang, X.X. Zhu, Tunable Upper Critical Solution Temperatures for Acrylamide Copolymers with Bile Acid Pendants, Biomacromolecules. 18 (2017) 2663-2668. doi:10.1021/acs.biomac.7b00860.

[124] G.C. Kresheck, H.A. Scheraga, The Temperature Dependence of the Enthalpy of Formation of the Amide Hydrogen Bond; the Urea Model, J. Phys. Chem. 69 (1965) 1704-1706. doi:10.1021/j100889a043.

[125] N. Shimada, H. Ino, K. Maie, M. Nakayama, A. Kano, A. Maruyama, Ureido-Derivatized Polymers Based on Both Poly(allylurea) and Poly(L-citrulline) Exhibit UCST-Type Phase 
Transition Behavior under Physiologically Relevant Conditions, Biomacromolecules. 12 (2011) 3418-3422.

[126] N. Shimada, M. Saito, S. Shukuri, S. Kuroyanagi, T. Kuboki, S. Kidoaki, T. Nagai, A. Maruyama, Reversible monolayer/spheroid cell culture switching by UCST-type thermoresponsive ureido polymers, ACS Appl. Mater. Interfaces. 8 (2016) 31524-31529. doi:10.1021/acsami.6b07614.

[127] N. Shimada, M. Nakayama, A. Kano, A. Maruyama, Design of UCST polymers for chilling capture of proteins, Biomacromolecules. 14 (2013) 1452-1457. doi:10.1021/bm400120y.

[128] A. Fujihara, K. Itsuki, N. Shimada, A. Maruyama, N. Sagawa, T. Shikata, S.-I. Yusa, Preparation of ureido group bearing polymers and their upper critical solution temperature in water, J. Polym. Sci. Part A Polym. Chem. 54 (2016) 2845-2854. doi:10.1002/pola.28183.

[129] A. Fujihara, N. Shimada, A. Maruyama, K. Ishihara, K. Nakai, S. Yusa, Preparation of upper critical solution temperature (UCST) responsive diblock copolymers bearing pendant ureido groups and their micelle formation behavior in water, Soft Matter. 11 (2015) 5204-5213. doi:10.1039/C5SM00499C.

[130] P. Mary, D. D. Bendejacq, M.-P. Labeau, P. Dupuis, Reconciling Low- and High-Salt Solution Behavior of Sulfobetaine Polyzwitterions, J. Phys. Chem. B. 111 (2007) 7767-7777. doi:10.1021/JP071995B.

[131] C.-Y. Chen, H.-L. Wang, Dual Thermo- and pH-Responsive Zwitterionic Sulfobataine Copolymers for Oral Delivery System, Macromol. Rapid Commun. 35 (2014) 1534-1540. doi:10.1002/marc.201400161.

[132] J.-T. Sun, Z.-Q. Yu, C.-Y. Hong, C.-Y. Pan, Biocompatible Zwitterionic Sulfobetaine CopolymerCoated Mesoporous Silica Nanoparticles for Temperature-Responsive Drug Release, Macromol. Rapid Commun. 33 (2012) 811-818. doi:10.1002/marc.201100876.

[133] F.G. Quiroz, A. Chilkoti, Sequence heuristics to encode phase behaviour in intrinsically disordered protein polymers, Nat. Mater. 14 (2015) 1164-1171. doi:10.1038/nmat4418.

[134] D. Matsukuma, T. Sambai, H. Otsuka, UCST-type phase transition driven by protein-derived polypeptide employing gelatin and chitosan, Polym. Adv. Technol. 28 (2017) 1636-1641. doi:10.1002/pat.4033.

[135] W. Li, L. Huang, X. Ying, Y. Jian, Y. Hong, F. Hu, Y. Du, Antitumor drug delivery modulated by a polymeric micelle with an upper critical solution temperature, Angew. Chemie - Int. Ed. 54 (2015) 3126-3131. doi:10.1002/anie.201411524.

[136] L. Hui, S. Qin, L. Yang, Upper Critical Solution Temperature Polymer, Photothermal Agent, and Erythrocyte Membrane Coating: An Unexplored Recipe for Making Drug Carriers with Spatiotemporally Controlled Cargo Release, ACS Biomater. Sci. Eng. 2 (2016) 2127-2132. doi:10.1021/acsbiomaterials.6b00459.

[137] M. Hei, J. Wang, K. Wang, W. Zhu, P.X. Ma, Dually responsive mesoporous silica nanoparticles regulated by upper critical solution temperature polymers for intracellular drug delivery, J. Mater. Chem. B. (2017). doi:10.1039/C7TB02429K.

[138] W.S. Li, X.J. Wang, S. Zhang, J.B. Hu, Y.L. Du, X.Q. Kang, X.L. Xu, X.Y. Ying, J. You, Y.Z. Du, Mild microwave activated, chemo-thermal combinational tumor therapy based on a targeted, thermal-sensitive and magnetic micelle, Biomaterials. 131 (2017) 36-46. doi:10.1016/j.biomaterials.2017.03.048. 
[139] G. Huang, H. Li, S.T. Feng, X. Li, G. Tong, J. Liu, C. Quan, Q. Jiang, C. Zhang, Z. Li, Self-assembled UCST-type micelles as potential drug carriers for cancer therapeutics, Macromol. Chem. Phys. 216 (2015) 1014-1023. doi:10.1002/macp.201400546.

[140] E.A. Repasky, S.S. Evans, M.W. Dewhirst, Temperature matters! And why it should matter to tumor immunologists., Cancer Immunol. Res. 1 (2013) 210-6. doi:10.1158/2326-6066.CIR-130118.

[141] M. Dunne, K. Hynynen, C. Allen, Thermosensitive nanomedicines could revolutionize thermal therapy in oncology, Nano Today. 16 (2017) 9-13. doi:10.1016/j.nantod.2017.08.001. 